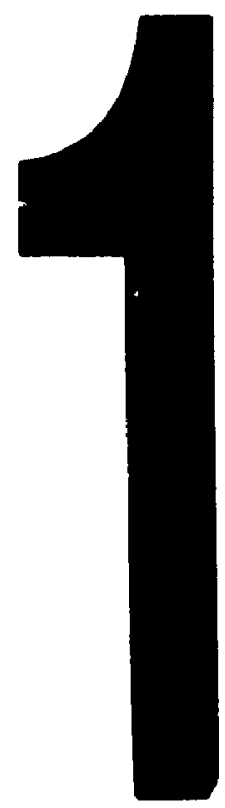

PM-1 $3^{1} \mathrm{~K}^{\prime \prime} \times 4^{\prime \prime}$ PHOTOGRAPHIC MICROCOPY TARGET NBS 1010a ANSI/ISO \#2 EQUIVALENT

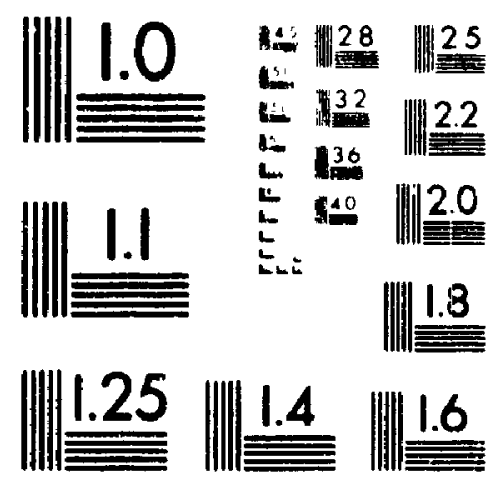

PRECISIONSM RESOLUTION TARGETS 
National Library

of Canada

Acquisitions and

Bibliographic Services Branch

395 Wellington Stree

Onawa. Ontario

K1A ON4
Bibliothèque natronale

du Canada

Direction des acquisitions et

des services bibliographiques

395, rue Wellirigton

Onawa (Onlario)
The quality of this microform is heavily dependent upon the quality of the original thesis submitted for microfilming. Every effort has been madie to ensure the highest quality of reproduction possible.

If pages are missing, contact the university which granted the degree.

Some pages may have indistinct print especially if the criginal pages were typed with a poor typewriter ribbon or if the university sent us an inferior photocopy.
La qualité de cette microforme dépend grandement de la qualité de la thèse soumise au microfilmage. Nous avons tout fait pour assurer une qualité supérieure de reproduction.

S'il manque des pages, veuillez communiquer avec l'ur:"orsité qui a conféré le grade.

La qualité d'impression certoines pages peut laisser à désirer, surtout si les pages originales ont été dactylographiées à l'aide d'un ruban usé ou si l'université nous a fait parvenir une phoiocopie de qualité inférieure.

La repiưuuction, même partielle, de cette microforme est soumise à la Loi canadienne sur le droit d'auteur, SRC 1970, c. C-30, et ses amendements subséquents.
Reproduction in full or in part of this microform is governed by the Canadian Copyright Act, R.S.C. 1970, c. C-30, and subsequent amendments. 


\title{
STUDIES ON CHEMICAL SPECIATION OF HEAVY METALS IN AQUEOUS, ENVIRONMENTAL SAMPLES
}

by

\begin{abstract}
AMINA LULA R. SEKALY
Laurea in Industrial Chemistry, Somali National University

Doctor in Research, University of Rome "La Sapienza"
\end{abstract}

A thesis submitted to

the Faculty of Graduate Studies and Research

in partial fulfilment of

the requirements for the degree of

Master of Science

Carleton University

Ottawa-Carleton Chemistry Institute

Ottawa, Ontario

Canada K1S 5B6

September, 1995 
Acquisitions and

Bibliographic Services Branch

395 Wellington Street

Ottawa, Ontario

KIA ON4
Direction des acquisitions et

des services bibliographiques

395. ne Wellington

Ottawa (Ontario)

K1A ON4
The author has granted an irrevocable non-exclusive licence allowing the National Library of Canada to reproduce, loan, distribute or sell copies of his/her thesis by any means and in any form or format, making this thesis available to interested persons.
L'auteur a accordé une licence irrévocable et non exciusive permettant à la Bibliothèque nationale du Canada de reproduire, prêter, distribuer ou vendre des copies de sa thèse de quelque manière et sous quelque forme que ce soit pour mettre des exemplaires de cette thèse i la disposition des personnes intéressées.
The author retains ownership of the copyright in his/her thesis. Neither the thesis nor substantial extracts from it may be printed or otherwise reproduced without his/her permission.
L'auteur conserve la propriété du droit d'auteur qui protège sa thèse. Ni la thèse ni des extraits substantiels de celle-ci ne doivent être imprimés ou autrement reproduits sans son autorisation.

ISBN $\quad 0-612-09014-0$

\section{Canadä}


Thesis contains black \& white photographs \&/or explanatory tables which when microfilmed may lose their significance. The hardcopy of the thesis is available upon request from Carleton University Library. 
The undersigned hereby recommend to the Faculty of Graduate Studies and Research acceptance of the thesis,

" STUDIES ON CHEMICAL SPECIATION OF HEAVY METALS IN AQUEOUS, ENVIRONMENTAL SAMPLES "

\author{
submitted by \\ AMINA LULA R. SEKALY \\ Laurea in Industrial Chemistry, Somali National University \\ Doctor in Research, University of Rome "La Sapienza"
}

in partial fulfilment of the requirements

for the degree of Master of Science
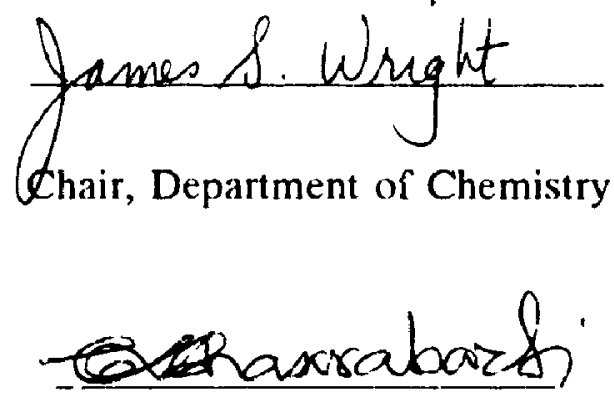

Thesis Co-supervisor

Miac guat to beck

Thesis Co-supervisor

Carleton University 


\begin{abstract}
The stability of aqueous environmental samples with respect to total dissol: ed heavy metal species in various container materials was studied. No significant loss of any of the metals studied was observed from Teflon containers for a period of two hours, whereas loss of some metals was observed in containers made of polyethylene or polypropylene.

Clogging and adsorption onto the ultrafiltration membranes during ultrafiltration were studied with a view to eliminating or minimizing these effects.

Kinetic studies of binding of $\mathrm{Ni}(\mathrm{II}), \mathrm{Cd}(\mathrm{II})$, and $\mathrm{Zn}(\mathrm{II})$ metal ions by Alcoa Activated Alumina and by Chelex -100 cation exchange resin in Rideau river waters were studied. Inductively-coupled plasma mass spectrometry (ICP-MS) was employed for quantitation of the metals. The kinetic data were analyzed by using the Iterative Deconvolution Method. Kinetic studies of Rideau river surf'ce waters showed that these metals were present as more than one kinetically distinguishable species.
\end{abstract}

ii) 


\section{ACKNOWLEDGMENTS}

I wish to thank my supervisor, Distinguished Research Professor Dr. C.L. Chakrabarti, for his confidence in my ability and for giving me the opportunity to work under his direction and supervision and for correction of this thesis. I also wish to thank my co-supervisor, Dr. M.H. Back, for her extraordinary patience in correcting my thesis and helpful discussions. I am grateful to Dr. D.C. Grégoire, Geological Survey of Canada, Ottawa, for allowing me use his inductively- coupled plasma mass spectrometer for this thesis research. 


\section{TABLE OF CONTENTS}

ABSTRACT

ACKNOWLEDGEMENTS

TABLE OF CONTENTS iv

LIST OF TABLES $\quad \mathbf{x}$

LIST OF FIGURES - xii

ORGANIZATION OF THE THESIS $\quad$ xvi

CHAPTER I

STUDIES ON THE STABILITY OF METAL

SPECIES IN AQUEOUS ENVIRONMENTAL SAMPLES

INTRODUCTION 1

1.1 Objectives 1

1.2 Loss of heavy metals during storage 2

1.3 Methods for sample preservation 3

1.4 Differentiation between "dissolved" and "particulate" metals 5

1.5 Materials for construction of sample containers and sampling apparatus 7

1.6 Cleaning procedures for sample containers 8

1.7 EXPERIMENTAL 9

1.7.1 Apparatus $\quad 9$

1.7.2 polyfluorocarbons (Teflon). polyethylene, polypropylene 13

$\begin{array}{ll}\text { 1.7.3 Cleaning procedures } & 14\end{array}$ 
1.7.4 Standards and reagents

1.7.5 Collection and priz-treatment of water samples

1.7.5 Determination of dissclved organic carbon (DOC)

1.8 RESULTS AND DISCUSSION

1.8.1 Dissolved organic carbon (DOC), and $\mathrm{pH}$

1.8.2 Stability of total dissolved metal in different container materials

1.9 CONCLUSIONS

\section{CHAPTER II}

A STUDY OF SOME PHYSICO-CHEMICAL ARTIFACTS PRODUCED

IN ULTRAFILTRATION OF N.ATURAL WATER SAMPLES

INTRODUCTION

$2.1 \quad$ Objectives

2.2 THEORY

2.2.1 Experimental factors affecting size fractionation by ultrafiltration

2.2.2 Some physico-chemical artifacts produced during size fractionation by ultrafiltration

2.2.2.1 Membrane clogging

2.2.2.2 Sample modification by solute adsorption onto the membrane 
2.3.1 Experimental approach

2.3.2 Reagents and materials

2.3.3 Preparation of silver sol

2.3.4 Preparation of clogged and semi-clogged membranes

2.3.5 Transimission Electron Microscopy (TEM) Analysis

2.3.6 Ultrafiltration cell

2.4 RESULTS AND DISCUSSION

2.5 CONClusions

2.6 FUTURE WORK

2.7 EXPERIMENTAL

2.7.1 Standards and reagents

2.7.2 Sample pre-treatment

2.7.3 Membrane pre-treatment

2.7.4 Apparatus and materials

2.8 RESULTS AND DISCUSSION

2.9 CONCLUSIONS 


\section{CHAPTER III}

KINETIC SPECIATION OF Ni(II), Cd(II), AND Zn(II) IN RIVER SURFACE

WATERS USING ACTIVATED ALUMINA .

$\begin{array}{ll}\text { INTRODUCTION } & 64\end{array}$

$\begin{array}{lll}3.1 & \text { Objective } & 66\end{array}$

$\begin{array}{lll}3.2 & \text { Research Plan } & 66\end{array}$

$\begin{array}{lll}\text { 3.3 Chelex-100 cation exchange resin } & 67\end{array}$

$\begin{array}{lrr}3.4 & \text {. Icoa Activated Alumina } & 68\end{array}$

$\begin{array}{lll}3.5 & \text { Evaluation of kinetic parameters } & 71\end{array}$

$\begin{array}{ll}\text { 3.5.1 The Graphical method } & 71\end{array}$

$\begin{array}{ll}\text { 3.5.2 Numerical analysis } & 72\end{array}$

3.5.2.1 The Iterative Deconvolution Method 72

$\begin{array}{lll}\text { 3.6 The Kinetic Model } & 74\end{array}$

$\begin{array}{ll}\text { 3.7 EXPERIMENTAL } & \mathbf{7 6}\end{array}$

$\begin{array}{lll}\text { 3.7.1 General procedure } & 76\end{array}$

$\begin{array}{lll}3.7 .2 & \text { Procedure } & 78\end{array}$

$\begin{array}{lll}3.7 .3 & \text { Treatment of samples } & \mathbf{8 0}\end{array}$

$\begin{array}{lll}3.7 .4 & \text { Reagents and Materials } & \mathbf{8 0}\end{array}$

$\begin{array}{lll}3.7 .5 & \text { Apparatus } & 81\end{array}$

$\begin{array}{llr}3.8 & \text { RESULTS AND DISCUSSION } & 82\end{array}$

3.8.1 Effects of concentration of Alcoa Activated Alumina and the concentration of metal ion on the kinetics of metal binding 
3.8.2 Comparison of kinetics of binding of $\mathrm{Ni}(\mathrm{II}), \mathrm{Cd}(\mathrm{II})$, and $\mathrm{Zn}$ (II) by Alcoa by Chelex-100 cation exchange resin and by Alcoa Activated Alumina from a model solution.

3.8.3 Results of kinetic analysis of $\mathrm{Ni}$ (II), $\mathrm{Cd}(\mathrm{II})$, and $\mathrm{Zn}$ (II) complexes in a Rideau surface water sample 


\section{LIST OF TABLES}

Table 1.1 Analysis line and instrumental conditions for graphite platform furnace atomic absorption spectrometry.

Table 1.2 Instrument operating conditions and data acquisition parameters for inductively coupled plasma mass spectrometry (ICP-MS) determination. 12

Table 1.3 Method used for cleaning.

Table 1.4 Dissolved organic carbon (DOC) and $\mathrm{pH}$ of rain, and snow-melt and river surface water samples.

Table 1.5 Time dependence of $\mathrm{pH}$ and dissolved lead in a snow-melt sample during storage (24hrs) in a $250 \mathrm{~mL}$ Teflon tlask at $22{ }^{\circ} \mathrm{C}$.

Table 1.6 Time dependence of $\mathrm{pH}$ and dissolved copper in a snow-melt sample during storage $(24 \mathrm{hrs})$ in a $250 \mathrm{~mL}$ Teflon tlask at $22^{\circ} \mathrm{C}$.

Table 2.1 Metal forms in natural water.

Taible 2.2 Membrane Characteristics.

Table 3.1 Effact of concentration of Alcoa Activated Alumina on the kinetics of binding of cadmium aquo ions by Alcon Activated Alumina from a model solution.

Table 3.2 Effect of concentration of Alcoa Activated Alumina on the kinetics of binding of zinc aquo ions by Alcoa Activated Alumina from a model solution.

Table 3.3 Effect of concentration of Activaled Alumina on the kinetics of binding of nickel aquo ions by Alcoa Activated Alumina from a model solution. $\quad 88$ 
Table 3.4 Effect of concentration of metal ions on the rate of binding by Alcoa Activated Alumina.

Table 3.5 Comparison of kinetics of binding of aquo ions by Alcoa Activated Alumina and by Chelex-100 cation exchange resin.

Table 3.6 Kinetically distinguishable components of nickel, cadmium, and zinc in a Rideau river surface water sample. 


\section{LIST OF FIGURES}

Figure 1.1 Loss of soluble species of cadmium, lead, copper, and zinc in a rain sample

as a function of storage time in a High Density Polyethylene bottle.

Figure 1.2 Loss of soluble species of cadmium and lead in a rain water sample as a

function of storage time in a polypropylent flask.

Figure 1.3 Loss of soluble species of copper and nickel in a rain water sample as a

function of storage time in a polypropylene flask.

Figure 1.4 Concentration of dissolved species of aluminum, copper, lead in a snow sample as a function of storage time in a Teflon flask.

Figure 1.5 Concentration of dissolved species of nickel and cadmium in a snow sample as a function of storage time in a Teflon flask.

Figure 1.6 Concentration of dissolved species of zinc, aluminum, and cadmium in a rain sample as a function of storage time in Teflon flask.

Figure 1.7 Concentration of dissolved species of copper, nickel, and lead in a rain sample as a function of storage time in Teflon Flask.

Figure 1.8 Concentration of dissolved species of copper, nickel, cadmium and lead in a Rideau river surface water sample as a function of storage time in a Teflon flask.

Figure 1.9 Stability of soluble species of zinc in a snow-rnelt :ample in diffeient container materials.

Figure 2.1 Percentage mass distribution of the Laurentian fulvic acid used

Figure 2.2 Schematic diagram of a modified "Amicon" ultrafiltraticn call used 
in this work.

Figure 2.3 Transmission electron microscopy (TEM) image of a thin section of a new

"unclogged" membrane

Figure 2.4 Transmission electron microscopy (TEM) image of a thin section of a

"clogged" membrane

Figure 2.5 Transmission electron microscopy (TEM) image of a thin section of a "partially clogged" membrane.

Figure 2.6 Effect of membrane pre-treatment on adsorption onto an ultrafiltration membrane.

Figure $2.7 \%$ Recovery of cadmium and lead as a function of volume of ultrafiltrate

Figure $2.8 \%$ Recovery of aluminum and copper as a function of volume of ultrafiltrate.

Figure 3.1 Summary of the experimental approach.

Figure 3.2 Schematic diagram of the ICP-MS used, connected on-line with a Teflon reactor.

Figure 3.3 Effect of concentration of Alcoa Activated Alumina on the rate of binding of cadmium.

Figure 3.4 Effect of concentration of Alcoa Activated Alumina on the rate of binding or zinc.

Figure 3.5 Effect of concentration of Alcoa Activated Alumina on the rate of binding of nickel.

Figure 3.6 Fercentage of nickel remaining in a model solution after binding 
by Chelex -100 and by Alcoa Activated Alumina.

Figure 3.6a Plots weighted residuals as a function of time of binding nickel by Chelex-100 (Curve a and b) and by Alcoa Activated Alumina

(Curve $\mathrm{c}$ and $\mathrm{d}$ ).

Figure 3.7 Percentage of cadmium remaining in a model solution after binding by Chelex-100 and by Alcoa Activated Alumina.

Figure 3.7a Plots weighted residuals as a function of time of binding cadmium by Chelex-100 (Curve $a$ and $b$ ) and by Alcoa Activated Alumina (Curve $c$ and $d$ ).

Figure 3.8 Percentage of zinc remaining in a model solution aftcr binding by Chelex-100 and by Alcoa Activated Alumina.

Figure 3.8a Plots weighted residuals as a function of time of binding zinc by Chelex-100 (Curve a and $b$ ) and by Alcoa Activated Alumina (Curve $c$ and $d$ ).

Figure 3-9 Percentage nickel remaining in a Rideau river surface water sample, as a function of time, after binding by Chelex-100, and plots of weighted residuals as a function of time.

Figure 3.10 Percentage nickel remaining in a Rideau river surface water sample, as a function of time, after binding by Alcoa Activated Alumina and plots of weighted residuals as a function.

Figure 3.11 Percentage cadmium remaining in a Rideau river surface water sample, as a function of time, after binding by Chelex-100 and plots of 
weighted residuals as a function of time.

Figure 3.12 Percentage cadmium remaining in a Rideau river surface water sample, as a function of time, after binding by Alcoa Activated Alumina and plots of weighted residuals as a function of time.

Figure 3.13 Percentage zinc remaining in the Rideau river surface water sample, as a function of time, after binding by Chelex-100 and plots of weighted residuals as a function of time. 


\section{ORGANIZATION OF THE THESIS}

The thesis is divided into three sections. The first section (Chapter 1) consists of a study of the stability of aqueous, environmental samples containing copper, lead, zinc, cadmium, nickel, and aluminum species when they are in contact with particular materials of which the containers are made of, and the dependence of the stability on the sample type. A range of container materials has been investigated, including high density polyethylene, polypropylen. and Teflon. Pyrex glass containers have been excluded a priori because severe loss of $\mathrm{Al}(\mathrm{III}), \mathrm{Pb}(\mathrm{II}), \mathrm{Cu}(\mathrm{II}), \mathrm{Cd}(\mathrm{II})$, and $\mathrm{Ni}(\mathrm{II})$ species stored without acidification in Pyrex glass containers has been reported [1]. Snow-melt, rain, and Rideau river surface water samples have been studied in this investigation.

The second section (Chapter 2) describes problems encountered during fractionation by ultrafiltration (UF), such as membrane clogging and adsorptive losses, and how these can be overcome.

The last section (Chapter 3) deals with the studies of the rate of uptake of the metal ions: nickel, cadmium, and zinc, by commercial Activated Alumina (ALCOA) in a model solution and in a sample of surface water from the Rideau river. The metal ions were quantitated by inductively coupled plasma mass spectrometry (ICP-MS), and the kinetic data were analyzed by the iterative deconvolution method. Each chapter consists of a short introduction describing the purpose of the study and its relation to the preceding chapter(s), a description of the experimental procedures, and a discussion of the results. 


\section{CHAPTER I}

\section{STUDIES ON THE STABILITY OF THE TOTAL DISSOLVED METAL SPECIES IN AQUEOUS, ENVIRONMENTAL SAMPLES}

\section{INTRODUCTION}

Natural waters are mixtures containing chemical species in a dynamic state. At the moment the sample is collected, it is likely to be exposed to conditions significantly different from the $c$ nditions at the source. Thus new chemical processes may alter the sample from its characteristics in the netural water. Ideally, it should be possible to avoid the problems associated with sample collection by using in situ methods of measurement. Most of these techniques are, unfortunately, not sufficiently sensitive for the determination of metals in unpolluted water samples. Therefore, environmental samples generally must be collected and transported into the laboratory for analysis. Consequently, considerable time may elapse between the collection of the sample and the initiation of the analytica:

procedure. As a result, the chemical composition at the time of analysis may not be representative of the original sample and such changes may have a profound impact on our understanding of the status of an ecosystem [2].

\subsection{OBJECTIVES}

The problems of loss of metals in storage presents considerable difficulties in the study of chemical speciation, which itself involves measurement of rate of loss of metals from the solution. The purpose of the present study was to investigate the preservation 
of total dissolved metal under various conditions as a search for a suitable method of storage.

First a general discussion of treatment of samples will be given followed by the pincedures followed in the present study.

\subsection{LOSS OF HEAVY METALS DURING STORAGE}

During sampling, handling and storage, transformation of species may occur for different reasons:

(1) adsorption or desorption on the container wall, or onto particulate matter,

(2) volatilization,

(3) oxidation or reduction,

(4) microbial degradation, causing chemical change, for example, degassing of $\mathrm{O}_{2}$, $\mathrm{CC}_{2}$, and $\mathrm{H}_{2} \mathrm{~S}[3-6]$.

Several approaches have been used in the study of storage losses of heavy metals:

(1) addition of radiotrace:s,

(2) synthetic solutions,

(3) addition of a metal ion whose loss can be readily followed.

All of these approaches may give unrealistic results, if the adsorption reactions are highly dependent on the chemical nature and the physical structure of the adsorbed species. Using the first method, these losses are overestimated because the equilibration time of the added radiotracer is different from the equilibration time of natural aqueous chemical species of the same metal [6]. 
The addition of a large concentration of metal ion may change the original composition of the sample, and the adsorptive behaviour of the added metal species may be quite different from that of the natural species. Therefore, it is difficult to generalize observations made with unspiked real samples since the results are specific to the nature of the adsorbed species which are often too difficult to characterize. As a result, contradictory results have been reported. Most of the disagreement can be traced to some workers using synthetic metal solutions and others using natural waters. In general, those testing synthetic solutions found serious losses [7-10] while, with the exception of Subramanian et al. [1], those using natural sea-water and fresh waters found that the losses of most metals were negligible [11-15]. Although losses of trace metal ions during storage have been investigated, the perind from time of sampling to the time when the first measurement was made, has not yet been considered. In this regard, the studies of Piotrowitz et al. [16] suggest that within this period, interruptions to the natural steadystate and destructive equilibria involving photooxidation and bacterial processes may result in changes in metal species distributions. The time constants for these processes may vary from hours to days. This problem can only be overcome either by performing in situ speciation measurements or by greatly reducing the time between the sampling and analysis.

\subsection{METHODS FOR SAMPLE PRESERVATION}

Several methods have been developed to preserve the sample and reduce its loss during storage. The most common changes, that preservation techniques attempt to 
minimize are physical changes, such as adsorption, precipitation and volatilization, and chemical changes, such as air oxidation, microbial degradation, and photochemical changes. These changes are minimized with a variety of techniques, including sample container, chemical additives, and temperature control. In particular the most widely uscd methods of preservation for total metal concentration in aqueous solutions involve acidification [6,1], refrigeration [6,1], freezing [6], addition of biocide [6], and filtration [6].

Acidification of aqueous samples before storage is not a solution for speciation measurements because it may destroy the identity of the chemical species present in the samples and may release metals from particulate matter, resulting in changes in metal speciation. It should also be kept in mind, for general trace-metal analysis, that acidification of fresh water samples can cause the precipitation of humic material, which usually carries down with it some heavy metals [17].

Although freezing of samples will stop any microbial activity, it cannot be indiscriminately applied to speciation studies for two main reasons:

i) the freezing process will break (lyse) cells. Consequently intracellular organic materials, and their associated trace metals will be freed, and the original identity or concentration of chemical species will not ke preserved;

ii) as the water sample freezes inwards, metal ions will continuously migrate to the liquid remaining in the centre of the container. Consequently this relatively high transient concentration of ions can cause irreversible hydrolysis and polymerization [17]. 
Refrigeration is not a very useful technique for preservation of chemical species because the biotic processes are still going on, albeit more slowly.

Filtration of aqueous ("whole") samples is often recommended for different reasons. First, filtration avoids any long term interaction of insoluble particles and dissolved trace compounds. Insoluble particles may dissolve slowly and thus change the pH and ionic strength of the sample [6]. This, in turn, may change the composition and partitioning between the solid and the liquid phases of the samples. Second, the particulate portion would gradually settle in the sampling bottle and reliable statistical recovery becomes very difficult. Third, inhomogeneities can result in low precision of an individual trace metal determination in the sample. Fourth, filtration is necessary to remove micro-organisms which would otherwise modify the medium, for example, by producing or consuming $\mathrm{CO}_{2}$, consuming phosphates, or releasing organic matter. It should be noted however that even after filtration, enzymatic activity may persist and could modify the nature and concentration of organic compounds [6].

\subsection{DIFFERENTIATION BETWECN "DISSOLVED" AND "PARTICULATE" METALS}

The chemical composition of natural waters is highly complex. A simple scheme to characterize a water sample involves dividing it into groups of constituents possessing similar properties. The most common classification is based on the distinction between two phases, dissolved and particulate. The separation is done by filtration through a membrane filter of $0.45 \mu \mathrm{m}$ pore size. By convention [18], the total soluble metal or 
"dissolved" phase is defined as that portion which is not retained on the $0.45 \mu \mathrm{m}$ membrane filter. The "particulate" phase is defined as the metal retained by the tilter (components with a size of $>0.45 \mu \mathrm{m}$ ). The dissolved metal includes inorganic metal complexes, ion pairs, low and high molecular weight complexes (such as meta! bound to humic and fulvic acids), and highly dispersed colloids. The distinction between "dissolved" and "particulate" material was first operationally defined by Goldberg et al. [19], who used filters with a nominal pore size of $0.5 \mu \mathrm{m}$. This !imit is widely adopted for discriminating between two size fractions, particulate and dissolved. It should be emphasized that the use of $0.45 \mu \mathrm{m}$ filters for discriminating between "particles" and "dissolved compounds" does not imply that a well defined cut-off limit exits in natural waters or is even achieved by such filtration. Although most (but not all) particles larger than the filter pore size are normally retained, many smaller particles (sometimes 10 to 1000 times smaller than the pore size) may also be retained. The main reasons for the limit being not exact are:

(i) the width of the filter pore size distribution, which depends primarily on the nature of the filter;

(ii) the coagulation properties of macromolecules and colloids in the bulk sample and at the filter surface;

(iii) the interactions of solutes, even of very small size, with the filter material; and

(iv) the wide range and shapes and possible conformational changes of aquatic colloids. 
Effects (ii) and (iii) arz often important so that filtration with $0.45 \mu \mathrm{m}$ filters cannot be viewed just as a sieving process, without physicochemical influences.

\subsection{MATERIALS FOR CONSTRUCTION OF SAMPLE CONTAINERS AND SAMPLING APPARATUS}

The optimum container materials and conditions for their use must be selected, in order to obtain reliable results from speciation measurements. This selection will reduce the amount of metal leaching from the container walis and also reduce losses of chemical species by adsorption on the container surface. The choice of container is determined both by its adsorptive properties and the presence of surface impurities. An excellent review of materials suitable for containers and apparatus required for trace and ultratrace analysis is available [20]. Detailed examination of trace elements in some materials that are significant in trace analysis has also been recorded [21]. The contamination contributed by walls of containers compete with those introduced by laboratory air in trace analysis. Several factors must be considered in the selection of the sample container:

* the cleanliness of the containers,

* the cost of the containers and associated costs for shipping the sample to the laboratory,

* the ease of use for field applications.

A range of container materials have been used [6], including polyethylene, polypropylene, Teflon, polycarbonate, and borosilicate glass. Glass has been shown to 
function as a weak ion exchanger [22]. In weakly acidic and slightly alkaline solutions, the negatively-charged silicic acid groups on the surface permit cation exchange [23-24]. Doremus [24] showed that the potential ion exchange capacity of soda glass is significantly higher than a standard polysulfonate resin. The introduction of borosilicate groups alters the adsorptive behaviour of the glass, resulting in an order of magnitude decrease in ion exchange "capacity". Soda glass containers should therefore be avoided.

The adsorption of metal ions on glasses and oxide surfaces has been the subject of many investigations, and it is now well established that the degree of adsorption is dependent on the ability of the metals to be hydrolysed. Little adsorption occurs in acid solutions where simple ionic metal species are present, but with increasing $\mathrm{pH}$ and the formation of hydrolysed metal ions having a reduced positive charge, increased adsorption is obsorved [25]. Significant adsorption occurs at a lower $\mathrm{pH}$ for the more readily hydrolysed metal ions such as $\mathrm{Fe}(\mathrm{III})$ and $\mathrm{Cr}(\mathrm{III})$ [6]. In general adsorptive losses are lower on polymer material than on Pyrex glass [6].

The suitability of container materials for trace metal based on their degree of contamination have been rated as follows: polyfluorocarbons (Teflon) very suitable; polyethylene, suitable; polypropylene moderately suitable; vitreous silica not suitable.

\subsection{CLEANING PROCEDURES FOR SAMPLE CONTAINERS}

Comprehensive cleaning procedures must always be adopted for trac: and ultratrace ana!ysis. A container blank of $0.1 \mathrm{ng}$ for a particular element is often needed. Several cleaning procedures were reported in the literature. Laxen and Harrison [26] 
recommended soaking linear-polyethylene bottles in $10 \%$ nitric acid for $\mathbf{4 8}$ hours at room temperature followed by a water rinse. Mart [14] recommended that polyethylene bottles be first treated with hot acid $\left(10 \% \mathrm{HCl}\right.$ heated to $70{ }^{\circ} \mathrm{C}$ for 4 days) before acid leaching, at room temperature but Nurnberg et al. [4] claimed that this treatment could activate the surface of the polyethylene and cause losses of metal by adsorption. For fresh water samples they found it necessary to remove these activated sites by first rinsing the bottle with a solution of calcium and magnesium sulphates. Mart [14] used $1 \mathrm{M}$ hydrochloric acid for the initial hot acid cleaning, although Laxen and Harrison [26] reported that polyethylene absorbs traces of $\mathrm{HCl}$, which interferes in the carbon-furnace AAS determination of some metals, and in the determination of copper by ASV. Cleaning steps vary with the chemical behaviour of the element undergoing analysis. Therefore, it is appropriate to describe in detail the cleaning procedure adopted.

\subsection{EXPERIMENTAL}

\subsubsection{APPARATUS}

An atomic absorption spectrometer (Perkin-Elmer Model 5000) with a Zeeman background corrector (Perkin-Elmer Zeeman, Model 5000) equipped with an autosampler, and an inductively-coupled plasma mass spectrometer (Perkin Elmer Sciex Elan-5000) were used in the determination of total metal in the soluble phase. For graphite furnace spectrometry (GFAAS), an HGA-500 graphite furnace, fyrolytically-coated graphite tubes (Perkin-Elmer catalog No.109322) and laboratory made piatforms fabricated from anisotropic graphite were used. The manufacturer's recommended operating conditions 
for the spectrometer were followed. Argon gas was flushed through the graphite tube at a flow rate of $300 \mathrm{~mL} / \mathrm{min}$,during the drying, pyrolysis, and cleaning but was stopped during the atomization step. The interruption of gas flow during the atomization step is a capability of the furnaca programmer and generally improved detection limits. Table 1.1 presents the instrumental parameters used with the graphite platform furnace atomic absorption spectrometer. For the determination of metal concentrations, 10-20 $\mu$ l of the sample was injected into the graphite furnace by an autosampler (Perkin Elmer Model AS-40), where it was dried, charred and atomized. The signal was measured in the peak area mode. Each completed dctermination was foliowed by a 3-s clean-up step of the graphite tube at $2600^{\circ} \mathrm{C}$.

For inductively-coupled plasma mass spectrometry (ICP-MS), the sample solution was continuously delivered using a peristaltic pump at a flow rate of $1 \mathrm{ml} \mathrm{min}^{-1}$ through a solution nebulizer to the ICP :orch where it was dried, atomized and ionized. The ionic species were then analyzed according to their mass/charge ratio by a quadrupole mass analyzer, followed by signal detection with a channel electron multiplier. The signal (counts $\mathrm{s}^{-1}$ ) was monitored as a function of time. Table 1.2 lists experimental conditions and the data acquisition protocol for the ICP-MS determination.

Laboratory pH measurements were performed using a combined glass electrode (Accumet-pH electrode) and a digital Fisher-Scientific pH-meter (mod_l Accumet 925). 
TABLE 1.1 Analysis line and instrumental conditions for graphite platform furnace atomic absorption spectrometry

\begin{tabular}{ccccc}
\hline Element & Analysis line & Pyrolysis & \multicolumn{2}{c}{ Atomization parameters } \\
& & Temperature ${ }^{\circ} \mathrm{C}$ & Temp. & Duration \\
& & & ${ }^{\circ} \mathrm{C}$ & sec. \\
\hline $\mathrm{Al}$ & 309.2 & 1300 & 2400 & 7 \\
$\mathrm{Cd}$ & 228.8 & 400 & 1600 & 4 \\
$\mathrm{Cu}$ & 324.8 & 1200 & 2300 & 5 \\
$\mathrm{Ni}$ & 232.0 & 1000 & 2400 & 8 \\
$\mathrm{~Pb}$ & 283.3 & 500 & 1900 & 5 \\
$\mathrm{Zn}$ & 213.9 & 500 & 2000 & 5 \\
\hline
\end{tabular}


TABLE 1.2 ICP-MS hardware, operating conditions and data acquisition parameters for ICP-MS determination

Inductively Coupled Plasma

Radio frequency generator

$35 \mathrm{MHz}$

Distance from load coil to

sample orefice

$17 \mathrm{~mm}$

Radio frequency power

$1000 \mathrm{~W}$

Coolant argon flow rate

$15.0 \mathrm{~L} \min ^{-1}$

Auxiliary argon flow rate

$850 \mathrm{~mL} \mathrm{~min}^{-1}$

Carier argon flow rate

$900 \mathrm{~mL} \mathrm{~min}^{-1}$

Sample flow rate

$1.0 \mathrm{mLmin}^{-1}$

Mass Spectrometer

Sampler nickel

$1.14 \mathrm{~mm}$ orefice

Skimmer nickel

$0.89 \mathrm{~mm}$ orefice

Resolution

high

Dwell time

$1000-5000 \mathrm{~ms}$

Scan mode

Peak hop

Point/spectral peak 


\subsubsection{POLYFLUOROCARBONS (Teflon), POLYETHYLENE, POLYPROPYLENE}

Three types of container materials have been tested for their adsorption properties with respect to trace metals over a period of 2 hours: high-density polyethylene, polypropylene, and Tetlon. Teflon containers were also investigated over a period of 24 hours using snow sample. The containers used were screw-cap bottles and screw-cap flasks. Container volumes were 1000,500 and $250 \mathrm{~mL}$ for high-deissity polyethylene and $250 \mathrm{~mL}$ for polypropylene and Teflon. Polytetrafluoroethylene is the most chemically stable polymeric material currently available, and, only molten alkali metals and elemental fluorine are reported to react with it. Its disadvantages are permeability to gases and solvents. Teflon (TFE) and Teflon (FEP) are polytetrafluoroethylene and fluorinated ethylene-propylene, respectively. The good stability of Teflon (TFE) has been observed for Teflon (FEP) also. Microscopic examination of the (FEP) bottles show the presence of many fine particles embedded in the walls, up to about $7 \mu \mathrm{m}$ below the surface. Laser probe spectroscopy analysis of these particles detected iron, zinc, aluminum, nitrogen, copper, and manganese among the constituents [20]. These inclusions may play a role in ultratrace analysis of iron and zinc. However, these impurities can be removed, in part, by extended cleaning.

Polyethylene is the most common polymer material in the laboratory, mainly because of it low price, and resistance to aqueous solutions of standard and reagents. Polypropylene is harder and more rigid than conventional polyethylene; it adsorbs trace quantities of most ions from dilute aqueous solutions. 


\subsubsection{CLEANING PROCEDURES}

All the containers were cleaned with the procedure suggested by John R. Moody and R.M. Lindstrom [21] Table 1.3. Before use, any containers found to give blanks, using ultrapure water acidified to $\mathrm{pH} 1.0$ with nitric acid, with concentrations of trace mi iai three times bigger than standard deviation of the blank were rejected. The 0.45 $\mu \mathrm{m}$ filters (GELMAN) were soaked in $0.5 \% \mathrm{HNO}_{3}$ (ULTREX II) for 24 hours, followed by a rinse with ultrapure water, to leach out trace metals.

TABLE 1.3 Method used for Cleaning Containers

1. Fill with $1+1 \mathrm{HCl}$ (AR grade).

2. Allow to stand one week at room temperature.

3. Empty and rinse with ultrapure water.

4. Fill with $1+1 \mathrm{HNO}_{3}$ (AR grade).

5. Allow to stand one week room temperature.

6. Empty and rinse with ultrapure water.

7. Fill with ultrapure water 18.2 megohm.

8. Allow to stand several weeks or until need, changing water periodically to ensure continued cleaning.

Adopted from Ref. [27]. 


\subsubsection{STANDARDS AND REAGENTS}

All stock solutions contained $1 \%(\mathrm{v} / \mathrm{v}) \mathrm{HNO}_{3}$, ULTREX-brand (The Baker Chemical Co., USA). The stock solution, containing $1000 \mu \mathrm{g} / \mathrm{L}$ of each element "ras prepared and stored separately in high-density polyethylene bottles. For lead, $1.5994 \mathrm{~g}$ of $\mathrm{Pb}\left(\mathrm{NO}_{3}\right)_{2}$ (Fisher Scientific A.C.S. reagent) was dissolved in ultrapure water, and diluted to $1 \mathrm{~L}$ with ultrapure water. The stock solution for copper was prepared by dissolving $0.9995 \mathrm{~g}$ copper metal in $10 \mathrm{~mL}$ concentrated nitric acid, ULTREX-brand, and diluted to $1 \mathrm{~L}$ with ultrapure water. The nickel stock solution was prepared by dissolving $0.9997 \mathrm{~g}$ of $\mathrm{Ni}$ metal powder $(99.999 \%$ pure, SPEX) in concentrated nitric acid, ULTREX-brand, and diluted to $1 \mathrm{~L}$ with ultrapure water. A stock solution of aluminum was prepared by dissolving $0.5000 \pm 0.004 \mathrm{~g}$ aluminum powder (SPEX) ir $20 \mathrm{~mL} \mathrm{HCl}$ $\mathrm{H}_{2} \mathrm{O}(1: 1)$ (the $\mathrm{HCl}$ was Ultrex brand) with heating and diluting to $500 \mathrm{n}_{4}$ with ultrapure water. A reagent solution $\left(1000 \mu \mathrm{g} \mathrm{m}^{-1}\right)$ of $\mathrm{Zn}$ was purchased from BDH. For Cd, 1.1528 $\pm 0.0001 \mathrm{~g}$ of $\mathrm{CdO}$ (Baker Analyzed Reagent, $99.1 \%$ pure, dried at $100{ }^{\circ} \mathrm{C}$ for 2 hours)

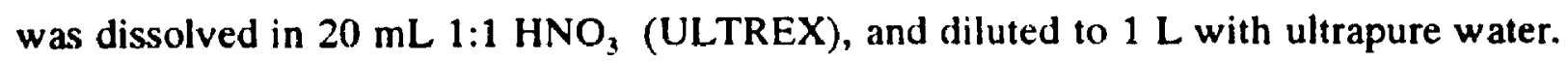

The standards of all elements contained $1 \%(\mathrm{v} / \mathrm{v}) \mathrm{HNO}_{3}$ and were prepared daily by serial dilution of the stock solutions with ultrapure water immediately prior to their use. Ultrapure water of resistivity $18.2 \mathrm{megohm}-\mathrm{cm}$ was obtained directly from a Mill-Q2 Water Purification System (Millipore Corporation).

\subsubsection{COLLECTION AND PRE-TREATMENT OF WATER SAMPLES}

Samples of rain and snow were collected at a site on the roof top of the chemistry 
building at Carleton University. A water sample (5 litres) from the Rideau River was collected using a pre-cleaned polyethylene water sampler. Immediately after collection, the samples were filtered through a $0.45 \mu \mathrm{m}$ filter. For each filter, $500 \mathrm{~mL}$ of ultrapure water was first passed through the filter followed by a small portion of the sample to condition the filter. Then this $500 \mathrm{~mL}$ of the filtrate was discarded to avoid any dilution of the sample. The filtrate was used in subsequent work. When using graphite furnace atomic absorption spectrometry, $1 \mathrm{~mL}$ aliquots of the test solutions were acidified with $10 \mu \mathrm{L}$ of concentrated nitric acid in small vials. For analysis by ICP-MS, the samples were transferred into a cleaned container which was connected directly to the tube of the nebulizer of the ICP-MS.

\subsubsection{DETERMINATION OF DISSOLVED ORGANIC CARBON (DOC)}

The inorganic carbon (IC) and the total carbon (TC) concentrations were measured using a Total Organic Carbon Analyzer (Model TOC-5000). The TC was determined by combusting the water samples at $680^{\circ} \mathrm{C}$ and using the catalyst recommended for regular sensitivity measurement (P/N 017-42801-01). The combustion product $\left(\mathrm{CO}_{2}\right)$ was carried, by purified air and oxygen at a flow rate of $150 \mathrm{~mL} / \mathrm{min}$ and was detected by a nondispersive infrared gas analyzer (NDIR) [28]. 
The IC components in the sample were determined by converting into $\mathrm{CO}_{2}$ in the IC reaction vessel containing the $\mathrm{IC}$ reagent (a solution of phosphoric acid). The $\mathrm{CO}_{2}$ formed was also detected by NDIR [28]. The DOC concentrations in rain, snow and river surface water samples were determined by subtracting the Inorganic Carbon (IC) concentrations from the Total Carbon (TC) concentrations.

\section{8 RESULTS AND DISCUSSION}

\subsubsection{DISSOLVED ORGANIC CARBON, AND pH}

Table 1.4 presents the Dissolved Organic Carbon (DOC), and the $\mathrm{pH}$ of the samples of rain, snow-melt and Rideau River surface water. The $\mathrm{pH}$ of the Rideau River water and the snow-melt were relatively constant. The values were: $\mathrm{pH}=8.0 \pm 0.1$ for Rideau River water, and $\mathrm{pH}=5.5 \pm 0.1$ for snow-melt. The $\mathrm{pH}$ of the rain water, however, varied from day to day from $\mathrm{pH}=5.5$ to $\mathrm{pH}=7.0$. These large variations can be attributed to the presence of gases such as nitrogen oxides $\left(N O_{x}\right)$ and sulphur dioxide $\left(\mathrm{SO}_{2}\right)$ in the atmosphere. It was observed that after a long period of rain the water was

neutral, probably due to removal of the oxides by the first rain fall. As expected, the DOC content was higher in river surface water than in atmospheric precipitation. 
TABLE 1.4 Dissolved organic carbon (DOC) and pH of rain, snow-melt and river surface water samples.

\begin{tabular}{|c|c|c|c|}
\hline Sample Type & Date of collection & $\mathrm{pH}$ & DOC ppm \\
\hline Rain & June 15,1993 & 5.5 & $\therefore$ \\
\hline Rain & July 10,1993 & 7.0 & - \\
\hline Rain & Aug. 18, 1993 & 5.4 & - \\
\hline Rain & Oct. 21,1993 & 6.8 & - \\
\hline Rain & Nov. 2, 1993 & 5.5 & - \\
\hline Rain & Nov. 6, 1993 & 5.0 & - \\
\hline Rain & Nov. 15, 1993 & 4.6 & 3.4 \\
\hline Rain & Dec. 12,1993 & 4.8 & 1.6 \\
\hline Snow-melt & Nov. 22, 1993 & 5.5 & - \\
\hline Snow-melt & Jan. 6, 1994 & 5.5 & - \\
\hline Snow-melt & Feb. 24, 1994 & 5.4 & 1.0 \\
\hline Snow-melt & Feb. 25, 1994 & 5.5 & 0.7 \\
\hline Snow-melt & Mar. 10, 1994 & 5.3 & 1.1 \\
\hline Snow-melt & Mar. 11, 1994 & 5.6 & 1.4 \\
\hline River surface water & Nov. 24, 1993 & 8.1 & - \\
\hline River surface water & Mar. 11, 1994. & 7.9 & 6.6 \\
\hline
\end{tabular}

* not determined. 


\subsubsection{STABILITY OF TOTAL DISSOLVED METALS IN VARIOUS CONTAINER MATERIALS}

Although the literature contains valuable data, some of them are contradictory [715]. As well, the period elapsed from time zero to the time when the first measurements are made, has not always been considered [6]. This may be as long as eight hours, although two to three hours is typical [6]. In this regard, the studies of Piotrowitz et al. [16] suggest that perhaps storage for these periods causes within this period, interruptions to the natural steady-state and destructive equilibria involving photooxidation and bacterial processes and may result in changes in metal species distributions. The time constants for these processes may vary from hours to days. This problem can only be overcome either by performing in situ speciation measurements or by greatly reducing the time between the sampling and analysis. Consequently, we have in our work reduced as much as possitle the time between sample collection and analysis. Within 20 minutes after collection, the samples were filtered through a $0.45 \mu \mathrm{m}$ membrane and analyzed by GFAAS. The operating conditions are listed in Table 1.2.

Figure 1.1 shows the percentage of loss of $\mathrm{Pb}$ (II), $\mathrm{Cu}(\mathrm{II}), \mathrm{Cd}(\mathrm{II})$, and $\mathrm{Zn}$ (II) from a rain sample filtered through the $0.45 \mu \mathrm{m}$ filter and stored in a High Density Polyethylene (HDPE) container as a function of storage time. The pH of the sample was $5.5 \pm 0.1$. The percent loss of each element was determined relative to the initial "time zero" measured concentration. The determinations were done by GFAAS. The data points of Fig. 1.1 represent the average of three atomizations of each test solution in duplicate containers. The peak-area mode was used as a measure of the concentration of 


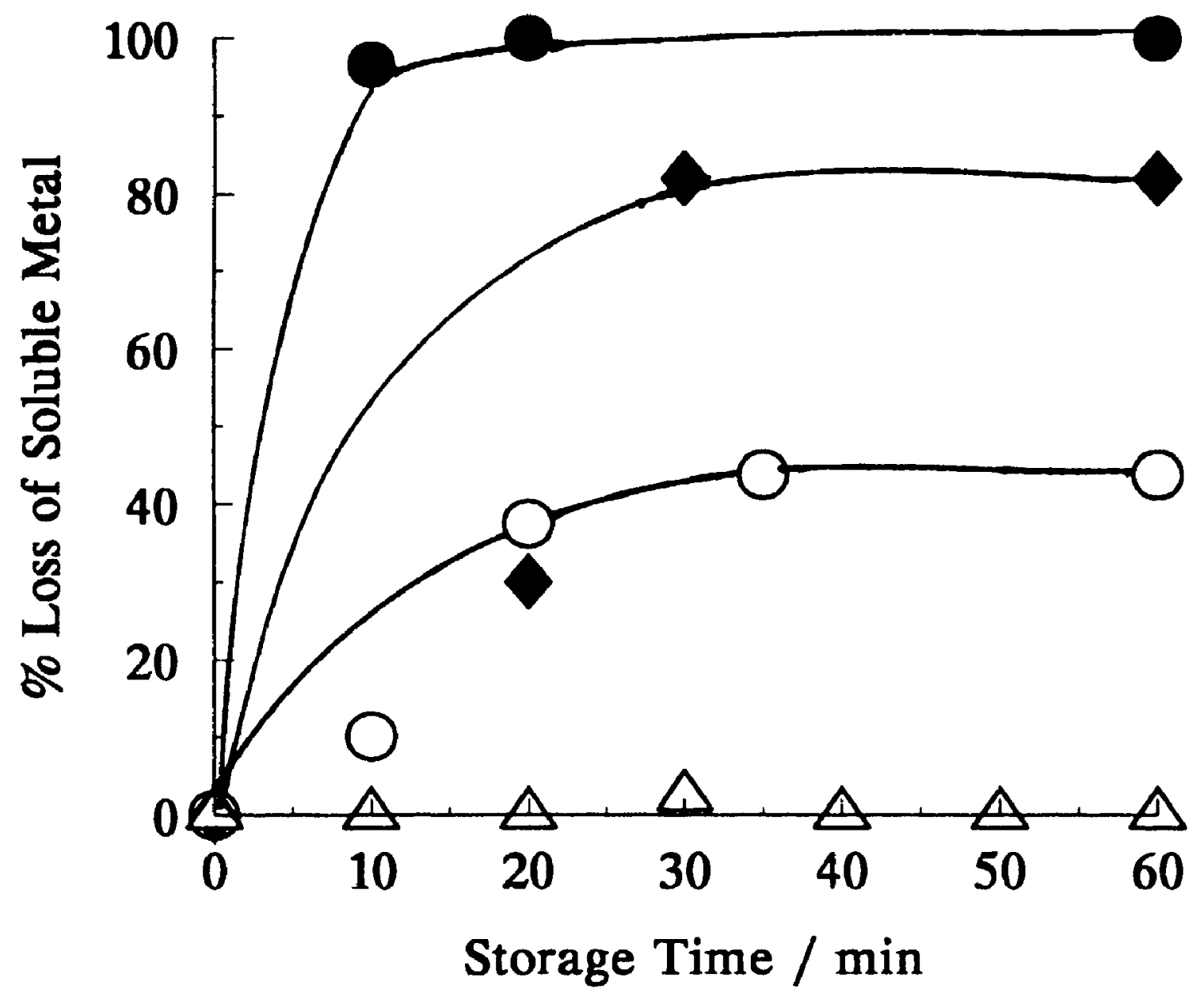

Figure 1.1 Loss of soluble species of cadmium, lead, copper, and zinc in a rain sample as a function of storage time in a High Density Polyethylene bottle at $22^{\circ} \mathrm{C}$. pH $5.5 \pm 0.1$. Determined by GFAAS. Date of collection: June 15, 1993. - $\mathrm{Pb}, \bullet \mathrm{Cu}, \circ \mathrm{Cd}$, and $\Delta \mathrm{Zn}$. 
each of the metals in the soluble phase. From Fig. 1.1 it can be seen that the losses of soluble lead, cadmium, and copper are most rapid in the first 10, 25, and 30 minutes, respectively. These losses are probably mainly due to adsorption. The storage time is too short, for processes such as microbial degradation or regrowth of particles to be important. It can be seen from this figure that only for soluble species of $\mathrm{Zn}$ (II) does short-term storage of rain water samples in HDPE containers result in no loss.

Graphite furnace atomic absorption spectrometry is a discrete sampling system. To obtain shorter intervals betw'cen measurements and to avoid prolonged contact time between sample and sample delivery apparatus, which may lead to other losses and contamination inductively-coupited plasma mass spectrometry with continuous sampling was used. The hardware and the operating conditions of the ICP-MS are listed in Table 1.2.

Figures 1.2 and 1.3 show the percentage of loss of $\mathrm{Cd}(\mathrm{II}), \mathrm{Pb}(\mathrm{II}), \mathrm{Cu}(\mathrm{II})$ and $\mathrm{Ni}(\mathrm{II})$ from the dissolved phase from a rain water sample collected on Nov. 6, 1993. After filtration through $0.45 \mu \mathrm{m}$ filter the rain sample was stored in a polypropylene flask. The total metal concentration in the dissolved phase was measured immediately and was then monitored for two hours. Figure 1.2 show the loss of soluble $\mathrm{Cd}$ (II) and $\mathrm{Pb}$ (II) species. In Fig. 1.3 it can be seen that half of the losses of $\mathrm{Cu}(\mathrm{II})$ and $\mathrm{Ni}(\mathrm{II})$ occur in the first 30 minutes. This supports our findings from previous experiments using GFAAS and suggests that time is a critical factor in the loss of soluble metal species from solutions in HDPE and polypropylene containers. Thus, in polypropylene containers, the percentage of losses of soluble metal from rain samples in two hours are, for $\mathrm{Cd}(\mathrm{II})$ and 


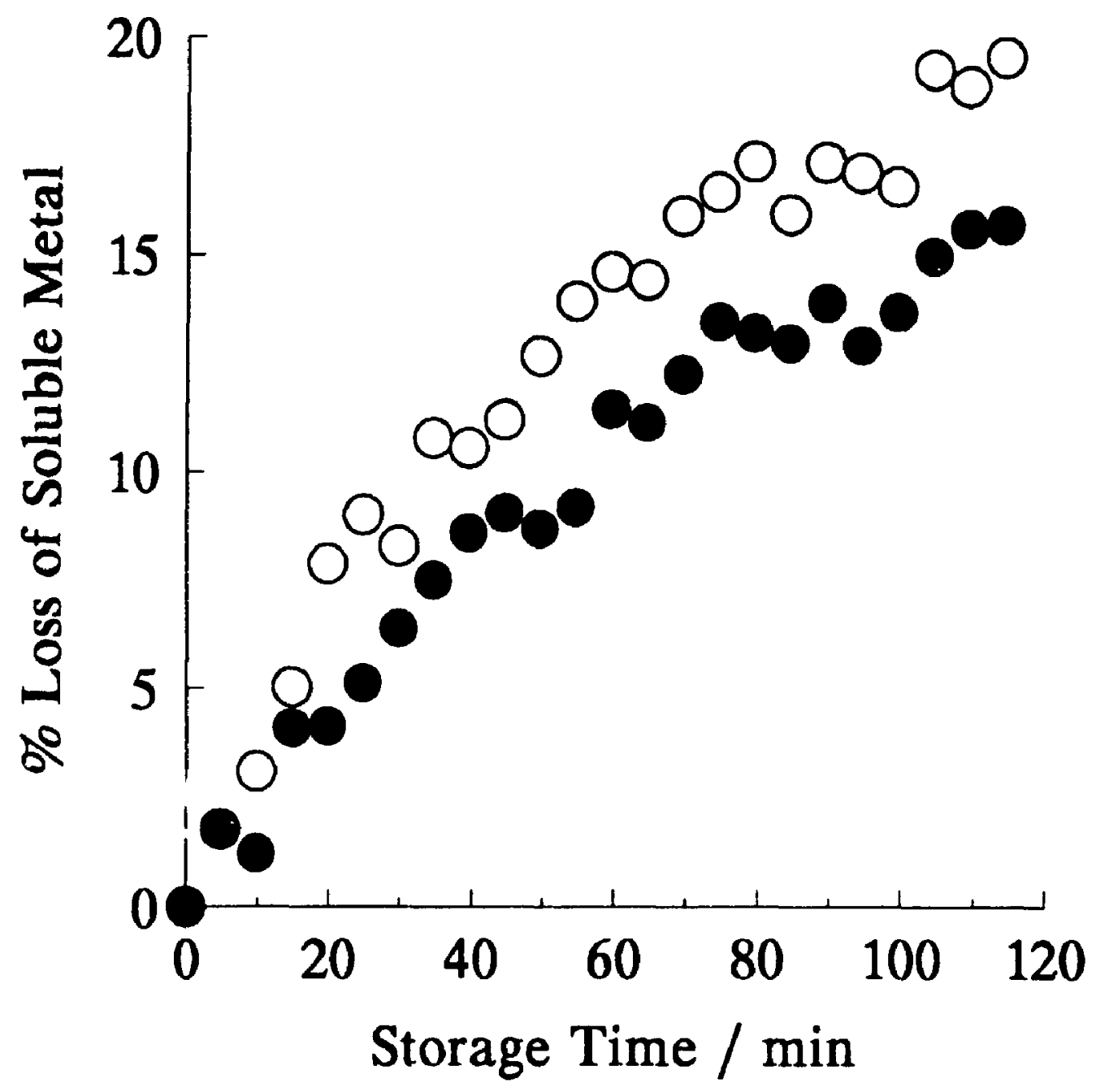

Figure 1.2 Loss of soluble species of cadmium and lead in a rain water sample as a function of storage time in a polypropylene flask at $22^{\circ} \mathrm{C} ; \mathrm{pH} 5.0 \pm 0.1$. Determined by ICP-MS. Date of collection: Nov. 6, 1993. $\circ \mathrm{Cd}, \bigcirc \mathrm{Pb}$. 


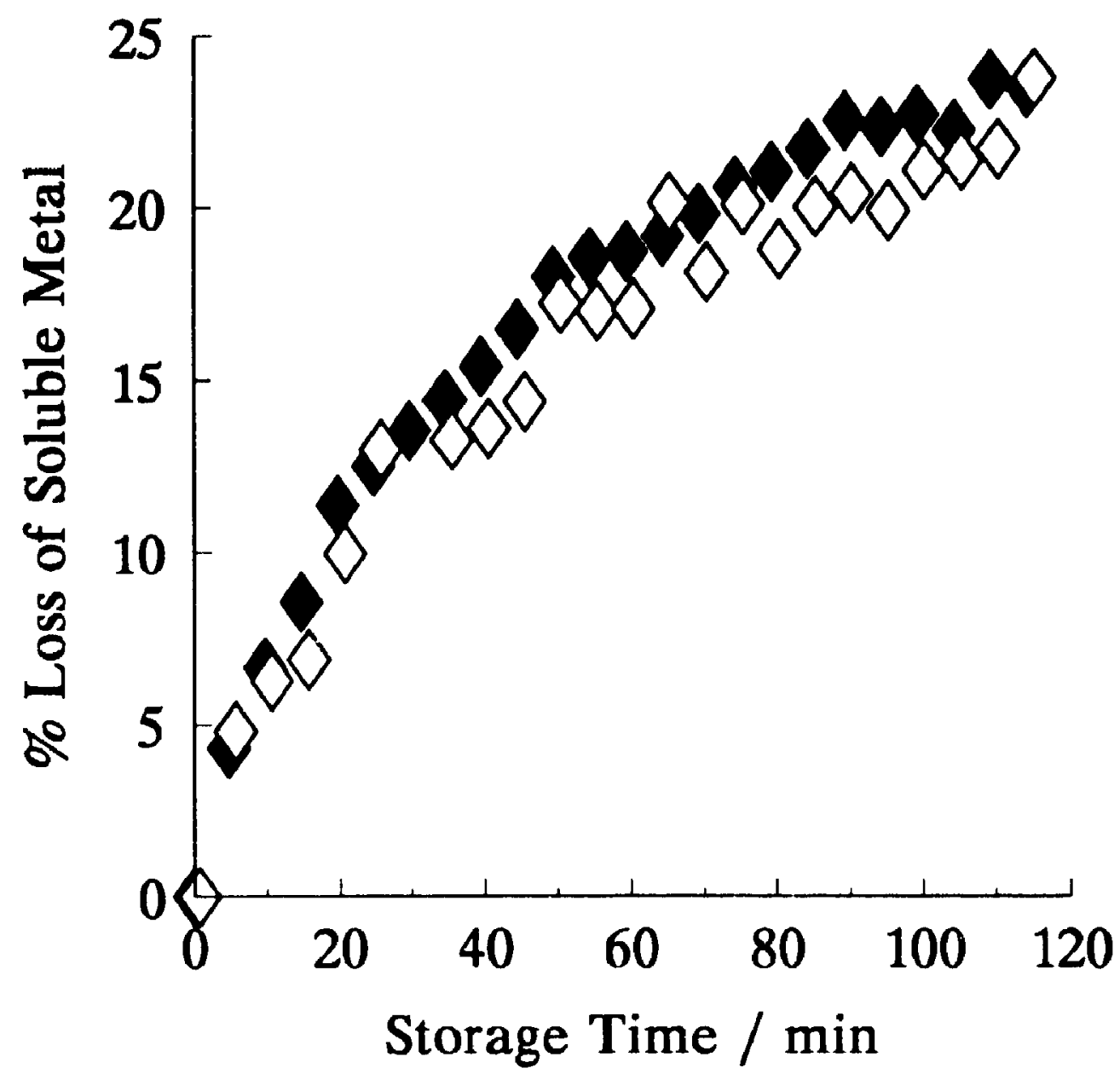

Figure 1.3 Loss of soluble species of copper and nickel in a rain water sample as a function of storage time in a polypropylene flask at $22^{\circ} \mathrm{C} ; \mathrm{pH} 5.0 \pm 0.1$. Determined by ICP-MS. Date of collection: Nov. 6,1993. $\bullet \mathrm{Cu}, \diamond \mathrm{Ni}$. 
$\mathrm{Pb}$ (II) species, approximately $20 \%$ and $15 \%$, and for $\mathrm{Cu}(\mathrm{II})$ and $\mathrm{Ni}(\mathrm{II}), 24 \%$ and $21 \%$, respectively. This adsorptive behaviour of hydrophobic organic polyiners such as polyethylene and polypropylene is believed to involve ion exchange at the charged double layer on the polymer surface. The existence of a negative surface charge has been confirmed by electrosmosis measurements [6].

Teflon containers were tested next. The concentrations of dissolved $\mathrm{Al}(\mathrm{III}), \mathrm{Pb}(\mathrm{II})$, $\mathrm{Cu}(\mathrm{II}), \mathrm{Ni}(\mathrm{II})$, and $\mathrm{Cd}(\mathrm{II})$ species in a snow sample stored in a Teflon flask were monitored over a period of two hours (Fig. 1.4 and 1.5). The total metal concentrations in the dissolved phase were constant within the experimental uncertaint $y$ for all the time monitored. Further measurements were made over a longer time. Another snow sample was collected, melted at room temperature and filtered through a $0.45 \mu \mathrm{m}$ filter. The filtrate was subdivided into three sub-samples and stored in 3 Teflon flasks. After 24 hours of storage the concentration of soluble lead and copper remained constant within the experimental error (<5\%) (Tables 1.5 and 1.6). Table 1.5 and 1.6 show also that the $\mathrm{pH}$ values remained constant during the 24 hours.

The results showed that a Teflon flask was a good container for a snow sample. Further experiments were done to investigate the use Teflon containers for rain and river surface water and to explore the effect of ti:e matrix composition.

For the rain samples the concentrations of dissolved $\mathrm{Zn}$ (II), $\mathrm{Al}(\mathrm{III}), \mathrm{Cd}(\mathrm{II}), \mathrm{Cu}(\mathrm{II})$, $\mathrm{Ni}(\mathrm{II})$, and $\mathrm{Pb}(\mathrm{II})$ species were constant over a period of two hours for all six elements of interest (Fig. 1.6 and 1.7). Similarly, the concentrations of dissolved $\mathrm{Ni}(\mathrm{II}), \mathrm{Cu}$ (II), $\mathrm{Cd}$ II), and $\mathrm{Pb}(\mathrm{II})$ species in the river surface water sample at $\mathrm{pH} 8.1$ were constant over 


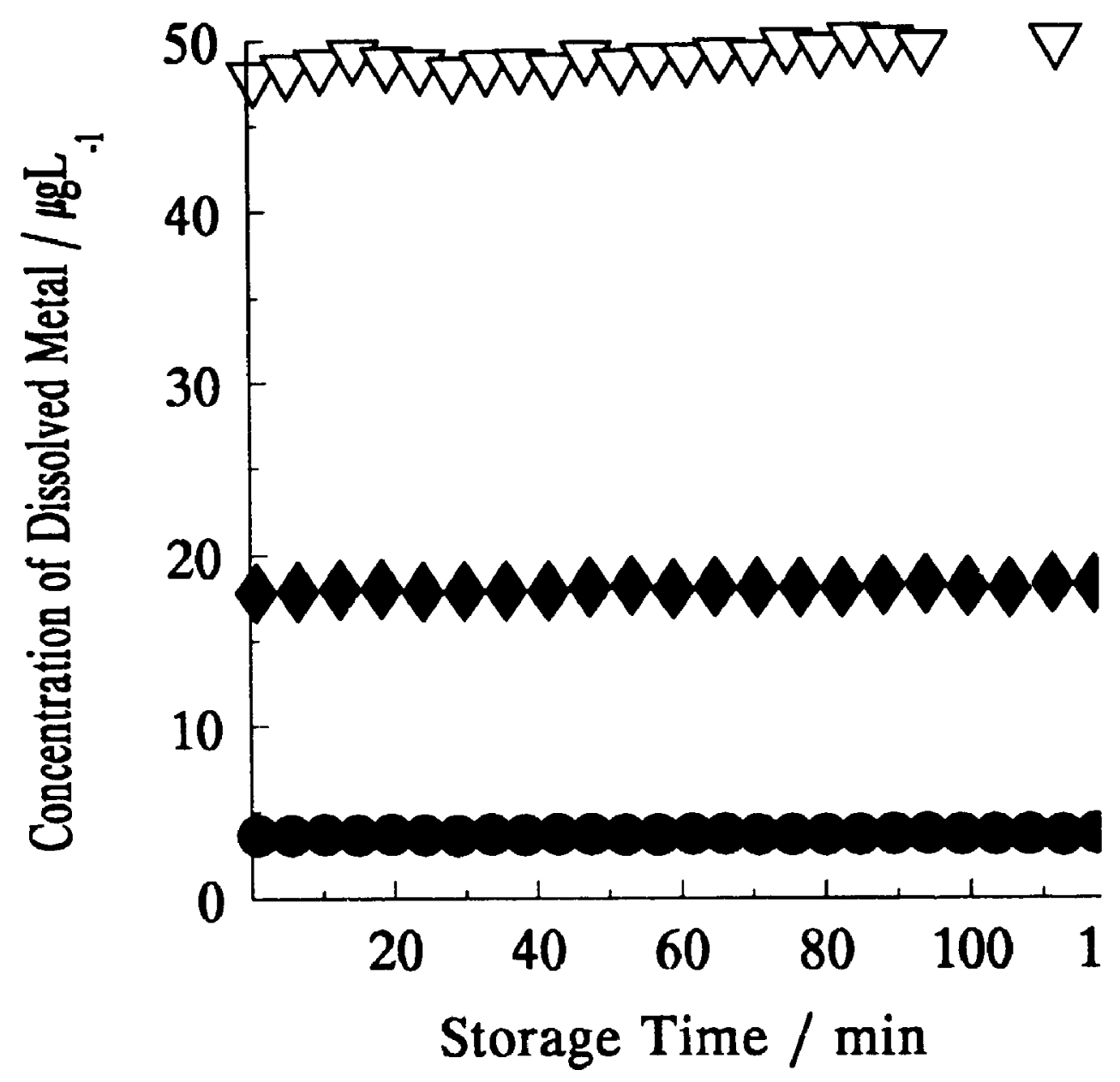

Figure 1.4 Concentration of dissolved metals in a snow sample as a function of storage time in a Teflon flask at $22^{\circ} \mathrm{C} ; \mathrm{pH} 5.5 \pm 0.1$. Determined by ICP-MS. Date of Collection: Nov. 22, 1993. $\nabla \mathrm{Al}, \diamond \mathrm{Cu}, \odot \mathrm{Pb}$. 


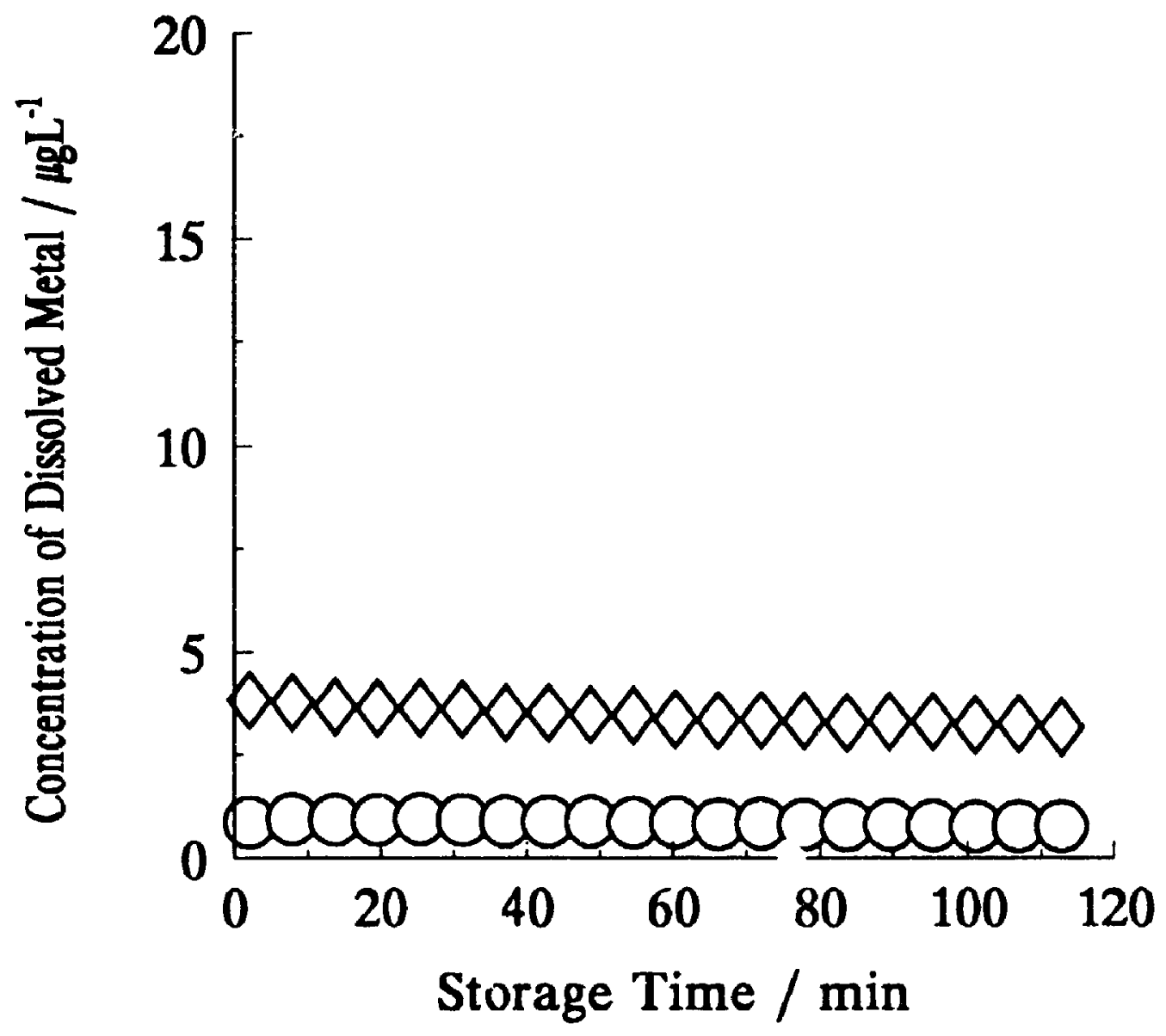

Figure 1.5 Concentration of dissolved metals in a snow sample as a function of storage time in a Teflon flask at $22^{\circ} \mathrm{C}$; pH $5.5 \pm 0.1$. Determined by ICP-MS. Date of Collection: Nov. 2, 1993. $\diamond \mathrm{Ni}, \circ \mathrm{Cd}$. 


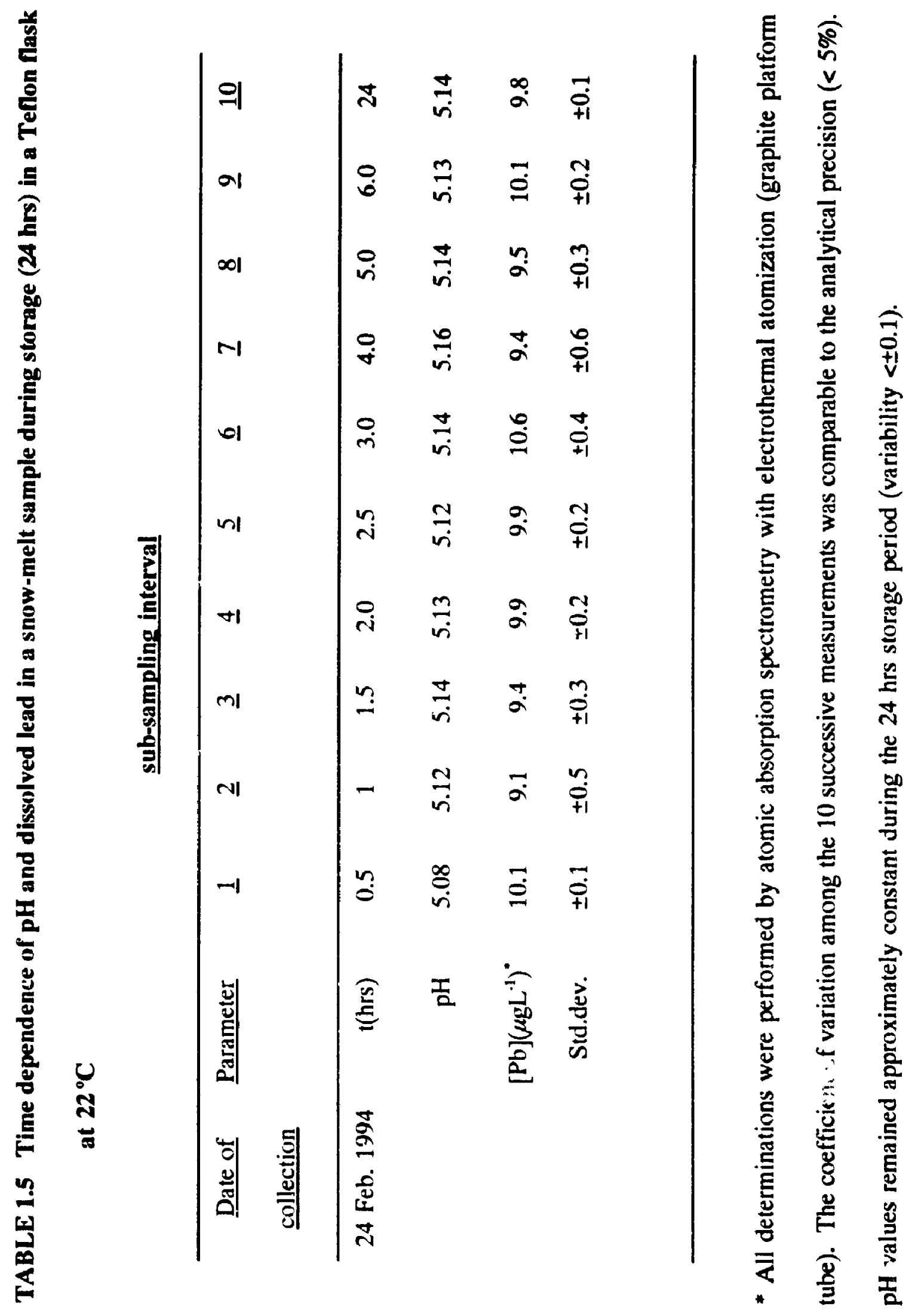




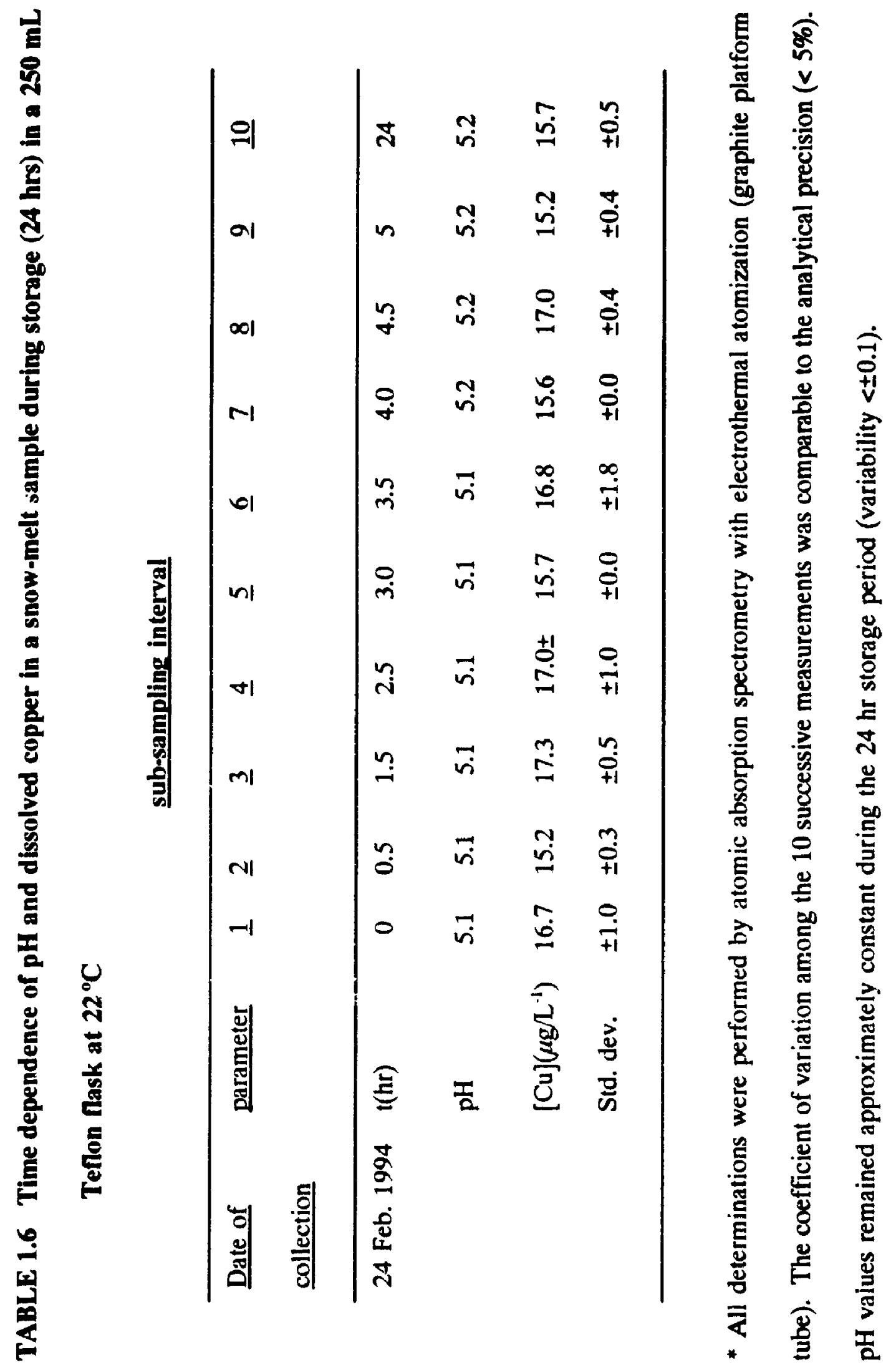




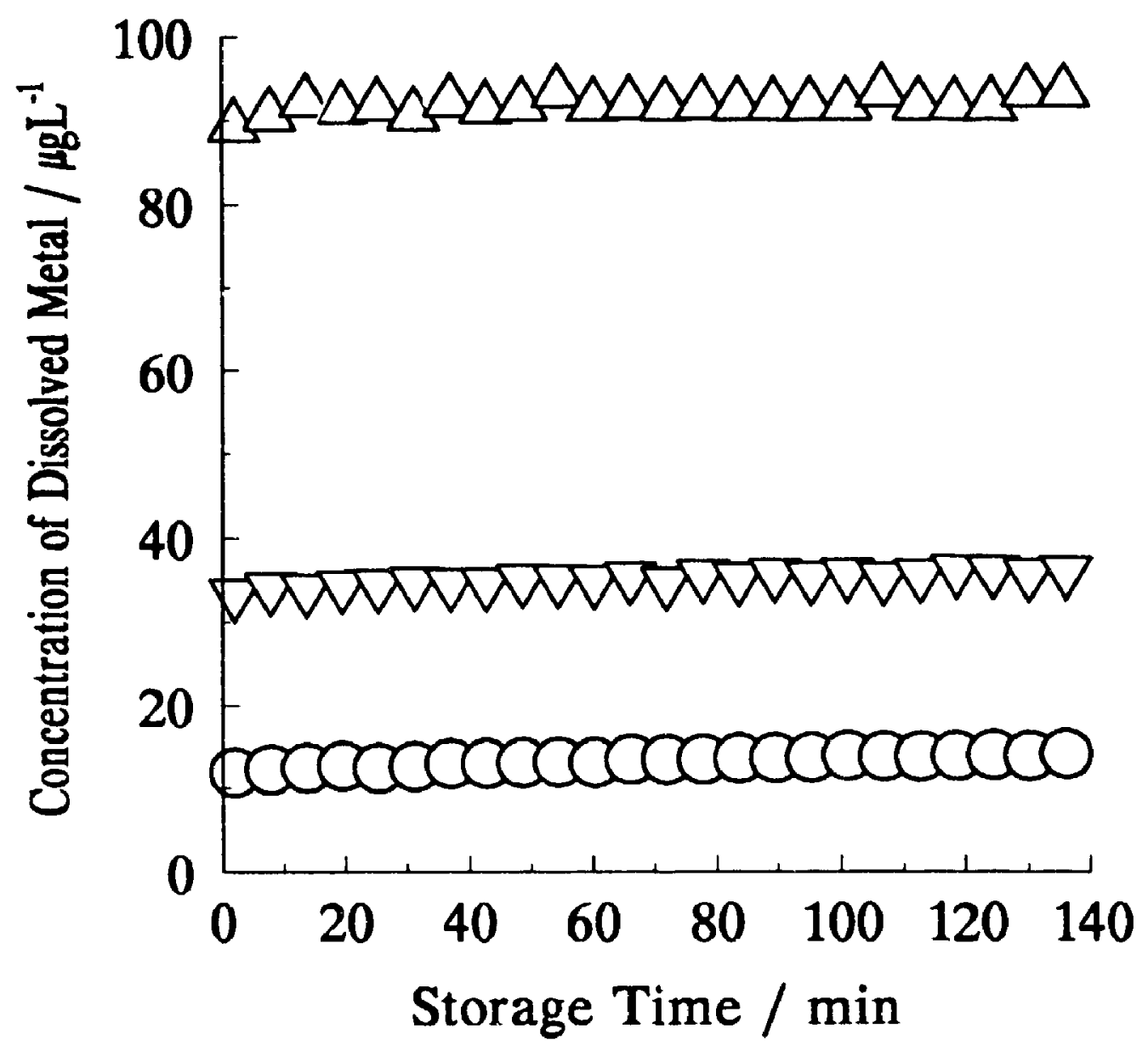

Figure 1.6 Concentration of dissolved species of zinc, aluminium, and cadmium in 9 rain sample as a function of storage time in Teflon flask at $22^{\circ} \mathrm{C}$; $\mathrm{pH} 5.5 \pm 0.1$. Determined by ICP-MS. Date of collect:on: Nov. 2, 1993. $\Delta \mathrm{Zn}, \nabla \mathrm{Al}$, and $\circ \mathrm{Cd}$. 


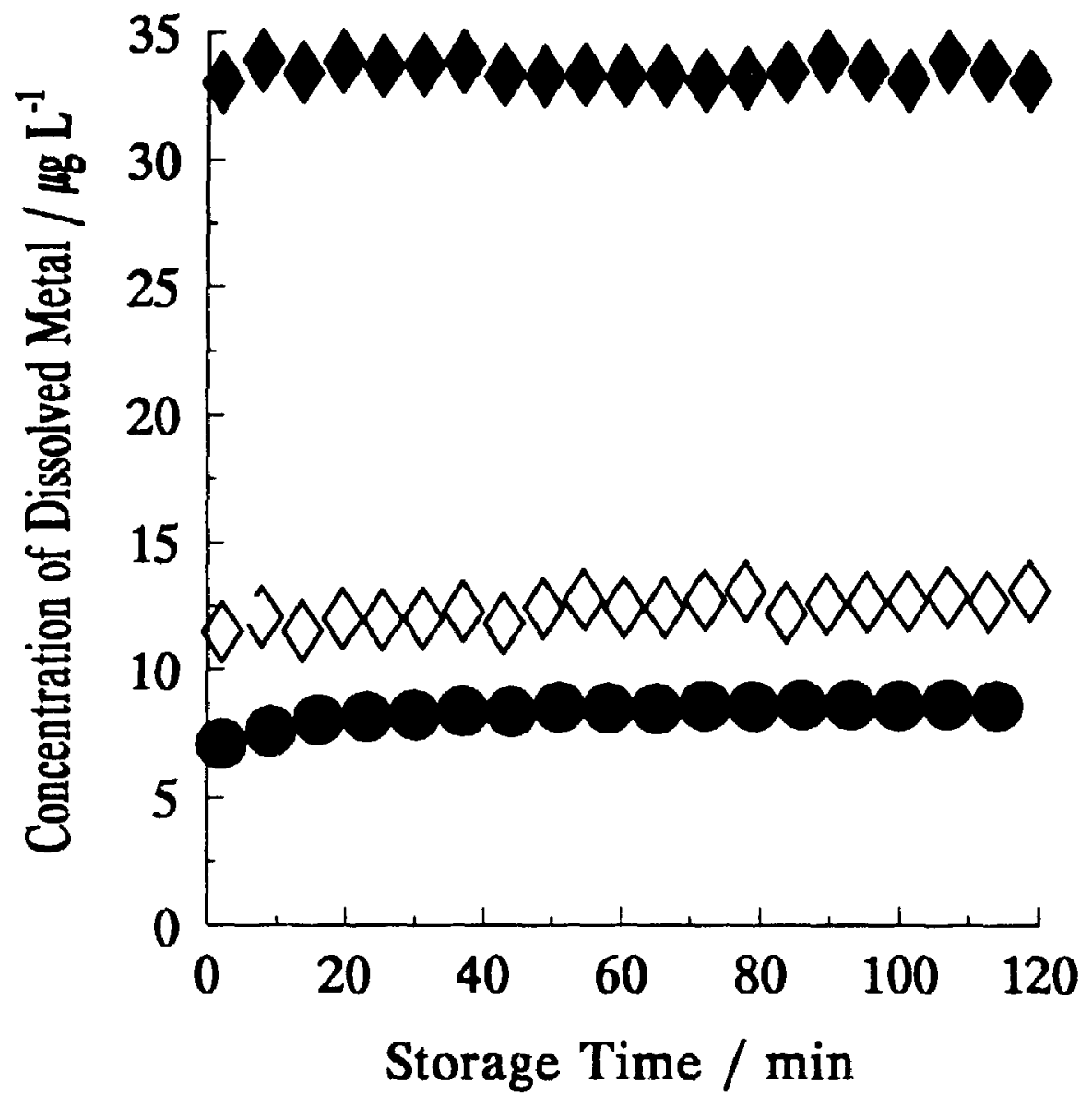

Figure 1.7 Concentration of dissolved species of copper, nickel, and lead in a rain sample as a function of storage time in Teflon Flask at $22^{\circ} \mathrm{C}$; pi $5.5 \pm 0.1$

Determined by ICP-MS. Date of collection: Nov. 2, 1993. $\mathrm{Cu}, \triangle \mathrm{Ni}, \mathrm{Pb}$. 
a period of two hours for all four elements of interest (Fig. 1.8).

Figure 1.9 shows percentage loss of dissolved zinc species from a snow-melt sample stored in three flasks, each made of a different material: high-density polyethylene, polypropylene, and Teflon. As can be seen, there is no loss for zinc species in any of the containers. High-density polyethylene and polypropylene have been reported [29] to contain $200 \mu \mathrm{g} / \mathrm{ml}$ of zinc. Zinc is often used as a catalyst in the manufacture of polymers employed as construction materials for these containers. Probably the observed stability of zinc in the snow sample is the result of fortuitous balancing of the loss of zinc from the snow sample with the gain of zinc arising from its leaching out of the walls of the containers. It may also be due to the absence of any biological transformation or lack of formation of any colloidal or ion-exchangeable species likely to be adsorbed onto container surface. These results are in agreement with those of A.W. Strumpler [7]. He reported no loss of zinc in polyethylene container from a synthetic solution. The results obtained in this work permit one to draw a number of useful conclusions, even though individual data may be open to some uncertainty. Contrary to the popular helief, it appears that not all plastic containers such as polypropylene and high density polyethylene are good for storage in trace analysis. 


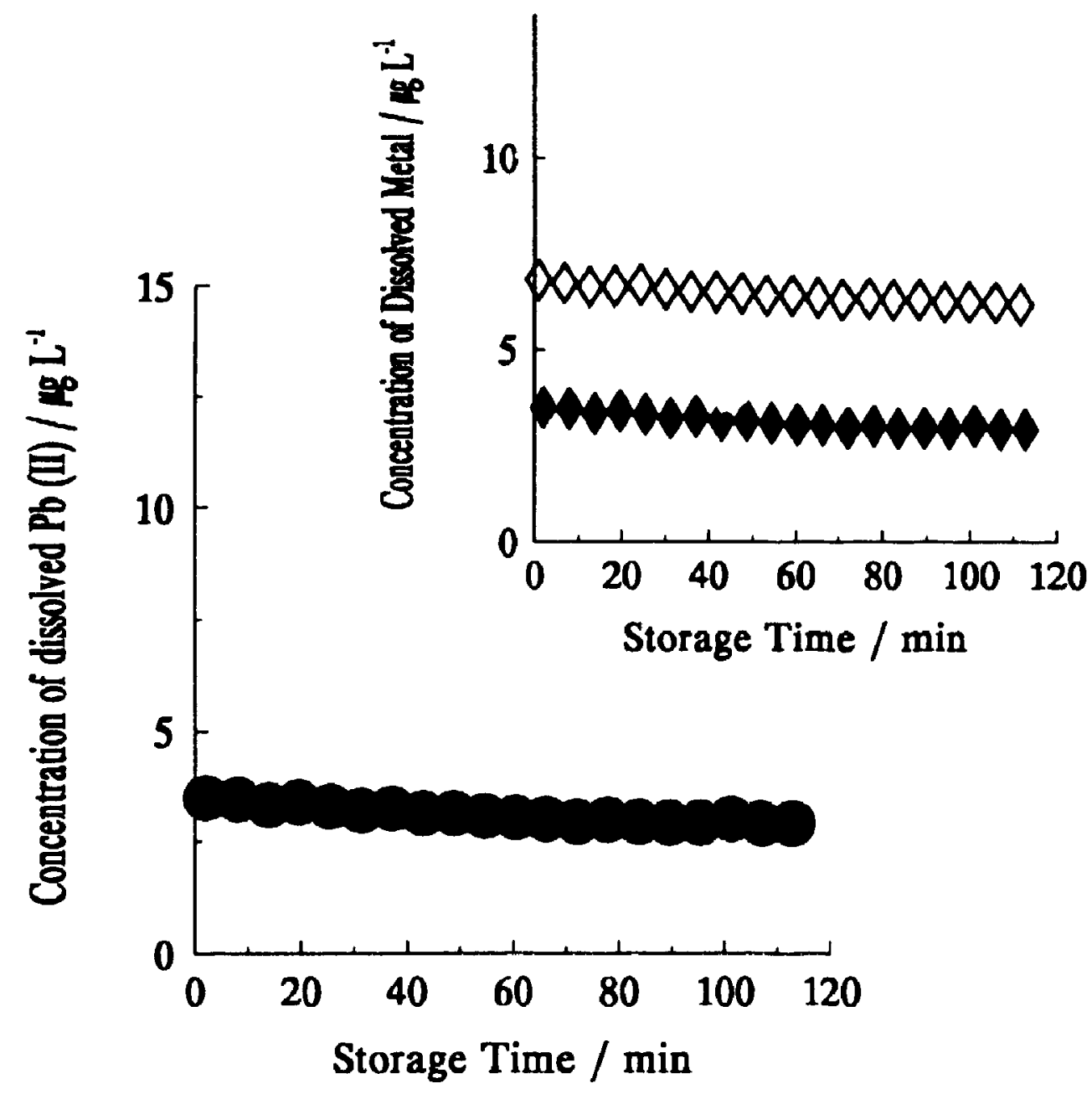

Figure 1.8 Concentration of dissolved species of copper, nickel, cadmium and lead in a Rideau river surface water sample as a function of storage time in a Teflon flask at $22^{\circ} \mathrm{C} ; \mathrm{pH}=8.1$. Determined by ICP-MS. Date of collection $=$ Nov. 24, 1993. $\bullet=\mathrm{Cu}, \nabla=\mathrm{Ni}$, and $\bigcirc=\mathrm{Pb}$. 


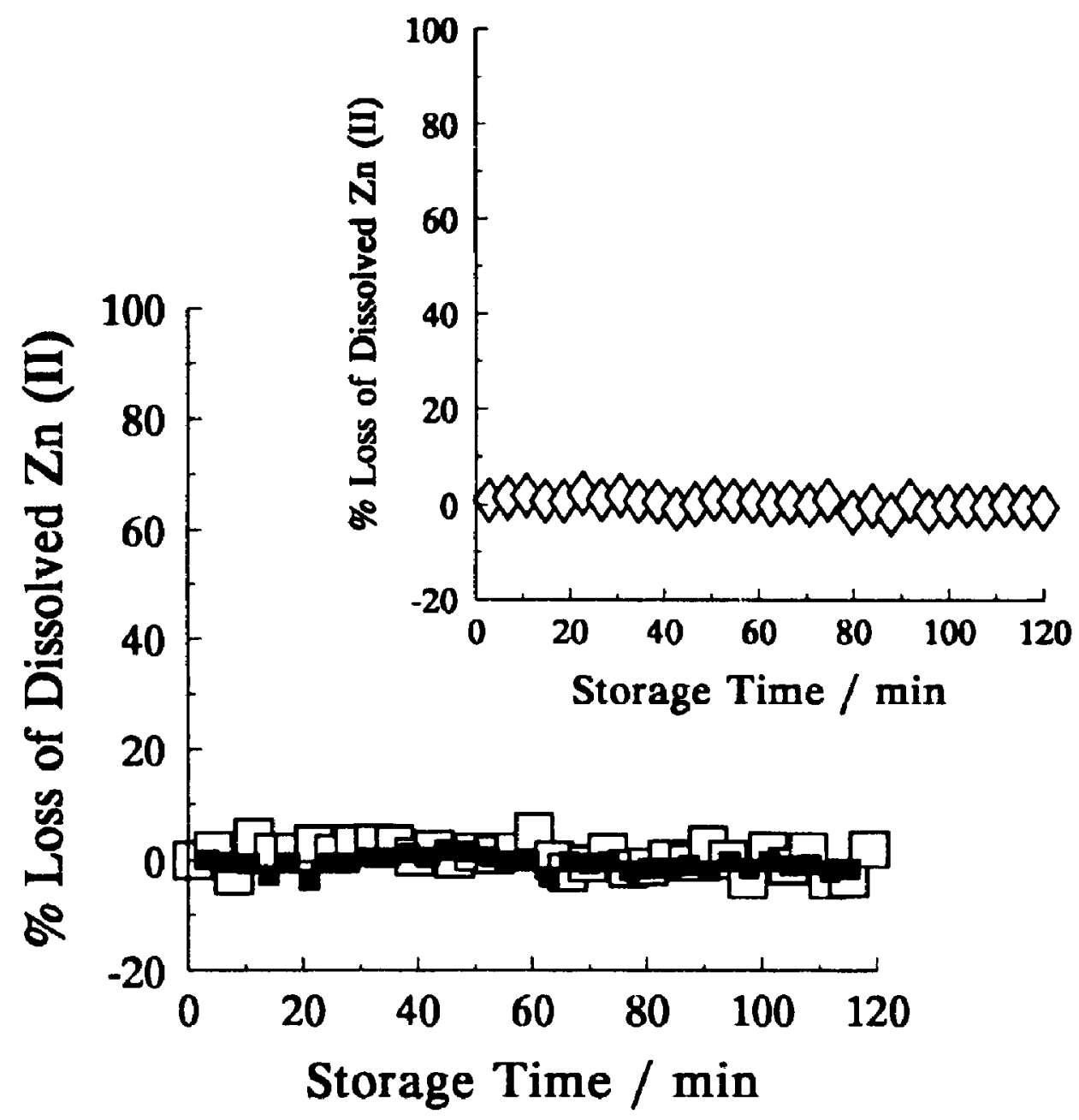

Figure 1.9 Stability of soluble zinc in a snow-melt sample in different con tainer materials at $22^{\circ} \mathrm{C}$; pH $5.5 \pm 0.1$. Date of collection: Jan. 6, 1994. $\square$ Teflon flask, $\square$ High density polyethylene flask, $\triangle$ Polypropylene tlask. 


\subsection{CONCLUSIONS}

The preservation of samples encompasses both field and laboratory activities and includes choice of sample container and protocol of sampling, storage, handling and measurements. Storage in Teflo: containers was found to be the most reliable way of preventing loss of dissolved metal species in rain, snow, and rive water samples. No change in concentrations of the total dissolved metals in snow was observed in Teflon containers during a period of observation of 24 hours . Thus, of the materials studied, Teflon is the best for construction of containers and best preserves the integrity of dissolved metal species (Pb (II), $\mathrm{Cu}(\mathrm{II}), \mathrm{Cd}(\mathrm{II}), \mathrm{Ni}(\mathrm{II}), \mathrm{Al}(\mathrm{II}), \mathrm{Zn}(\mathrm{II})$ in rain, snow and river surface water samples. Dissolved ziric species are stable in all the containers. This may be due to rapid equilibration of the zinc between the solution and the container material. Complete stability of simples cannot always be achieved for every constituent of the sample, nor can all the constituents be stabilized with the same method and with the same degree of success. 


\section{CHAPTER II}

\section{A STUDY OF SOME PHYSICO-CHEMICAL ARTIFACTS PRODUCED IN ULTRAFILTRATION OF NATURAL WATER SAMPLES}

\section{INTRODUCTION}

The crucial importance of defining the speciation (physico-chemical forms) of metals in natural water is now well established $[26,30-31]$. Our knowledge of metal speciation however, is still inadequate and the available results are often confusing and contradictory [32]. Therefore, there is a clear need to improve experimental methods of speciation of metals in water, in order to validate existing methods, as well as to highlight their weaknesses, and to indicate areas for further study.

The wide range of metals species in natural water can be classified according to their size association (Table 2.1). Indeed, Guy and Chakrabarti [33] have suggested that differentiation by size, in conjunction with studies of the chemical behaviour of the size grouping, may serve as a definite speciation scheme. Such an approach has the advantage of recognizing the size continuum of the metal species ano :mproving the conventional, but arbitrary, distinction between "soluble" and "particulate" metal based on the ability or inability to pass through a $0.45 \mu \mathrm{m}$ filter.

Various techniques have been used to separate trace-elements in natural water by size [34-35]. The most frequently used techniques are: filtration, ultrafiltration, gel filtration and dialysis. The ultrafiltration technique (UF) is extensively used to separate 
dissolved compounds into various molecular-weight ranges by using a variety of membrane filters. Each membrane has a characteristic nominal molecular weight cut-off (MWCO) limi', which is opcrationally defined as the molecular weight at which $90 \%$ of uncharged molecules are retained [36]. Retention of $100 \%$ of molecules of the particular MWCO is seldom achieved in practice, even for substances of molecular size much larger than the porosity of the membranes, due to the linear structure of some of the molecules. In fact MWCO limits of compounds depend on their structure, their configuration and their charge. In addition all membranes contain a small proportion of large size pores v. hich allow the passage of a small amount of high molecular compounds. Thus, it is not possible to separate these compounds into exart molecular weight range which are independent of the structure of the compounds. Hence the differentiation of metal species by ultrafiltration is by size, shape and charge rather than by molecular weight [37-38].

Applications of ulirafiltration in environmental studics include, among other subjects:

1- Size fractionation and pre-concentration of organic and inorganic colloids from natural waters [39!.

2- Determination of complex-formation constants for complexes $M_{\mathcal{L}}$ between a metal $M$ and a ligand $L$ [36].

3- Isolation and purification of humic compounds [40].

Size fractionation experiments on natural waters have shown $[39,40]$ that some metal ions pass through the filters, independent of the cut-off level of the membranes, while others are partially or strongly retained during ultrafiltration. This selective 
retention is attributed to colloid formation in the solution, for example, formation of iron oxyhydrates, or to complexation with high molecular weight organic ligands [39]. Among these organic compounds, humic acid (HA) and fulvic acid (FA) are important because of their high complex formation constants with metals, especially with the transition group [5].

The need for a better understanding of the behaviour of humic compounds during ultrafiltration motivated research [41] on ultrafiltration of $\mathrm{HA}$ and FA through flat membranes Amicon XM300 (cut-off $300 \mathrm{kDa}$ ), XM50 (cut-off $50 \mathrm{kDa}$ ) and UM2 (cut-off $1 \mathrm{kDa}$ ). Surprisingly it was reported that FA retention by the UM2 membrane was greater than that of HA, although the FA has a much Inwer molecular weight. It was also reported that retention of HA, was almost the same on XM50 and UM2 flat membranes, despite the difference in cut-off levels (50 kDa vs $1 \mathrm{kDa})$. One of the authors' conclusions was that high concentrations of electrolytes strongly reduce reintion; however, small variations in solute concentration had no effect on retention.

The investigations mentioned showed the difficulty of comparing results obtained with different ultrafiltration membranes and showed that several factors, frequently of empirical nature, may effect the retention of humic compounds. Furthermore a number of artifacts may result directly or indirectly from the ultrafiltration process and should be considered in choosing the best ultrafiltration conditions. 


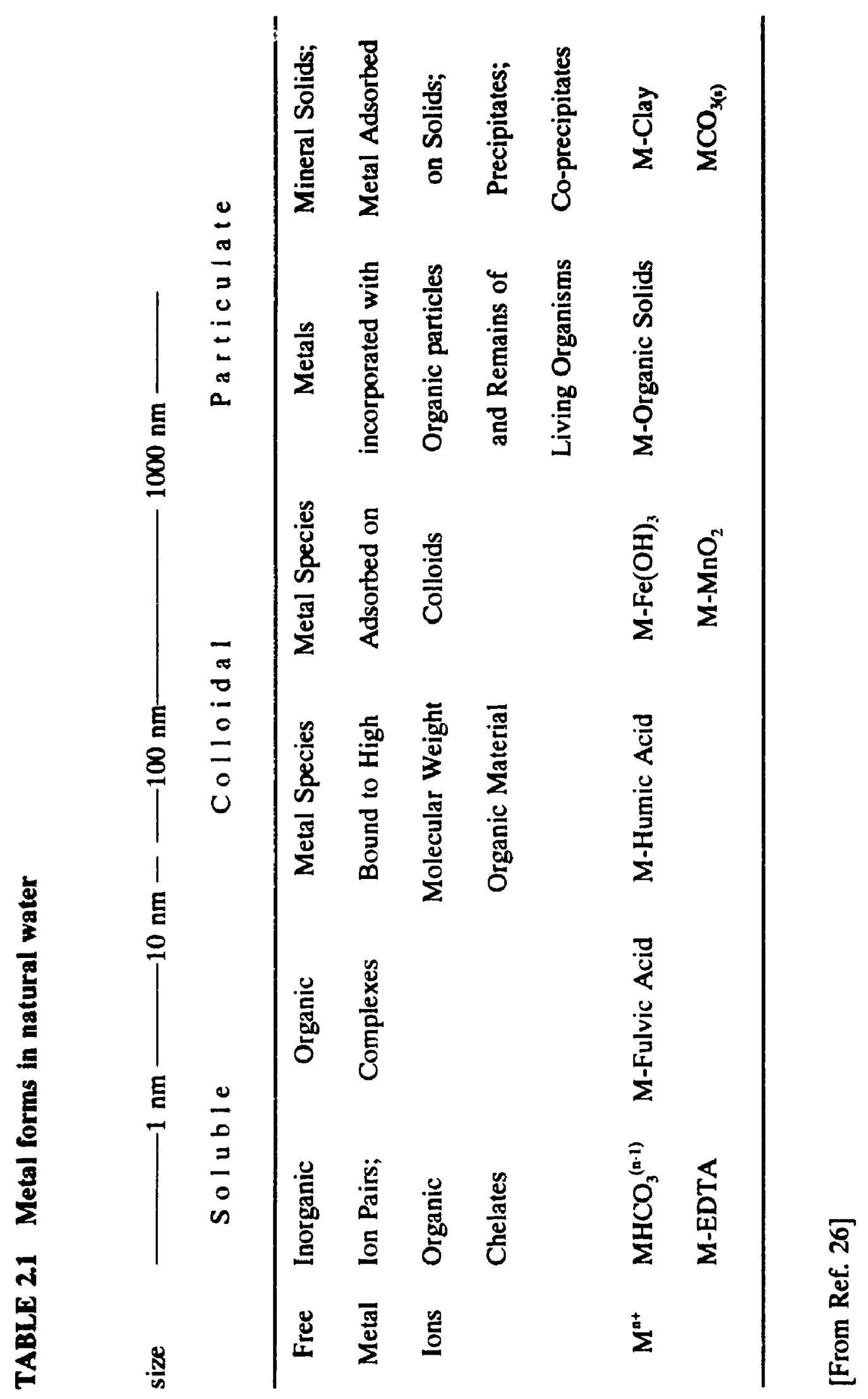




\subsection{OBJECTIVES}

The purpose of this work is to study some physico-chemical artefacts, such as clogging and adsorption onto the ultrafiltration membranes, that may occur on ultrafiltration of natural water samples during chemical speciation by size fractionation.

The importance of this objective derives from the potential impact of such artifacts on speciation. Clogging of membranes by retained colloids such as humic compounds, may reduce the effective pore size; consequently, at constant pressure, the water flow, and overall concentration of the compounds passing through the ultrafilter are reduced. If clogging occurs, then the size fractionation will not be reliable. Adsorption of the metal species onto the membrane surface will shift the distribution of the species to larger size fractions thus changing the speciation.

By identifying such artifacts their effects may be eliminated or minimized.

\subsection{THEORY}

In ultrafiltration there are four factors that determine the total flux which crosses the membrane

(i) convective transport of solvent in response to a hydrostatic pressure $\Delta \mathrm{P}$

(ii) reverse transport of solvent by diffusion due to an osmotic pressure $\Delta \pi$

(iii) transport of solute along with the solvent (convection);

(iv) transport of solute in the same direction as in (iii), but by ditfusion in 
response to the concentration gradient $\left(C_{1}>C_{2}\right)$.

Among these factors, effects (i)and (iii) are generally considered dominant because $\Delta \mathrm{P}>\mathbf{\Delta} \boldsymbol{\pi}$.

When ultrafiltration is used as a separation tool of two solutes, $A$ and $B$, having different diameters, $d_{A}$ and $d_{B}$, a membrane with pore diameter, $d_{p}$, such that $d_{A} \gg d_{p}>d_{B}$ should be used. In this way B, being present at the same concentration on both sides of the membrane, does not influence $\Delta \pi$.

Furthermore, the molecular weight of the compound retained, $A,\left(M_{w}{ }^{\wedge}\right)$ is large and $\Delta \pi$ which is inversely proportional to $M_{w}{ }^{\wedge}$, tends towards zero. Finally, since $\Delta C_{B}$ $=C_{B}$ (cell) $-C_{B}$ (filtrate) $\rightarrow 0$, transport of $B$ by diffusion is negligible.

In actual aquatic media, these conditions are never rigorously realized since there is always a solute fraction having size close to $d_{p}$. Therefore, all four effects must then be considered simultaneously.

\subsubsection{EXPERIMENTAL FACTORS AFFECTING SIZE FRACTIONATION BY ULTRAFILTRATION}

The principal factors that should be considered for the application of membranes to aquatic media are:

1) The degree of hydrophilicity. When the degree of hydrophilicity increases the surface adsorption of aquatic organic compounds often decreases.

2) The solution flow $\left(\mathrm{J}_{w}\right)$. This shou!d be constant and rigorously controlled during size fractionation. If a flow decrease is observed it is generally attributed to 
plugging of the pores.

3) The membrane electric charge. This plays an essential role in the retention of aquatic compounds, which are often charged.

4) Pore size and pore size distribution. The membrane should have a narrow pore size distribution and this characteristic should be reproducible from membrane to membrane.

\subsubsection{SOME PHYSICO-CHEMICAL ARTIFACTS DURING SIZE FRACTIONATION BY ULTRAFILTRATION}

Ultrafiltration has been extensively used for size fractionation of compounds and particles in natural waters despite the numerous problems encountered in this technique. These prohlems can be classified into three categories:

1- Accumulation of colloids at the membrane surface resulting in the gradual decrease in the effective pore size, and clogging of the membrane.

2- Adsorption of trace compounds onto the membrane and the pore walls.

3- Rupture of biological celis leading to a change in speciation due to an increase in organic matter, nutrients, and trace metal(s) in the sample, especially at high ultrafiltration pressures.

4- Contamination of the sample by dissolution of trace impurities in the membrane. The first type of problem is particularly relevant when filtration is used to characterize the properties of the whole spectrum range of colloids and macromolecules. The second one is most important when dealing with trace compounds, typically $<10^{-7} \mathrm{M}$. 
Membrane clogging is an important industrial problem [42]. Since the earlier papers of Sheldon [43-44], however, who systematically compared the cut-off limits of various membranes, few investigations have been made of the effects of natural waters on membranes.

\subsubsection{MEMBRANE CLOGGING}

A major problem in ultrafiltration is clogging of the membrane by retained particles or colloids. The rate at which water will pass through the filter is a function of the pore size, $r_{p}$, and of the pore density. During ultrafiltration compounds may accumulate at the membrane surface, reducing gradually the effective pore size and the pore density. Consequently, at constant pressure, the flow rate of solvent drops and in addition the concentrations of coinpounds passing through the filter may be reduced. Clogging is most frequen:ly caused by build-up of colloidal materials, primarily humic acids, on the membrane. Metal oxides, especially iron oxides, can also cause clogging. Understanding of the processes leading to clogging is important in order to minimize it. For reliable size fractionation clogging must be avoided. One method to monitor clogging is the measurement of the flow rate of the solution. Solution flow $J_{w}$ should be constant and rigorously controlled to obtain a reliable size fractionation. A decrease in $\mathrm{J}_{\mathrm{w}}$ is generally attributed to plugging of the pores. The flow rate, $J_{w}$, may be expressed as

$$
J_{v}=\frac{e r_{p}^{2} \Delta P}{8 \eta \tau 1}
$$


where $\varepsilon$ is the porosity of the membrane, $r_{p}$ is the average pore radius, $\Delta P$ is the difference in pressure on the two sides of the membrane, $\eta$ is the viscosity of the solvent(in our case water); 1 is the thickness of the membrane, and $\tau$ is the tortuosity factor (equal to 1 for an ideal membrane).

The clogging problem can be partially solved by changing the membrane filters once the flow rate starts to decrease. The best procedure, however, is to use a preultrafilter step in order to remove larger particles.

\subsubsection{SAMPLE MODIFICATION BY SOLUTE ADSORPTION ONTO THE MEMBRANE}

Losses by adsorption onto the membrane and the filtration vessel may occur during ultrafiltration. Adsorption on the vessel may occur on any container [20] and was discussed in the previous chapter. Little is known on the exact role played by compounds which adsorb on pore walls and modify the pore properties. Modification of pore size, charge, and hydration properties may be expected. An additional problem is the retention of small molecules, which should pass through the membrane, by adsorption on the material already deposited on the membrane. Since adsorption reactions are highly dependent on the chemical nature and physical structure of the adsorbed species it is very difficult to compare experiments done with synthetic solutions and those done with natural water.

Adsorption losses on the membrane could be due to various interactions between the dissolved ions and the membrane. The main types of interactions are the result of [45] 
(i) electric and hydration properties of the solute and the membrane;

(ii) conformational changes of the solute in the membrane;

(iii) modifications of the membrane surface by adsorption of solute.

The first two types of interactions are particularly important for solutes whose size is similar to the pore size. On net negative membranes, the electrolyte cation can act simultaneously through masking and by competing for adsorption sites [36]. In general, therefore, adsorption decreases as the electrolyte concentration and the charge of the electrolyte cation increase.

\section{MEMBRANE CLOGGING}

\subsection{EXPERIMENTAL}

\subsubsection{Experimental approach}

Clogging by macromolecules such as fulvic acids causes changes in the properties of the membrane during ultrafiltration.

Recently, some authors [46] used silver particles with transmission electron microscopy to study membrane clogging due to protein deposition.

It is well known that colloidal silver particles having a particle size of less than $10 \mathrm{~nm}$ can be made [47]. Their electron density allows to be easily distinguished from the polymeric material of the membrane by transmission electron microscopy.

Silver particles with a smaller size than the membrane pore size will pass through the membrane. If clogging occurs, however, the silver particles will be retained. Colloidal silver solution was ultrafiltered using a new and used membranes. The 
membranes where later observed using transmission electron microscopy.

\subsubsection{REAGENTS AND MATERIALS}

Silver nitrate $\left(\mathrm{AgNO}_{3}\right)$ and sodium borohydride $(\mathrm{NaHB})$ were obtained from Aldrich Chemical Co. Ultrapure water was provided by a MilliQ system (18 M $\Omega-\mathrm{cm}$ ). The Laurentian fulvic acid was obtained from Dr. D.S. Gamble [48]. The range of molecular weight and the distribution of the Laurentian fulvic acid used in this work is shown in Fig.2.1. As can be seen only $35 \%$ of molecules of fulvic acid have a molecular weight less than 1000 , which is the M.W. cut-off of the membrane used. A range of commercial "Amicon" membranes were used, the characteristics of which are described in Table 2.2. The YM series are hydrophillic membranes [49].

\subsubsection{Preparation of silver sol}

Silver sol [46] was prepared by adding $1 \mathrm{~mL}$ of $1 \times 10^{-3} \mathrm{M}$ silver nitrate to $3 \mathrm{~mL}$ of ice-cold $2 \times 10^{-3} \mathrm{M}$ sodium borohydride. The solution was stirred vigorously with a magnetic stirrer, and a clear yellow sol formed almost immediately. The sol was heated to about $60^{\circ} \mathrm{C}$ and cooled to room temperature. The $\mathrm{pH}$ of the dilute sol was 9.2. The average diameter of the silver particles was $8.3 \mathrm{~nm}$ [47]. 


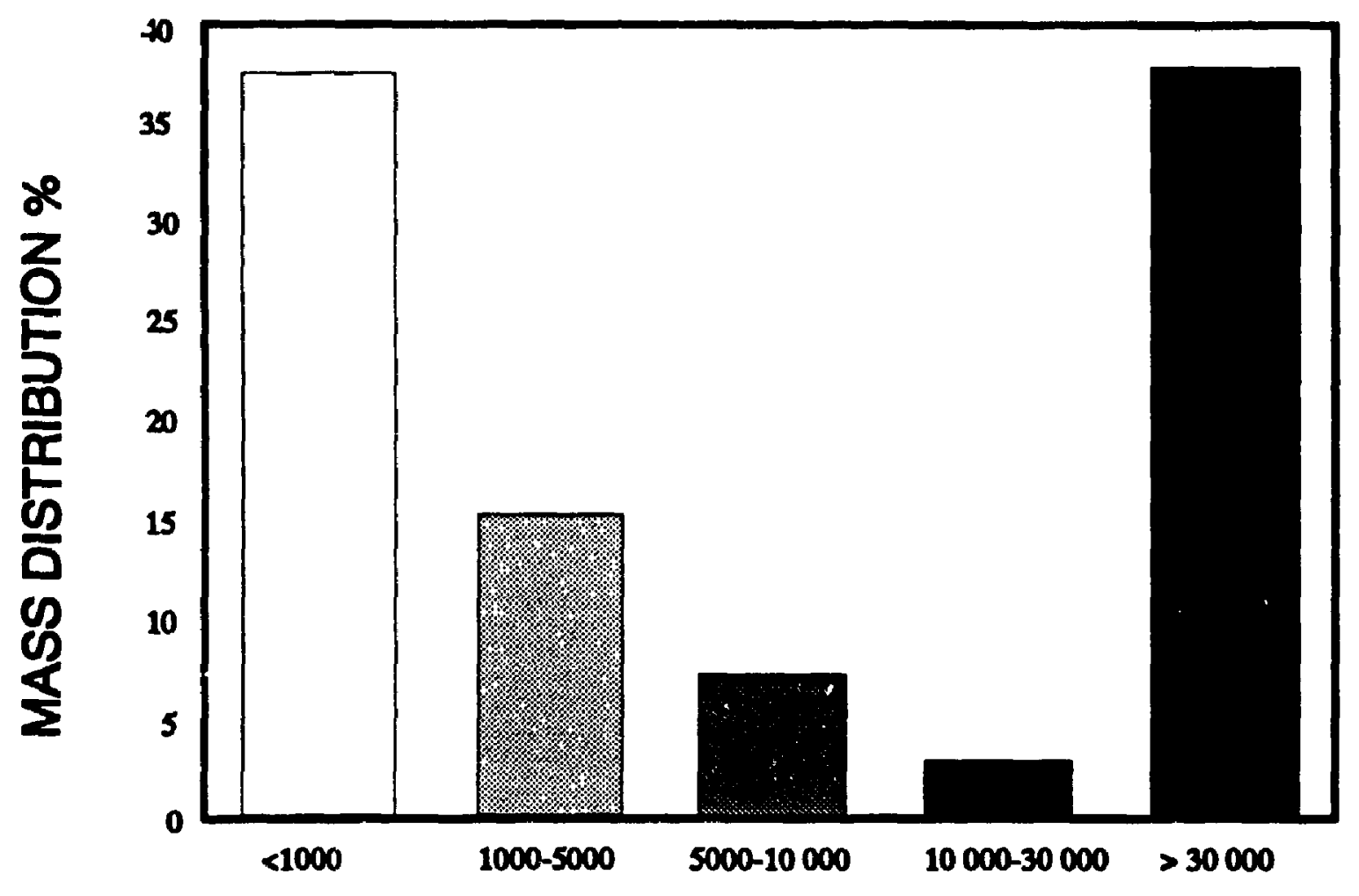

MOLECULAR WEIGHT RANGE

Figure 2.1 Percentage mass distribution of the Laurentian fulvic acid used [48]. 
TABLE 2.2 Membrane characteristics [49]

\begin{tabular}{cccc}
\hline $\begin{array}{c}\text { Membrane type } \\
\text { "Amicon" }\end{array}$ & Hydrophobicity & Polymer material & $\begin{array}{c}\text { Molecular weight } \\
\text { cut-off (Dalton) }\end{array}$ \\
\hline YM1 & low & reconstituted & 1,000 \\
& & cellulose & \\
YM30 & low & reconstituted & 30,000 \\
& & cellulose & \\
\hline
\end{tabular}




\subsection{Preparation of clogged and semi-clogged membranes}

All ultrafiltration tests we'e performed in an "Amicon" modified cell of $400 \mathrm{~mL}$ capacity. Clogged membranes were prepared by ultrafiltering $100 \mathrm{~mL}$ of Laurentian Fulvic acid, $5 \mu \mathrm{g} /$, pH 8, through an "Amicon" YM1 membrane (M.W. cut-off 1,000) at $14 \mathrm{psi}$, followed by washing the membrane with $10 \mathrm{~mL}$ of ultrapure water to remove labile, unbound fulvic molecules from the membrane surface. The fulvic acid used for the clogged membranes was previously filtered through a $0.45 \mu \mathrm{m}$ filter. For the semiclogged membrane the fulvic acid was first filtered through a $0.45 \mu \mathrm{m}$ filter and then ultrafiltered through an "Amicon" YM30 membrane. The characteristics of the fulvic acid used are presented in Fig. 2.1.

The membrane was then used to filter silver particles to examine the membrane clogging in ultrafiltration.

\subsubsection{Transmission Electron Microscopy (TEM) Analysis}

Ultrafiltration membranes prepared as described above were cut into $1-2 \mathrm{~mm}^{2}$ pieces and wet twice with $100 \mathrm{~mL}$ ethanol for $15 \mathrm{~min}$. They were embedded in Spurr's resin using a series of ethanol : resin mixtures (30\%; $50 \%$ and $80 \%$ resin) and allowed to stand for 1 hour in each solution. The resin was polymerized at $60^{\circ} \mathrm{C}$ for 8 hours. Thin sections were cut using a diamond knife mounted in an LKB ultramicrotome. Observations and photographs were made with a Philips 420 transmission electron microscope (TEM). 


\subsubsection{Ultrafiltration cell}

The ultrafiltration cell was a modified " Amicon" stirred cell. Two cells, each of $200 \mathrm{~mL}$ capacity were put together (see Figure 2.2). The flow rate of the iltrate was changed by changing the pressure of the $\mathrm{N}_{2}$. Gas-tight seals were made with O-rings. At the bottom of the cell an "Amicon" filter, $62 \mathrm{~mm}$ in diameter, was mounted flat against a Teflon support frit by an O-ring. Just above the fiiter a magnetic bar encased in plexiglass and held between two punsters stirred the solutions in response to a magnetic plate. 


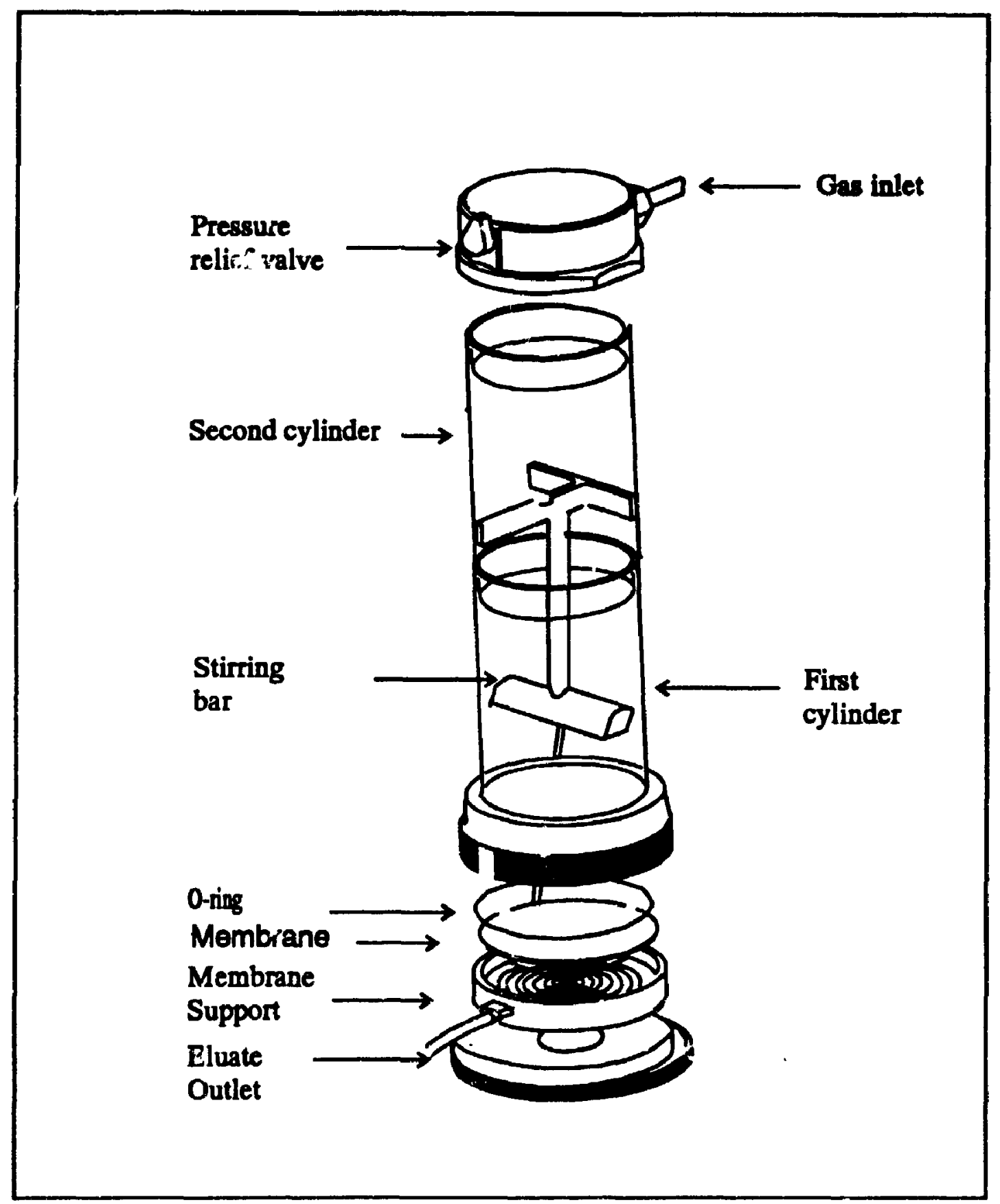

Figure 2.2 Schematic diagram of a modified "Amicon" ultrafiltration cell used in this work. 


\subsection{RESULTS AND DISCUSSION}

\section{Results obtained with unclogged, clogged and partially-clogged membranes}

The transmission electron microscope (TEM) photographs were taken during scanning. The main focus was to observe the distribution of the silver particles on the surface or in the pore of each membrane. Figure 2.3 presents the transmission electron microscopy image (magnification $31,500 \mathrm{x}$ ) of the surface of an "Amicon YM1" membrane (M.W. cut-off 1,000 ) showing a cross section of an unclogged membrane surface with clean membrane pores. Figure 2.3 presents a membrane surface photographed after filtering only $60 \mathrm{~mL}$ of an $\mathrm{Ag}$ sol, $1 \times 10^{-3} \mathrm{M}$, at $14 \mathrm{psi}$, followed by a brief rinse with ultrapure water. No silver deposit is visible throughout the membrane, indicating a complete passage of silver colloid particles through the membranes pcres. Figure 2.4 presents a thin-section TEM micrograph (magnification 31,500 x) of "Amicon YM1" (M.W. cut-off 1,000 ) of a clogged membrane. This membrane was used for the ultrafiltration of Laurentian fulvic acid $5 \mu \mathrm{g} / \mathrm{L}, \mathrm{pH} 8.0 \pm 0.5$ at $14 \mathrm{psi}$ as described ir, the preceding section. The fulvic acid used was pre-filtered through a $0.45 / \mathrm{m}$ filter. Then $100 \mathrm{ml}$ of the fulvic acid was ultrafiltered through the membrane followed by washing with $10 \mathrm{~mL}$ of ultrapure water to remove unbound molecules of fulvic acid from the membrane surface. Then the membrane was used to ultrafilter $60 \mathrm{~mL}$ of a solution of 1 x $10^{-3} \mathrm{M}$ silver colloid at $14 \mathrm{psi}$. In figure 2.4 black silver deposits are evident on the surface of the membrane, suggestin $n_{\downarrow}$, lat the fulvic acid had clogged the membrane pores. When $60 \mathrm{~mL}$ of silver sol was filtered through an unclogged membrane, no silver deposits were visible on the surface of the membrane (Fig. 2.3). Figure 2.4 indicates that 


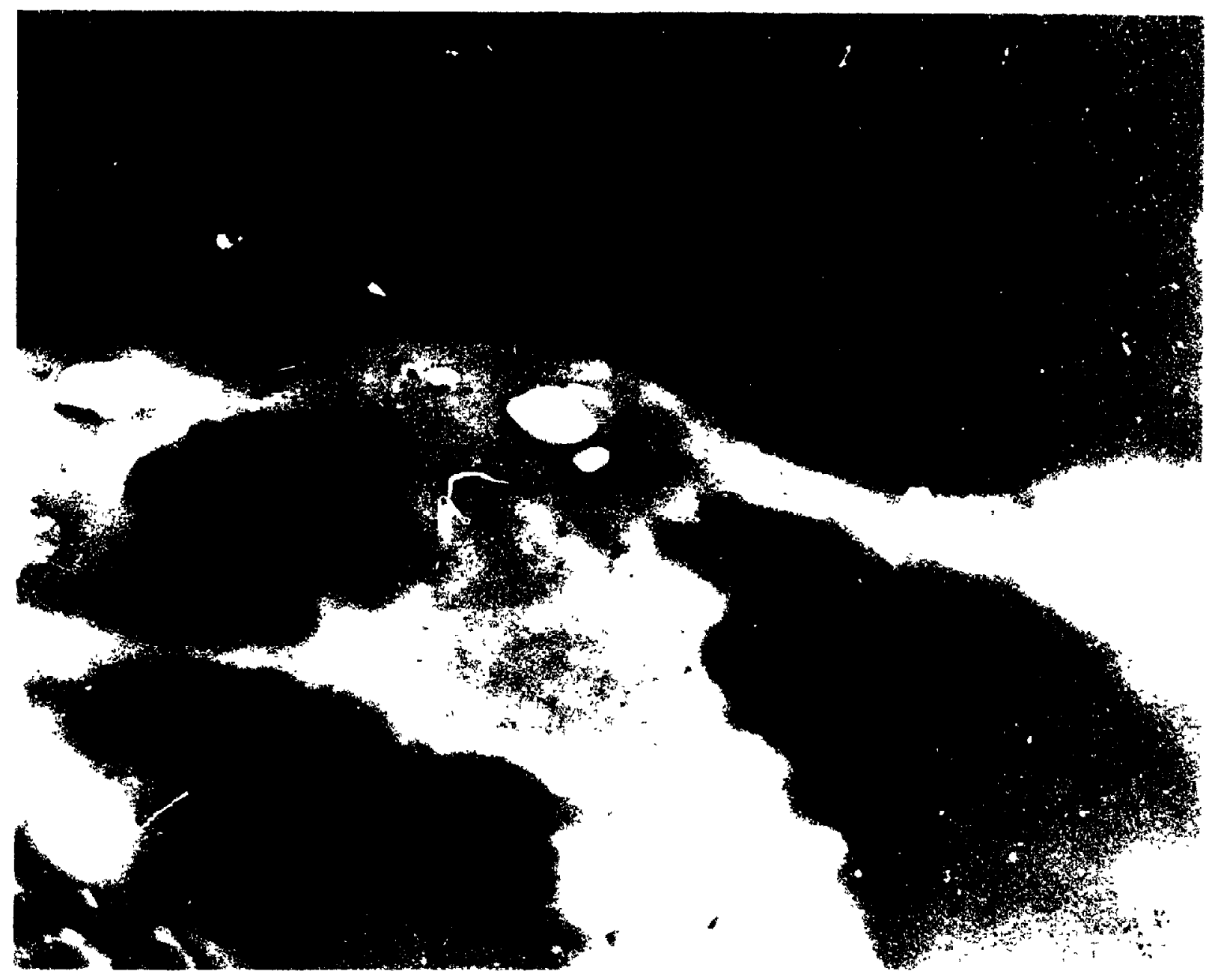

Figure 2.3 Transmission electron microscopy (TEM) image (x 31,500) of a thin section of a new "unclogged" "Amicon YM1" membrane (M.W. cut-off $1,000)$ 


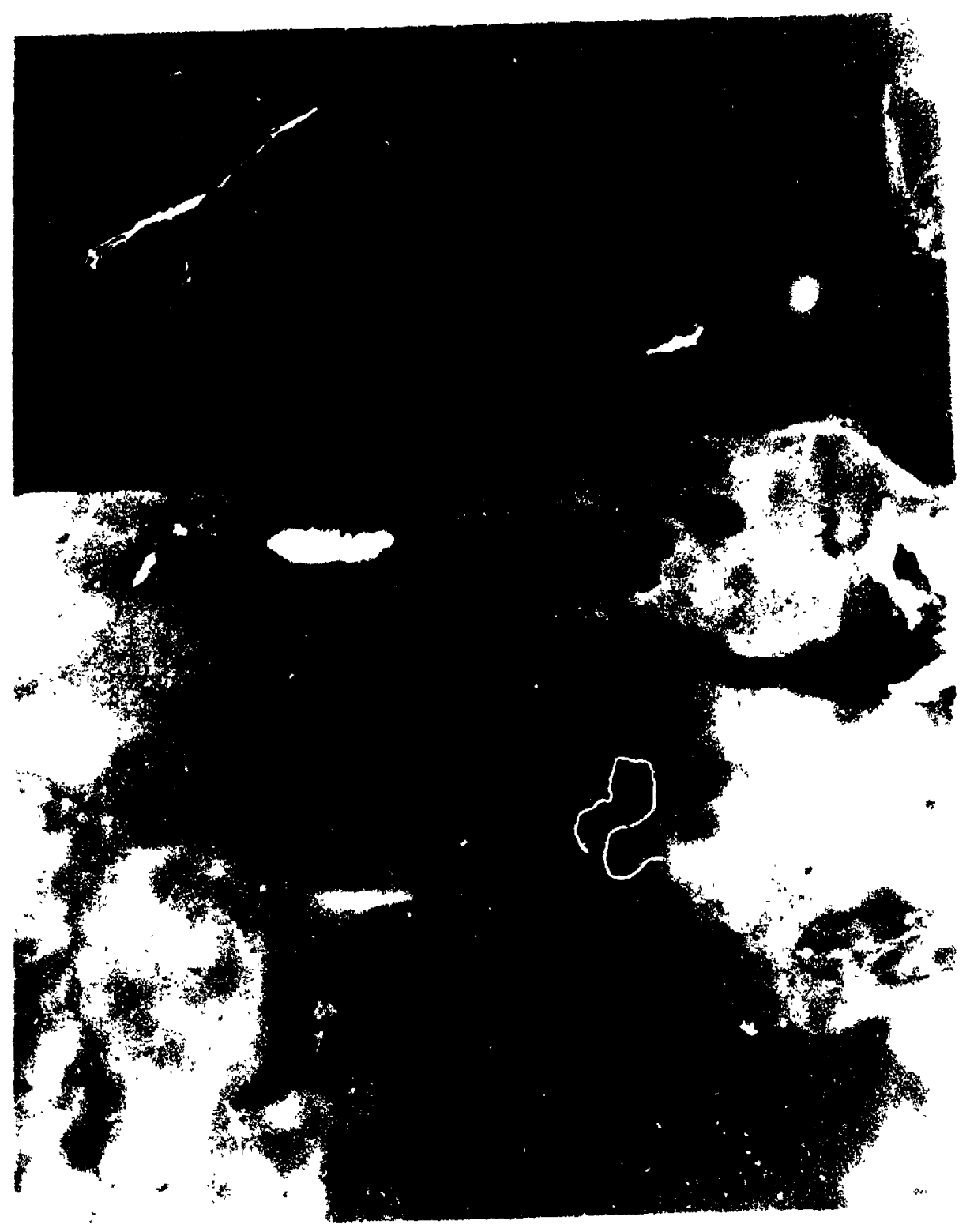

Figure 2.4 Transmission electron microscopy (TEM) image (x 31,500) of a thin section of a "clogged" "Amicon" YM1 (M.W.cut-off 1,000) membrane by Laurentian fulvic acid $5 \mu \mathrm{g} / \mathrm{L}, \mathrm{pH} 8.0 \pm 0.5$ 
the clogging of the "Amicon" membranes is mainly on the surface, but it does not exclude the possibility of clogging within the pores. Further experiments were performed using "Amicon" YM1 membranes to investigated a way of minimizing membrane clogging. Figure 2.5 shows a thin-section TEM micrograph (magnification 31,500 x) of an "Amicon YM1" (M.W. cut-off 1,000) membrane, showing a cross-section of a partially-clogged membrane surface. Figure 2.5 shows a membrane which was used for the ultrafiltration of Laurentian fulvic acid $5 \mu \mathrm{g} / \mathrm{L}, \mathrm{pH} 8.0 \pm 0.5$. In this case the fulvic acid was prefiltered through a $0.45 \mu \mathrm{m}$ filter and an "Amicon" YM30 M.W. 30,000 ultrafilter, prior to ultrafiltration on the YM1 membrane. After ultrafiltration of the fulvic acid the membrane was used to ultrafilter $60 \mathrm{~mL}$ of a solution of $1 \times 10^{-3} \mathrm{M}$ silver colloid at 14 psi. In Fig. 2.5 the black deposit of silver is less than that in Fig. 2.4. Hence, prefiltration of the solution of fulvic acid greatly decreased the clogging of the membrane, but did not completely eliminate it. 


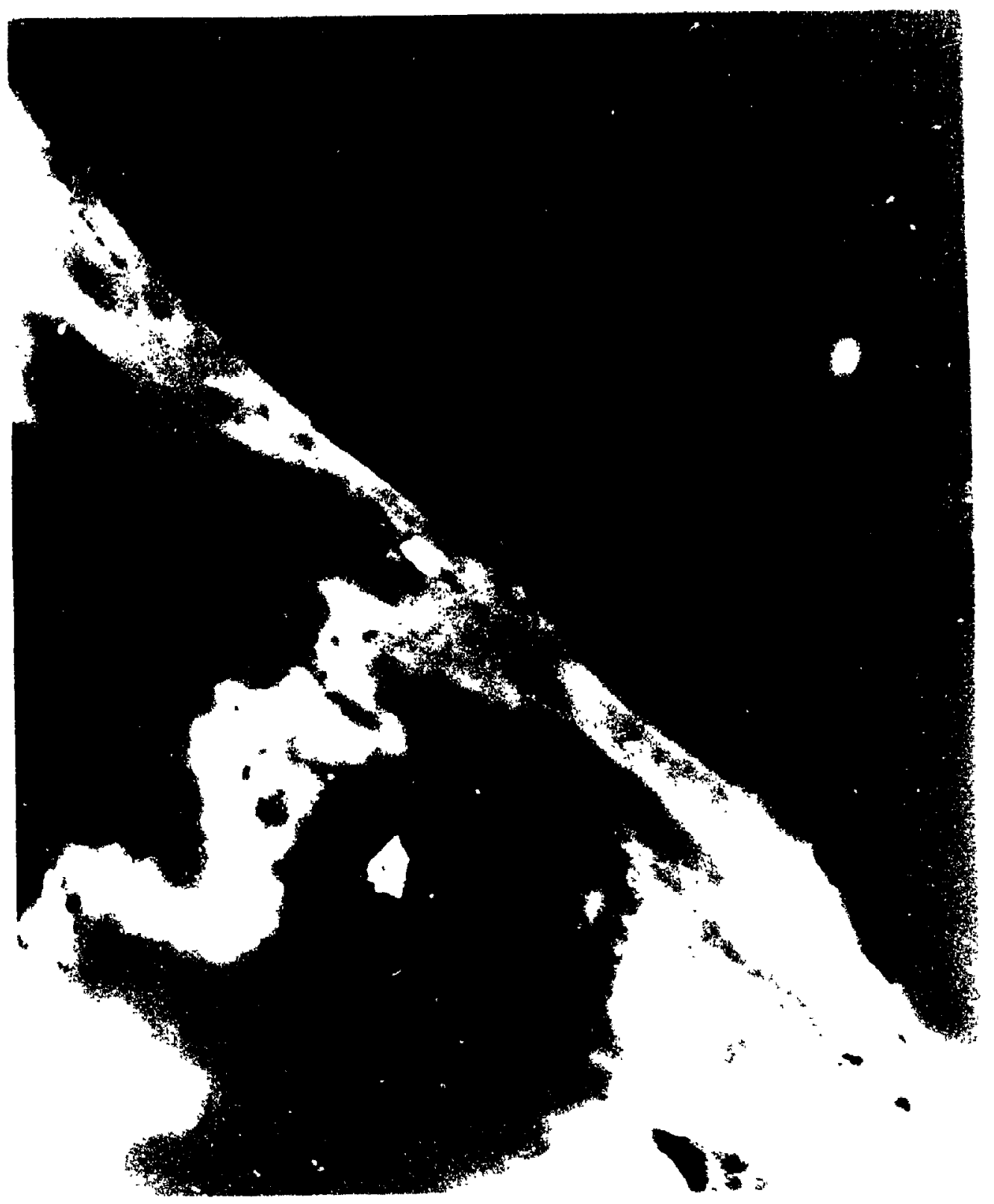

Figure 2.5 Transmission electron microscopy (TEM) image (x 31,500) of a thin section of a partially clogged "Amicon" YM1 (M.W.cut-off 1,000) membrane. 


\subsection{CONCLUSIUUNS}

Ultrafiltration of silver colloid coupled with transmission electron microscopy can be used to detect membrane clogging by humic and fulvic substances present in natural water samples. Electron microscopy of membrane cross sections shows passage of silver colloid particles through the clean membrane which highlight the pore structures. With Fulvic acid clogged membranes, these colloids are restricted from entering or passing through the membrane matrix. By pre-ultrafiltering the Laurentian fulvic acid with a membrane of large pore size in order to reduce the molecules of high molecular weight, clogging was minimized but not eliminated. These results suggest that cascade filtration is more reliable than parallel ultrafiltration.

\subsection{FUTURE WORK}

It is well known that the characteristics of fulvic acid and humic acid are affected by the $\mathrm{pH}$. Therefore, the effect on membrane clogging of varying the $\mathrm{pH}$ of fulvic and humic acid solutions should be of interest. It is also important to determine the volume of a solution which can be ultrafiltered before clogging takes place.

\section{MEMBRANE ADSORPTION}

\subsection{EXPERIMENTAL}

\subsubsection{Standard and reagents}

All the chemicals used were Merck Analytical reagent grade unless otherwise stated. Standard solutions for calibration were made by serial dilution of $1000 \mathrm{ng} \mathrm{mL}^{-1}$ stock 
solutions in a final medium of $1 \% \mathrm{HNO}_{3}$ ULTREX. With due consideration to the relative abundances the following isotopes were selected for intensity measurement: ${ }^{63} \mathrm{Cu}$, ${ }^{66} \mathrm{Zn},{ }^{111} \mathrm{Cd},{ }^{208} \mathrm{~Pb}$ and ${ }^{27} \mathrm{Al}$.

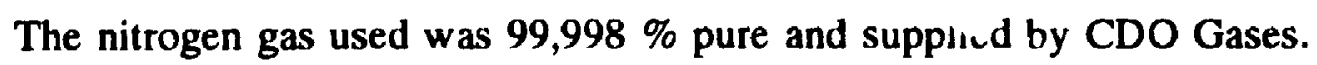

\subsubsection{Sample pre-treatment}

Snow samples were collected on the roof of the chemistry building, melted at room temperature and filtered through $0.45 \mu \mathrm{m}$ filter. The filtrate was stored in a Teflon bottle at $4{ }^{\circ} \mathrm{C}$ until analysis. Synthetic solutions were prepared from the stock solutions and the $\mathrm{pH}$ was adjusted with $\mathrm{NaOH}$.

\subsubsection{Membrane pre-treatment}

Amicon ultrafiltration membrane of various molecular weight cut-off were used.

The membranes were treated by the following steps:

1) $10 \mathrm{~mL}$ of a solution of $1 \times 10^{-2} \mathrm{M} \mathrm{Ca}\left(\mathrm{NO}_{3}\right)_{2}$ was passed through the filter.

2) The membrane was rinsed with ultrapure water $\left(18.2 \mathrm{Mohm}-\mathrm{cm}^{-1}\right)$ and $10 \mathrm{~mL}$ ultrapure water was passed through the membrane.

3) The membrane was rinsed with the sample.

4) The sample of a model solution or a snow sample, was ultrafiltered through the membrane. 


\subsubsection{Apparatus and Material}

An inductively coupled plasma mass spectrometer (ICP-MS) and a graphite furnace atomic absorption spectrometer (GFAAS) were used for determination of heavy metals in the solution before filtration and in the filtrate. The ICP-MS employed was Perkin Elmer Sciex Elan model 5000. The hardware and the operating conditions were given in Table 1.2. The GFAAS employed was Perkin Elmer model 5000 with a power supply HGA model 500 and with Zeeman background correction. The operation conditions are those in Table 1.1.

An Amicon ultrafiltration cell of capacity $200 \mathrm{~mL}$, which was later modified, was employed (see Figure 2.2) in conjunction with Amicon ultrafiltration membranes of various molecular weight cut-off (see Table 2.2).

\subsection{RESULTS AND DISCUSSION}

The effect of membrane pre-treatment upon ultrafiltration of dilute aluminium solution is shown in Fig. 2.6. When an aluminium solution was ultrafiltered through an "Amicon" YM1 membrane (M.W. 1,000) without pre-treatment, significant loss of aluminium occurred, but when the of membrane was pre-treated with $1 \times 10^{-2} \mathrm{Ca}\left(\mathrm{NO}_{3}\right)_{2}$ the losses were not significant.

Figure 2.7 shows the percentage recovery of $\mathrm{Cd}(\mathrm{II})$ and $\mathrm{Pb}$ (II) in the ultrafiltrate of a snow sample collected on January, 12, 1995. The sample was ultrafiltered using an "Amicon YM3" membrane which was pre-treated with $1 \times 10^{-2} \mathrm{M} \mathrm{Ca}\left(\mathrm{NO}_{3}\right)_{2}$. As the figure shows, the mean percentage of recovery of $\mathrm{Cd}$ (II) $(97 \%)$ is higher than the mean 


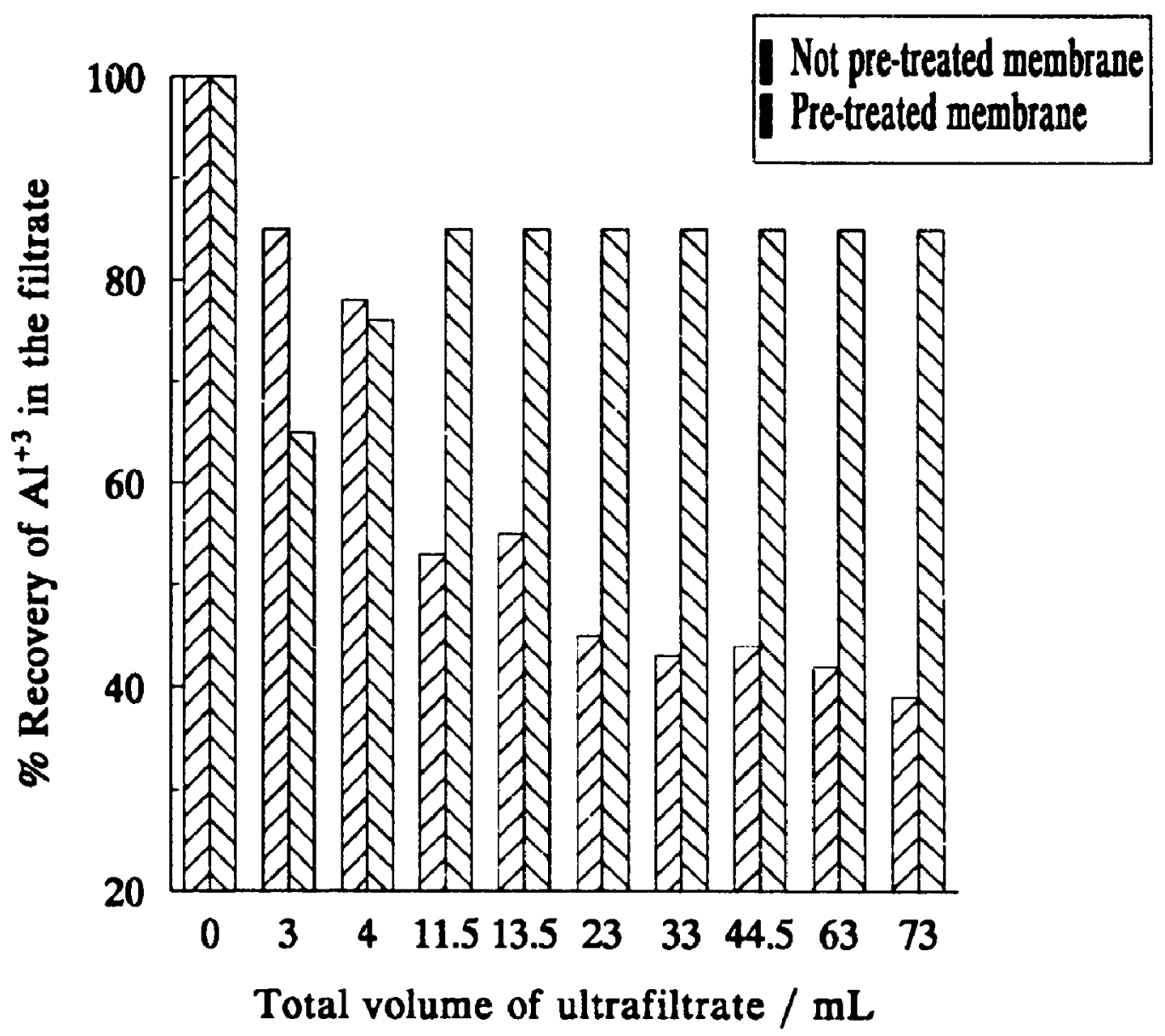

Figure 2.6 Effect of membrane pre-treatment on adsorption of $\mathrm{Al}^{+3}$ from a model solution onto an "Amicon YM1" membrane. Measured by GFAAS. 


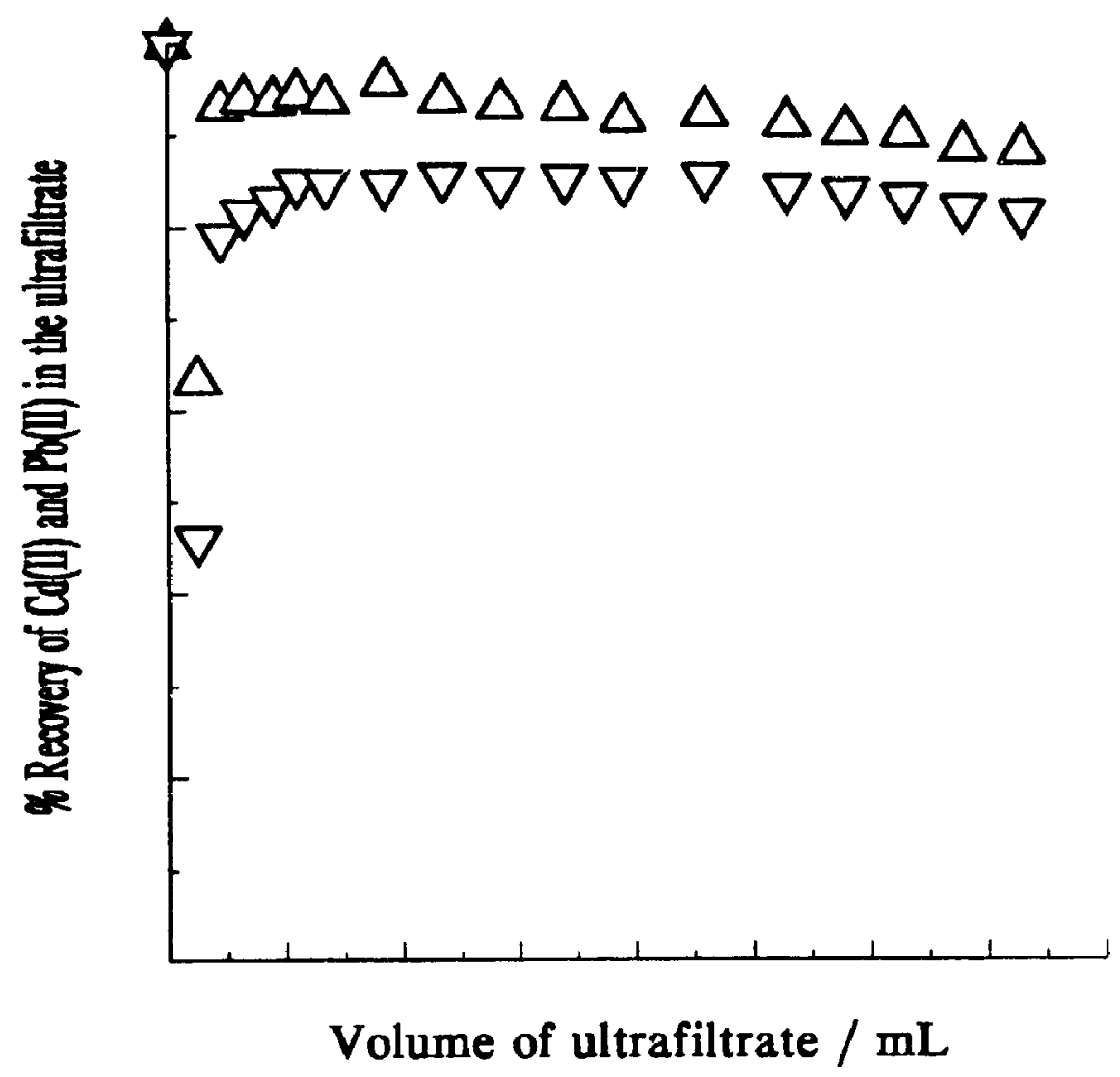

Figure $2.7 \%$ Recovery of $\triangle \mathrm{Cd}$ and $\nabla \mathrm{Pb}$ in the ultrafiltrate of a snow sample collected on Jan. 12 1995. $\mathrm{pH} 4.2 \pm 0.5$. The ultrafiltration membrane YM3 (M.W. cut-off 3000) was pre-treated with $1 \times 10^{-2} \mathrm{M} \mathrm{Ca}\left(\mathrm{NO}_{3}\right)_{2}$. Measured by ICP-MS. 
percentage of recovery of $\mathrm{Ph}(\mathrm{II})$ which is $86 \%$. The initial decrease in recovery is not due to losses, but it was an artifact due to dilution since the membrane were saturated of the washing solution.

Figure 2.8 shows, the percentage of recovery of $\mathrm{Cu}$ and $\mathrm{Al}$ in the same ultrafiltrate of the snow sample collected on January, 12, 1995. As the figure shows, the mean percentage of recovery of $\mathrm{Al}$ (III) (97\%) is higher than the mean percentage of recovery of $\mathrm{Cu}$ which is $87 \%$. In this figure the initial decrease was also due to a dilution effect. 


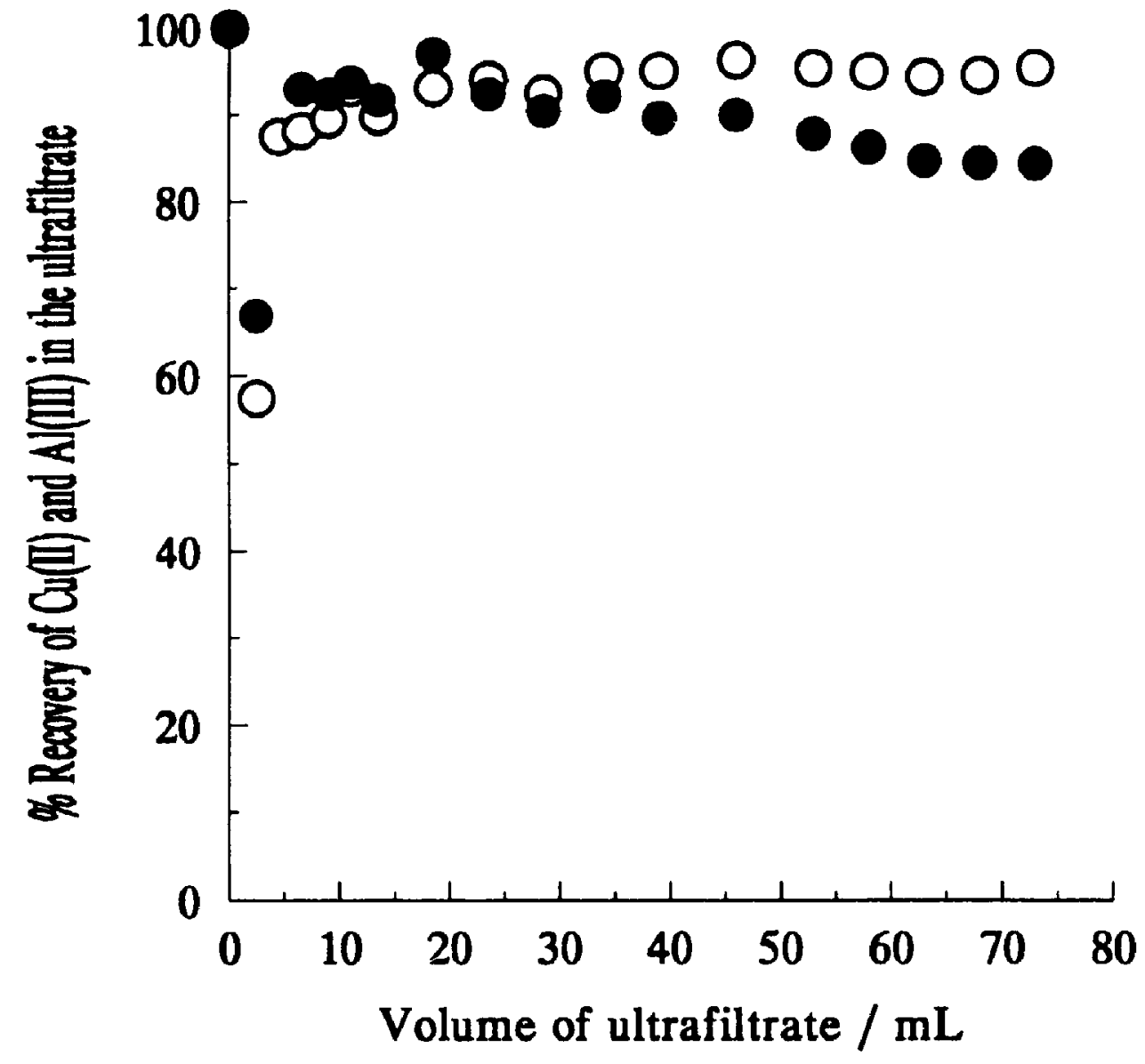

Figure $2.8 \%$ Recovery of $\mathrm{Al}$ and $\mathrm{Cu}$ in the ultrafiltrate of a snow sample collected on Jan. 12,1995 . pH $4.2 \pm 0.5$. The ultrafiltration membrane YM3 (M.W. cut-off 3000) was pre-treated with $1 \times 10^{-2} \mathrm{M} \mathrm{Ca}\left(\mathrm{NO}_{3}\right)_{2}$. Measured by ICP-MS. 


\subsection{CONCLUSIONS}

Although much work remain to be done on adsorption losses onto the ultrafiltration membrane, the importance of membrane pre-treatment, has been demonstrated, both for model solutions and for natural water samples. The pre-treatment with a calcium solution reduces adsorption probably because the $\mathrm{Ca}^{++}$ions compete for the adsorption sites.

The results have important consequences in the application of ultrafiltration to speciation of heavy metal in natural water samples. Care must be taken in defining the experimental conditions when ultrafiltration is used as a speciation tool.

\subsection{FUTURE WORK}

It is of interest to study the effect of other salts of calcium to determine whether the anion plays a role in the conditioning. It is also of interest to study the effect of the charge and size of the cation that is used in pre-treatment, for example by comparison of the salts $\mathrm{KNO}_{3}, \mathrm{LiNO}_{3}, \mathrm{Ca}\left(\mathrm{NO}_{3}\right)_{2}$. 
CHAPTER III

KINETIC SPECIATION OF Ni(II), Cd(II), and Zn(II) SPECIES IN RIDEAU RIVER SURFACE WATERS BY ALCOA ACTIVATED ALUMINA

\section{INTRODUCTION}

The determination of specific chemical forms of trace metal in natural waters, referred to as "speciation", is veiy important for understanding the biogeochemical cycling and pathways of elements in the environment and for assessirg their environmental impact. According to the "Free Metal-Ion Hypothesis", bioavailability and toxicity are thought to depend on the concentration of free metal ions in the sample [50-53].

The speciation of trace metals in natural water systems is controlled by the interaction of the metal ions with irorganis anions, organic ligands, reactive surfaces, such as clay mineials, or organisms. According to M.S. Shuman, B.J. Collins, P.J. Fitzgerald and D.J. Olson [54] organic matter is especially important with respect to the regulation of the free metal ion concentration.

An important aspect with respect to hioavailability is the difference in the rate of uptake by an organism and the rate of dissociation from an adsorption complex, for example, with humic materials. When the dissociation from the adsorption complex is faster than the uptake by an organism, the distribution between the free metal ion and the metal organic complex may be calculated from the equilibrium constants. On the other hand, when the rate of uptake is frster than the dissociation rate, the uptake is controlled by the abiotic chenical k!netics $[53,55]$. Hoffman [55] discussed the chemical dynamics of a lake system and concluded that equilibrium calculations may be used when the 
kinetics of dissociation are fast with respect to the tesidence time in the lake, whereas for slow kinetics, the rates of dissociation become important.

Not many papers dealing with the determination of the rate of dissociation of metal ions bound io humic material, have appeared in the literature. Shuman et al.[54] used the rotating disk electrode (RDE) veltammetry in combination with anodic stripping voltammetry (ASV) to estimate the rate constants of dissociation of metal complexes. With the above method, it is possible to operationally define lability classes ranging from "very labile" to "inert", correspondin, "o la'ge, $10^{2} \mathrm{~s}^{-1}$, and small, $10^{-6} \mathrm{~s}^{-1,}$ dissociation rate constants, respoctively [56]. The RDE method, however, is hindered by a narrow experimental time range.

Langford and Khan [57] estimated a dissociation rate constant for a Fe-fulvic acid complex of about $10^{-2} \mathrm{sec}^{-1}$ at pit 1.5 from values of the stability constants and the rate constants for formation obtained photometrically by the stopped-flow method. The fulvic acid was derived from a Prince Edward Island podzol soil. Lavigne et al. [58] studied the dissociaticin of Ni complexes with humic material. They used [4-(2-pyridylazo) resorcinol (PAR) as a strong ligand to complex any released metal ion and monitored the reaction by measuring the PAR-M complex photometrically. An approximate Laplace transform was used to assign the number of species and a non-linear regression routine was used to obtain final values for the parameters. Olson et al.[59-60] also used PAR in their study of the dissuciation of $\mathrm{Cu}$ from estuamarine humic material. Olson et al.[5960] assumed that the initial complex first dissociates hefic the metal ion is complexed with the PAR. This is criled the disjunctive pathway. Thus, the rate of PAR-M complex 
formation is set equal to the rate of the first-order dissociation of the copper humate complex.

Y. Lu at al. [61] have studied Cd-fulvic acid systems with various $[\mathrm{FA}] /[\mathrm{M}]$ ratios by using Chelex-100 batch technique at $\mathrm{pH} 5.0$.

Hering and Morel [62] studied the rate of ligand-exchange reaction of copperaitrilotriacetate (CuNTA) complexes and copper-humate complexes with the florescent ligand calcein. Hering and Morel [62] found that the rate constants were pH depindent. Hence, an apparent rate constant was measured that depended not only on the properties of the humic material but also on the experimental conditions. For humic materials, this type of dependency is general, and it complicates the interpretation of the results.

\subsection{Objective}

The objective of this research was to study the kinetics of binding of $\mathrm{Cd}^{2+}, \mathrm{Ni}^{2+}$, and $\mathrm{Zn}^{2+}$ metal ions by Che!ex-100 and Alcoa Activated Alumina in water samples of Rideau river surface waters, in which these metals are present as complexes of naturallyoccurring complexing agents, such as humic substances.

\subsection{Research Plan}

This research was done in two parts as follows.

1. The kinetics studies of binding of $\mathrm{Ni}(\mathrm{II}), \mathrm{Cd}(\mathrm{II})$ and $\mathrm{Zn}$ (II) by Chelex -100 cation exchange resin and hy Alcoa Activated Alumina were done in model solutions (pH $8.2 \pm 0.1)$ containing mixtures of these metals as the nitrate. Inductively-coupled plasma 
mass spectrometry (ICP-MS) was used to measure the total metal concentration in solution as a function of time after adding Chelex-100 or Alcoa Activated Alumina. The kinetic data were analyzed by using the Iterative Deconvolution Method [63], a non-linear regression method, which uses the Levenberg-Marquardt algorithm [64].

2. Chelex-100 and Alcoa Activated Alumina were then used in a similar manner to study the kinetics of the removal of the metals in unpolluted surface waters of Rideau river, in which these metals are present as complexes of naturally-occurring complexing agents, such as humic acid and fulvic acid.

\subsection{Chelex-100 cation exchange resin}

Chelex-100, is a co-polymer of styrene-divinylbenzene containing imminodiaceic acid (IDA) as a chelating group. Its structure changes with $\mathrm{pH}$ as shown below [65]:
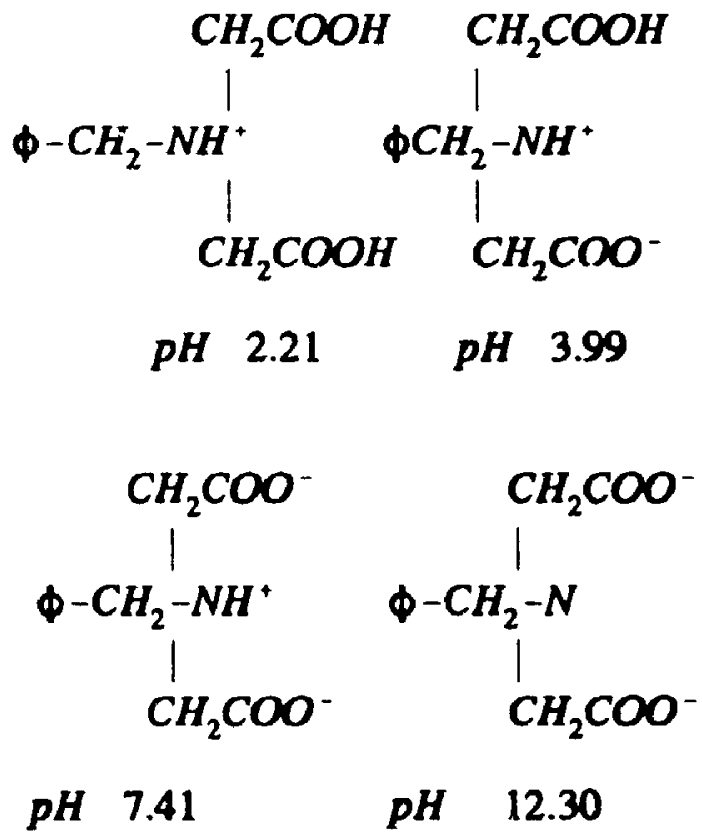

The resin has a pore size near $1.5 \mathrm{~nm}$, resulting in its exclusion of large molecules and colloidal particles [6]. Molecules or colloidal species which have diameters larger than 
$1.5 \mathrm{~nm}$ cannot penetrate into th: resin pores. Therefore, Chelex-100 provides a rapid method to distinguish between ionic metal and colloidal-associated metal species.

Chelating ion exchange resins, such as Chelex-100, have been used by a number of researchers $[61,63,66]$ for the speciation of metal in natural water samples. Both batch and column techniques have been used. The column technique is a transient technique with a time scale typically 6 to $9 \mathrm{~s}$, which depends on the flow rate and column length. The batch technique can be used in two ways. In one procedure the sample and the resin are equilibrated before the analysis is made. Kinetic data are not obtained. In the second procedure analysis is made at regular intervals after the addition of the resin to the sample. These measurements provide kinetic data relating to the stability of the metal complexes. These two procedures clearly give different type of information on the speciation of the metal.

\subsection{Alcoa Activated Alumina}

Alcoa Activated Alumina is a highly porous, granular form of aluminum oxide haring preferential adsorptive capacity for moisture and odour present in gases and some liquids. It is also used in water purification. Packed beds of Activated Alumina have been used to remove fluoride $[67,68]$, arsenic $[69,70]$, selenium [71], silica [72] and humic materials [73] from water. The mechanism is generally called adsorption and various types of adsorption mechanisms of metal ions on Activated Alumina have been proposed [73]. The properties of Alumina vary according to the method of preparation. Activated Alumina processes are sensitive to $\mathrm{pH}$, and cations are best adsorbed above $\mathrm{pH} 8.2$, which 
is the zero point of charge (ZPC). Below the ZPC the alumina surface has a net positive charge and behaves as an anion exchanger $[75,76,77]$.

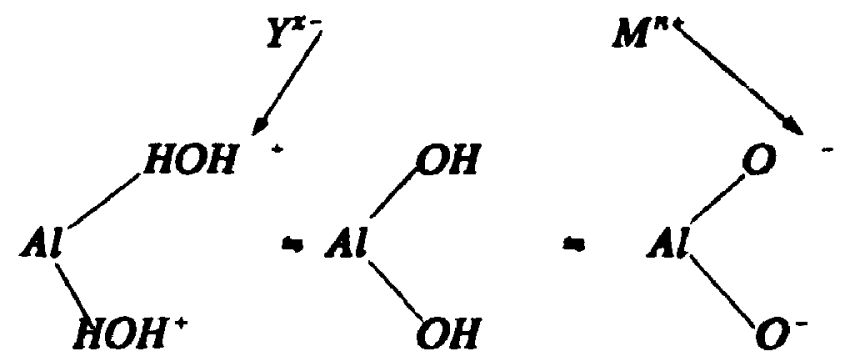

In addition to electrostatic effects o: the ionic solutes, Activated Alumina in common with many other hydrous metal oxides, shows a strong tendency to interact chemically with anions as well as with cations [78]. These chemical interactions have been explained in terms of complex formation [78].

If one represents a surface group of a hydrous metal oxide by $-\mathrm{MeOH}$, one can interpret the interactions with cations as a coordination with electron acceptors [81], for example:

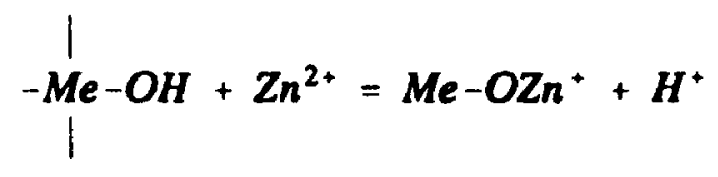

It is difficult to distinguish between exclusively coulombic interactions and complex formation interactions; there is a continuous transition between purely electrostatic ion exchange reactions and coordination by covalent bond formation [78].

Little systematic work has been reported on the kinetics of adsorption by cations on Activated Alumina, because of the difficulty of precise monitoring of the initial rapid 
rate of adsorption. This rapid adsorption reflects the fact that the adsorption is a surface phenomena and that the surfaces are readily accessible to the ions in solution [76]. The rate of adsorption, however, is likely to depend on experimental conditions such as $\mathrm{pH}$, electrolyte concentration, solid/solution ratio, temperature, and amount of agitation $[76,79]$. 


\subsection{Evaluation of Kinetic Parameters}

The success and reliability of kinetic methods of analysis depends critically on the treatment of the experimental data. There are several methods of data treatment, which can be grouped into two categories, as follows:

(i) graphical computation or graphical method [80,81]

(2) numerical analysis [82-84].

\subsubsection{The graphical method}

A very common graphical method for the treatment of first-order or pseudo-firstorder irreversible reactions, also called the Guggenhein method [85], uses a plot of $\ln$ (concentration of metal) against time.

For a two component system, $\mathrm{X}$ and $\mathrm{Y}$, that undergoes simultaneous first-order reactions, the sum of the concentration of the dissociating components at time $t$ is

$$
C_{t}=\left([X]_{t}+[Y]_{t}\right)=\left[X_{0}\right] \exp \left(-k_{x} t\right)+\left[Y_{0}\right] \exp \left(-k_{y} t\right)
$$

where $X_{0}$ and $Y_{o}$ are the initial concentration of the species being determined and $k_{x}$ and $k_{y}$ are the first-order rate constants for dissociation of $X$ and $Y$ respectively.

When the component with the larger rate constant, say $\mathbf{X}$, has disappeared, the logarithmic form of the integrated rate expression becomes:

$$
\ln \left[Y_{t}=\ln \left[Y_{0}\right]-k_{r} t\right.
$$


The concentration of the slowest component $\left[Y_{0}\right]$ can be estimated from the intercept of this plot at $t=0$ and the slope of this linear region provides the initial estimate of the rate

constant $k_{y}[80]$. The value of the rate constant obtained by this procedure may be further refined by non-linear regression analysis of equation (5).

For a system with two or more components the semilogarithmic first-order plot would be curved in the early stages of reaction and gradually become linear as the faster component is removed. Therefore, the plot is searuned for linear regions where a single component dominates the rate of loss.

The main disadvantage of this graphical method is that the faster-reacting species must be about $90 \%$ consumed before a reliable linear region can be obtained [82]. Thus if the number of components is large and the rate constants not very different it is difficult to obtain clear linear segments.

\subsubsection{Numerical analysis}

The success of numerical methods is mostly due to the development of instruments which can measure time-dependent signals with high accuracy and precision. The introduction of statistical packages have also made possible the utilization of hundreds of data points, readily available with computerized systems, which can give more accurate and precise determinations than the above mentioned graphical methods.

\subsubsection{The Iterative Deconvolution Method}

There are many methods for numerical analysis of data. In this study the Iterative 
Deconvolution Method [63], recommended by McKinnon et al. [86], is used. This method is based on non-linear regressiun (NLR) analysis. For this work the Statistical Package for Social Science (SPSS), which is on-line in the library network of Carleton University, was used. SPSS has two procedures for evaluating non-linear equations: i) constrained non-linear regression (CNLR) and ii) non-linear regression (NLR). The latter one, which uses the Levenberg-Marquardt algorithm for computing parameters estimates, was used.

In the Iterative Deconvolution Method [65] equation (7)

$$
C(t)=\sum_{i=1}^{n} C_{i}^{0} \exp \left(-k_{i} t\right)
$$

is fitted by non-linear regression assuming a number of components, starting with one and increasing until the sum of squares of the weighted residuals, defined as

$$
\text { Sum of squares of weighted residual }=\sum\left[\frac{C_{(t)}-C_{\pi(0)}}{\sqrt{C_{(t)}}}\right]^{2}
$$

achieves a minimum value. The kinetic analysis was further assessed by using the method of weighted residuals defined as:

$$
W \cdot R_{e}(t)=\frac{C_{e}(t)-C_{c}(t)}{\sqrt{C_{e}(t)}}
$$

where W.R.e $(t)$ is the weighted residual, $C_{e}(t)$ is the concentration of the metals remaining 
in the test solution measured at time $t$ after the binding by Alcoa Activated Alumina or Chelex-100 cation exchange resin, $C_{c}(t)$ is the calculated concentration obtained from the derived model parameters by non-linear regression analysis.

With the correct number of components the plots of the weighted residuals as a function of time will be randomly and uniformly distributed about zero throughout the course of the reaction. Non-uniform distribution of residuals, observed as curvature, indicates missing terms in the model [63].

\subsection{The Kinetic Model}

In natural water samples, metals are present as free ions and also bound to different complexants, organic or inorganic. Some complexants are polyfunctional, such as humic and fulvic acids. If dissociation of metal ions from such different bonding sites is thermodynamically favourable and the dissociation processes are independent and occur simultaneously, the dissociation rate will depend on the nature of the functional groups.

The kinetic model for kinetic analysis of multi-component systems developed by Olson and Shuman [59] and by Y. Lu et al.[63] assumes that the dissociation reaction of a complex $M L_{i}$ (where $L$ is the polyfunctional ligand and the subscript $i$, represents the different binding sites on $L$ for $M$ ) is slow compared with the binding of $M$ by the Chelex-100, used in their studies.

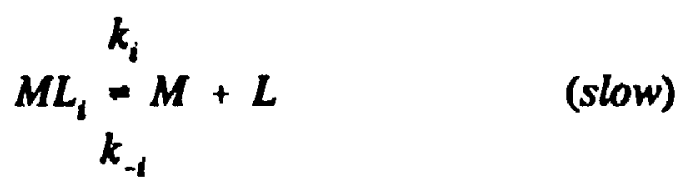




$$
M+\text { Chelex-100 }-M \text {-Chelex-100 }
$$

If we assume similar properties for the Alcoa Activated Alumina we may adopt a similar model, where the removal of $\mathrm{M}$ by Activated Alumina

$$
M+A \rightarrow M A
$$

(fast)

is fast compared to the reaction (10). Provided that a large excess of Activated Alumina is used the rate of reaction (12) will be pseudo-first order and the measured rate constants, $\mathbf{k}_{\mathbf{i}}$, will represent the dissociation of the complexes in reaction (10).

If, however, the metal complexes are removed by Alcoa Activated Alumina or Chelex-100 without pre-dissociation of the complex $\mathrm{ML}_{1}$, the removal may be represented as:

$$
M L_{i}+A^{k_{i}}+A M L_{i}
$$

or

$$
M L_{i}+\text { Chelex }-100 \stackrel{k_{i}}{\rightarrow} \text { Chelex }-100-M L_{i}
$$


and the rate constant measured for each component represents the reaction between metal complex and the Alcoa Activated Alumina and Chelex-100, respectively. Since the Alcoa Activated Alumina and the Chelex-100 is added in large excess, the reactions described by Eq. 13 and 14 are pseudo-first-order. Therefore, in both cases, the sum of the concentrations of all components in the sample at time $t$ can be described as;

$$
C(t)=\sum_{i=1}^{n} c_{i}^{0} \exp \left(-k_{i}\right)
$$

where $\mathrm{C}_{\mathrm{i}}^{\circ}$ is the initial concentration of $\mathrm{ML}_{\mathrm{i}}$, the ith metal species.

\subsection{EXPERIMENTAL}

\subsubsection{General procedure}

The approach used was a multi-component method of kinetic analysis. Kinetic measurements were made by swamping the sample with an excess of Alcoa Activated Alumina or Chelex-100 and monitoring the concentration of metal remaining in solution with ICP-MS. The inductively-coupled plasma mass spectrometry as monitoring mode in the kinetic analysis has two significant advantages. First, the ICP-MS has high sensitivity, low detection limits (parts-per-billion or less for some elements), wide dynamic range (up to 5 or 6 orders of magnitude), high precision $(0.5 \%-5 \%)$. Secondly, the short measuremeni time of milliseconds allows the collection of a large number of data points, making statistical analysis more reliable. A summary of the experimental approach is shown in Fig. 3.1. 


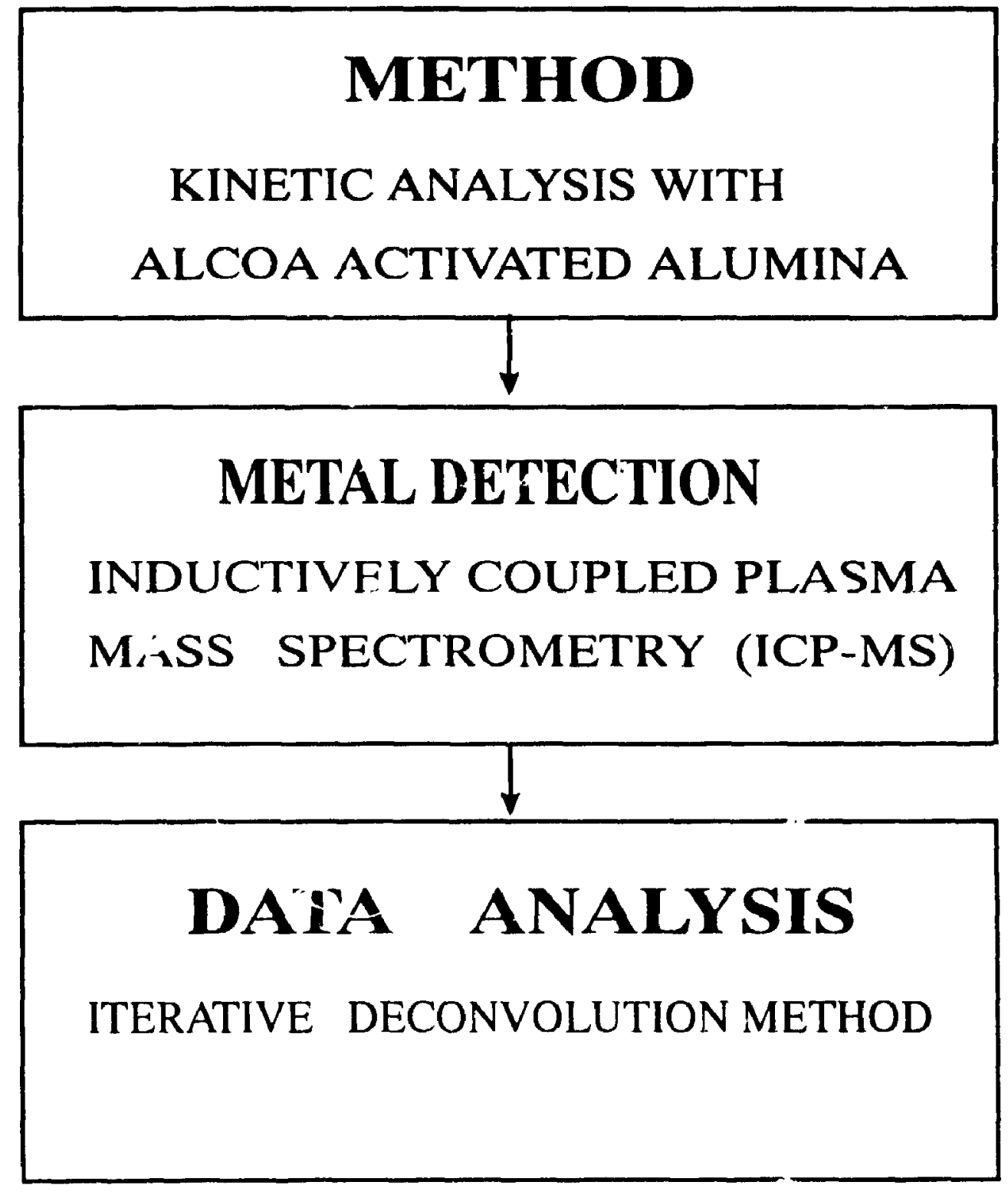

Figure 3.1 Summary of the experimental approach. 

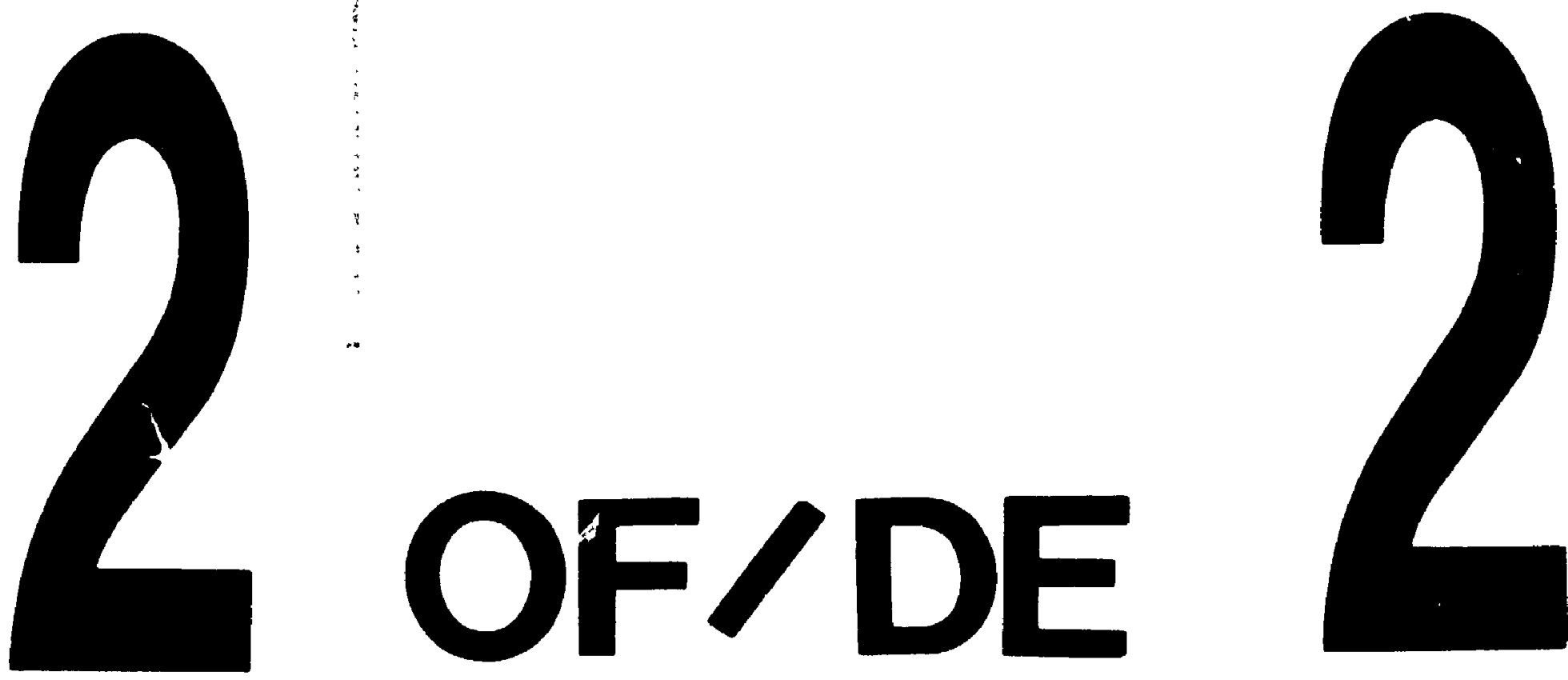

PM-1 31/2" $\times 4$ " PHOTOGRAPHIC MICAOCOPY TARGET NBS 1010a ANSI/ISO \#2 EOUIVALENT

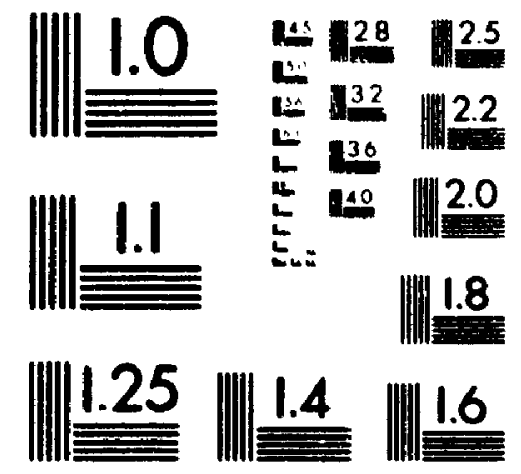

PRECISIONEM RESOLUTION TARGETS 


\subsubsection{Procedure}

In the first part, as mentioned in section 32 , the kinetics of binuing of $\mathrm{Ni}(1 \mathrm{I})$, $\mathrm{Cd}(\mathrm{II})$ and $\mathrm{Zn}$ (II) by Chelex-100 cation exchange resin and by Alcoa Activated Alumina were compared in model solutions ( $\mathrm{pH} 8.2 \pm(0.1)$ containing mixtures of these metals as the nitrate. Since the aftinity of Alcoa Activated Alumina towards cations depends on the $\mathrm{pH}[75-77]$, the $\mathrm{pH}$ of the solutions were maintained at $8.2 \pm 0.1$ for all the model solutions and the Rideau river water samples. The model solutions were prepared by spiking ultrapure water with an appropriate volume of the metal standard. The pH was adjusted with dilute $\mathrm{NaOH}$ solution, and the mixture equilihrated overnight, and the $\mathrm{pH}$ confirmed before running the experiments. An appropriate amount of Alcoa Activated Alumina and Chelex-100 were weighed for each experiment. Alcoa Activated Alumina was washed with ultrapure water, whereas Chelex-100 was washed with a buffer at pH 8.0. After addition of the Alcoa Activated Alumina or the Chelex-100 to the reactor, the mixture was stirred hy a magnetic stirring har and samples were continuously fed to the nebulizer. A nylon membrane prevented the solid phase from being drawn into the nebulizer. The metals remaining in solution (not bound by Alcoa Activated Alumina or Chelex-10(0) were quantitated by inductively coupled plasma mass spectrometer (ICP-MS).

Figure 3.2 shows a schematic diagram of the reactor with connection to the ICP-MS.

Rate constants were determined at various concentrations of Alcoa Activated Alumina and of metal ions to test for dependence of the rate constants on concentrations. Finally, Alcoa Activated Alumina and Chelex-10() were then used to study the kinetics of the rate of binding of metals in unpolluted surface waters of the Rideau river, in which 

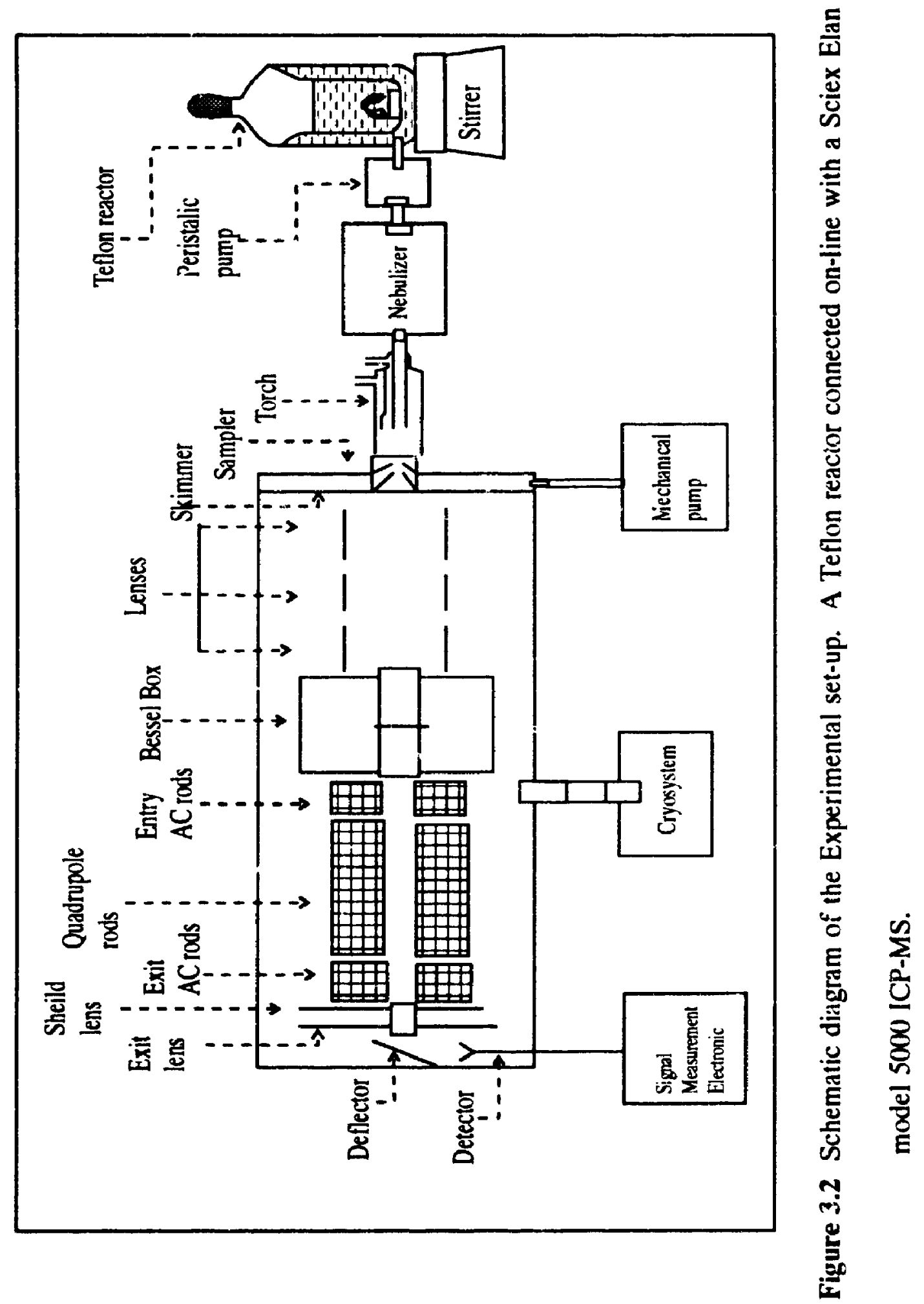
these metals are present as complexes of naturally-occurring complexing agents, such as humic acid and fulvic acid. The activated alumina selected for this study was manufactured by the Alcoa chemical plant in Vidalia, Louisiana, USA.

\subsubsection{Treatment of Samples}

The samples of Rideau River surface water were collected from a site at Carleton University using a pre-cleaned Teflon bottle. Since the concentration of the metals of interest in the river water was too low for kinetic study, the samples we:e spiked with standard solutions of $\mathrm{Cu}^{2+}, \mathrm{Zn}^{2+}, \mathrm{Cd}^{2+}, \mathrm{Ni}^{2+}$, and $\mathrm{Pb}^{2+}$ to give a concentration of a few micrograms per litre of each metal. The $\mathrm{pH}$ of the spiked sample was adjusted to $\mathrm{pH} 8.2$ \pm 0.1 with $\mathrm{NaOH}$ solution. The samples were equilibrated and filtered through a $0.45 \mu \mathrm{m}$ filter to separate the particulate matter from the dissolved phase. The filtrate was used for kinetic measurements.

\subsubsection{Reagents and Materials}

Stock solutions ( $1000 \mu \mathrm{g} \mathrm{ml}^{-1}$ ) of $\mathrm{Ni}, \mathrm{Cd}, \mathrm{Pb}$ and $\mathrm{Cu}$ were prepared by dissolving an appropriate quantity of nickel metal powder (SPEX, $99.999 \%$ ), CoiO (Baker, Analyzed reagent), $\mathrm{Pb}\left(\mathrm{NO}_{3}\right)_{2}$, (Fisher, A. ..S. reagent) and copper metal (99.9\% pure), in ultrapure nitric ar id (ULTREX II) and diluting to the appropriate volume with ultrapure water; the final solutions contained $1 \%(\mathrm{v} / \mathrm{v})$ ultrapure HNO. A standard solution (1000 $\left.\mu \mathrm{g} \mathrm{mL}^{-1}\right)$ of $\mathrm{Zn}$ was purchased from $\mathrm{BDH}$ Chemicals. Ultrapure water of resistivity $18.2 \mathrm{megohm}$ cm was obtained direct from a Milli-Q-Plus water purification system (Millipore 
Corporation). Ultrapure $\mathrm{HNO}_{3}$ (ULTREX II) was manufactured by J.T. Baker Inc., Phillipsburg, NJ, USA. Alcoa Activated Alumina (F-1 8-14 mesh) Aluminum Company of America LOT 231-62 and Chelex-100 resin (Bio-Rad, 100-200 mesh, sodium form ) was used. Alcoa Activated Alumina (F-1 8-14 mesh) was ground and sieved. The final size used was $115-170$ mesh.

\subsubsection{Apparatus}

Screw-capped Teflon bottles, $500 \mathrm{~mL}$ capacity, were used as reactors. These bottles were modified in the following way. An outlet for the solution was made with a valve and a nylon membrane to prevent solid particles from entering the orifice of the nebulizer of the inductively coupled plasma mass spectrometer. The reactors were precleaned following the procedure described in chapter 1.

Thu inductively coupled plasma mass spectrometer was a Perkin-Elmer SCIEX ELAN 5000 ICP-MS. Data acquisition, and storage, were performed with ELAN software which uses an IBM PS/2 Model 70 computer. Measurements from 0 to 2000-3000 seconds were made at regular intervals of $2 \mathrm{sec}$ after the solutions were mixed with Alcoa Activated Alumina or Chelex-100. The result was that 600 to 1000 data points spaced at regular intervals were obtained. The hardware and the of -rating conditions of the instrument are presented in Table 1.2. 


\subsection{RESULTS AND DISCUSSION}

\subsubsection{Effect of concentration of Alcoa Activated Alumina and the concentration of} metal inn on the kinetics of metal binding

To simplify the experimental and computational aspects of the kinetic method, experimental conditions were chosen under which first- or pseudo-first-order kinetics was applicable to equation (12). To test the validity of the above assumption the rate of binding of $\mathrm{Cu}$ (II), $\mathrm{Pb}(\mathrm{II}), \mathrm{Ni}$ (II), $\mathrm{Cd}(\mathrm{II})$, and $\mathrm{Zn}$ (II) from a model solution containing these metals as the nitrate was measured in solutions with $0.75,1.0$ and $1.5 \%(\mathrm{w} / \mathrm{w})$ Alcoa Activated Alumina (115-170 mesh). Although, the concentration of each metal in the solution was initially $30 \mu \mathrm{gL}^{-1}$ atter standing overnight the corcentrations were reduced, probably because of the basicity of the solution. For the results shown in Fig.3.3-3.5 the concentration of the metals at the time of the analysis was $\mathrm{Pb}$ (II) $9.6 \mu \mathrm{gL}^{-1}$, $\mathrm{Cu}(\mathrm{II}) 15 \mu \mathrm{gL}^{-1}, \mathrm{Cd}$ (II) $15 \mu \mathrm{gL}^{-1}, \mathrm{Zn}$ (II) $16.7 \mu \mathrm{gL}^{-1}$, and $\mathrm{Ni}(\mathrm{II}) 18 \mu \mathrm{gL}^{-1}$. These figures show the percentage of $\mathrm{Cd}(\mathrm{II}), \mathrm{Zn}(\mathrm{II})$, and $\mathrm{Ni}$ (II) remaining in the solution (not bound by Alcoa Activated Alumina) as a function of time.

The kinetic data were analyzed by using the lterative Deconvolution Method (see section 3.5.2.1) and the results are listed in Tables 3.1 to 3.3. The results showed that the rate of binding by Alcoa Activated Alumina increased when the concentration of the Alcoa Activated Alumina was increased from 0.75 to $1 \%(w / w)$, but remained almost the same when the concentration was further increased to $1.5 \%(w / w)$. In each case good agreement was obtained between the rate constants for each component in the solutior. containing $1 \%$ and $1.5 \%(\mathrm{w} / \mathrm{w})$ Alcoa Activated Alumina. The concentration 


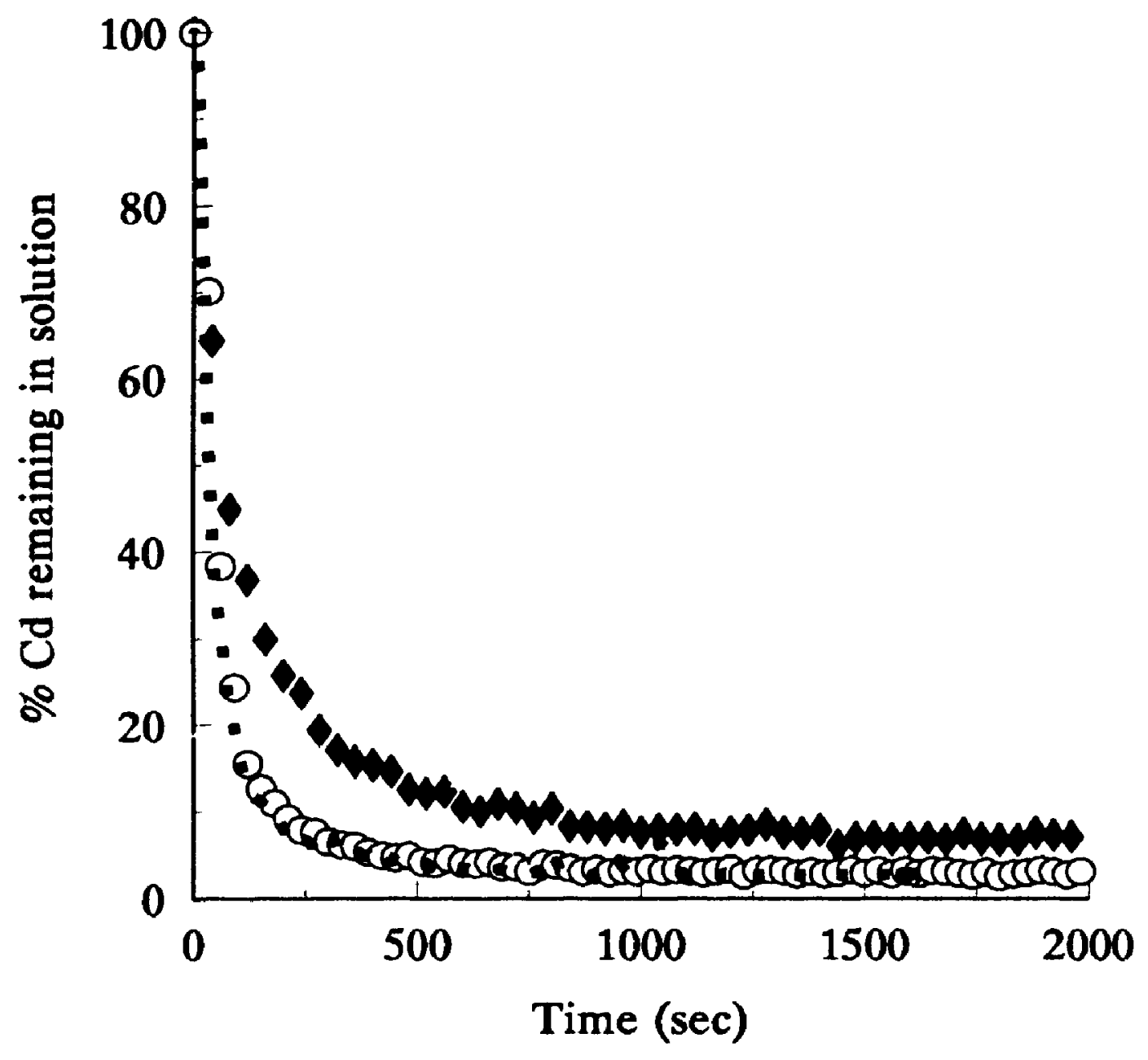

Figure 3.3 Effect of concentration of Alcoa Activated Alumina (115-170 mesh) on the rate of binding of cadmium. $\bullet 0.75 \%(w / w) ; 01 \%$ $(w / w) ; \ldots . .1 .5 \%(w / w)$. 


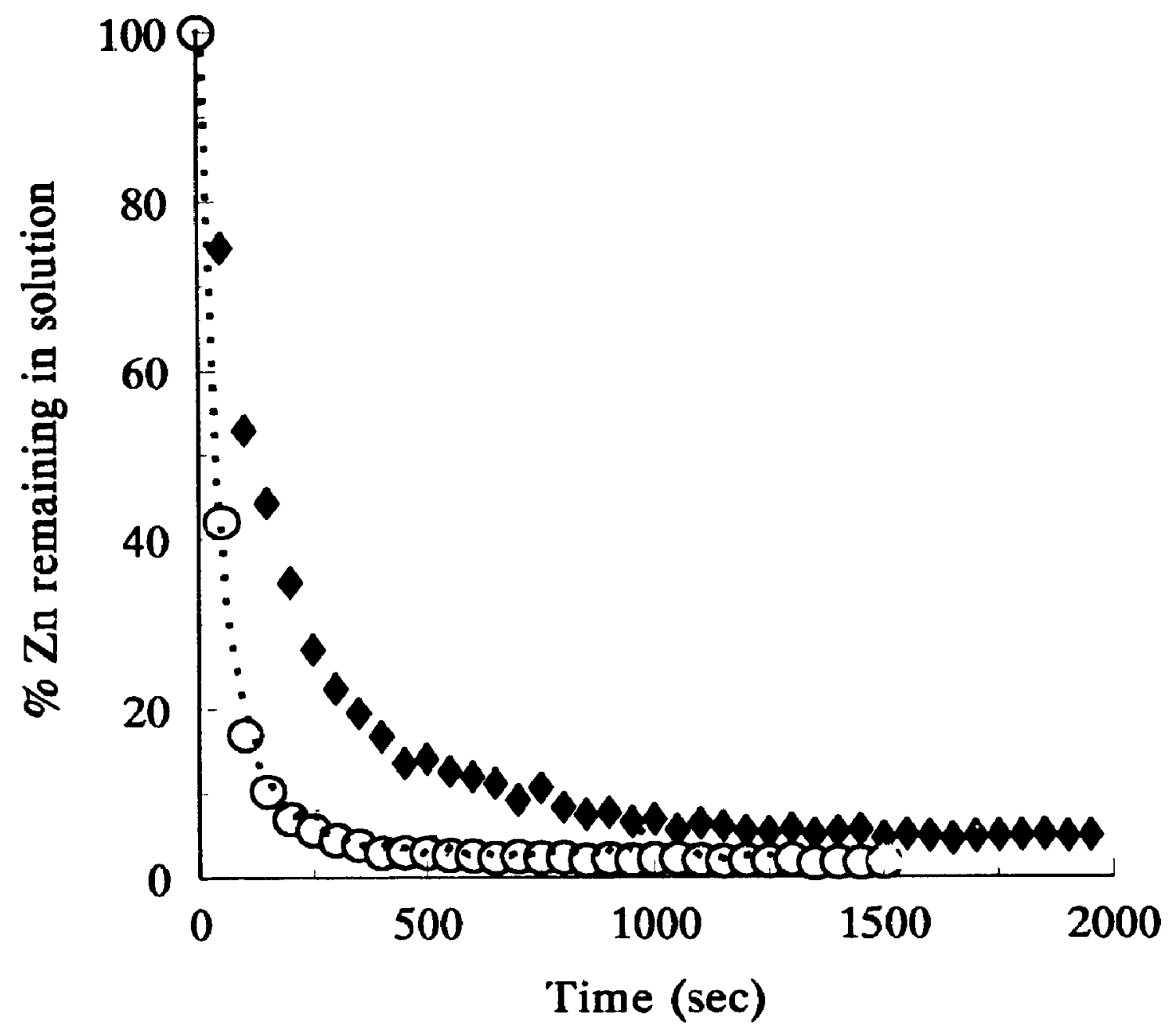

Figure 3.4 Effect of concentration of Alcoa Activated Alumina (115-170 mesh) on the rate of binding of zinc. $\bullet 0.75 \%(w / w) ; 01 \%$ $(w / w) ; \ldots . .1 .5 \%(w / w)$ 


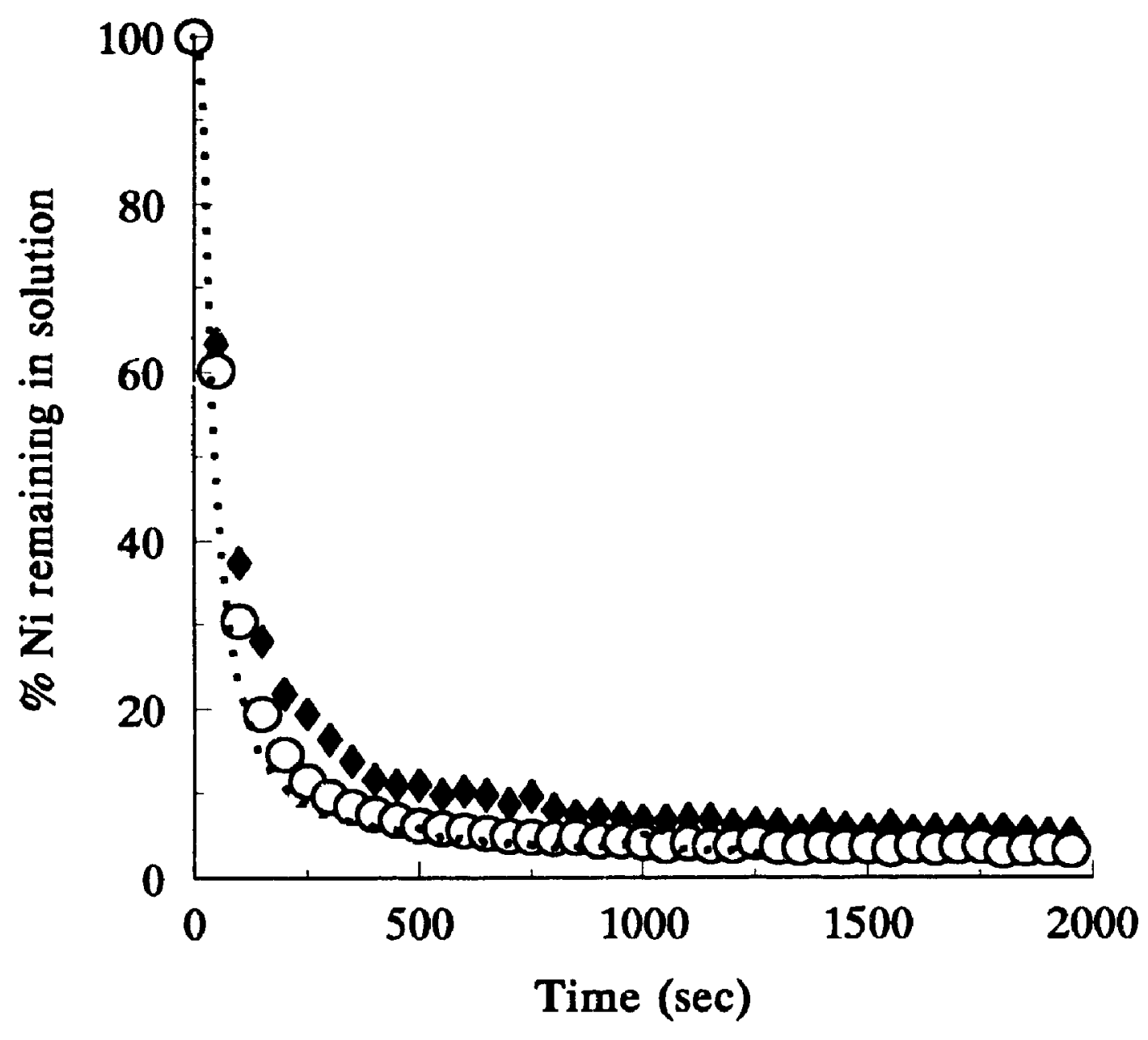

Figure 3.5 Effect of concentration of Alcoa Activated Aiumina (115-170 mesh) on the rate of binding of nickel. $0.75 \%(w / w) ; 01 \%$ $(w / w) ; \ldots . .1 .5 \%(w / w)$ 
Table 3.1 Effect of concentration of Alcoa Activated Alumina (115-170 mesh) on the kinetics of binding of cadmium aquo ions by $A$;oa Activated Alumina from a model sslution containing aquo ions of cadmium, nickel, zinc, lead, and copper.

\begin{tabular}{cccccc}
\hline Act.Alumina & $\mathrm{C}_{1}{ }^{0}$ & $\mathrm{k}_{1} \times 10^{-2}$ & $\mathrm{C}_{2}{ }^{0}$ & $\mathrm{k}_{2} \times 10^{-3}$ & Correlation \\
$\%(\mathrm{w} / \mathrm{w})$ & $\%$ & $\mathrm{~s}^{-1}$ & $\%$ & $\mathrm{~s}^{-1}$ & Coefncient \\
\hline 0.75 & $66 \pm 2$ & $1.7 \pm 0.1$ & $34 \pm 1.6$ & $2.0 \pm 0.1$ & 0.99 \\
1.0 & $90 \pm 1$ & $2.0 \pm 0.05$ & $10 \pm 0.7$ & $1.7 \pm 0.2$ & 0.99 \\
1.5 & $91 \pm 2$ & $2.4 \pm 0.07$ & $9.3 \pm 0.6$ & $1.8 \pm 0.1$ & 0.99 \\
\hline
\end{tabular}

Values after \pm signs are standard deviations of non-linear regression analysis. Since the total uncertainties of the analytical method, including that of the regression analysis, are greater than the values of the standard deviations shown above, only two significant figures in the values of the rate constants are justified. 
Table 3.2 Effect of concentration of Alcoa Activated Alumina (115-170 mesh) on the kinetics of binding zinc aquo lons by Alcoa Activated Alumina from a model solution containing aquo jons of cadmium, nickel, zinc, lead, and copper

\begin{tabular}{cccccc}
\hline $\begin{array}{c}\text { Act. Alumina } \\
\%(w / w)\end{array}$ & $\mathbf{C}_{1}{ }^{0}$ & $\mathbf{k}_{1} \times 10^{-2}$ & $\mathrm{C}_{2}{ }^{0}$ & $\mathrm{~K}_{2} \times 10^{-3}$ & Correlation \\
\hline 0.75 & $79 \pm 6$ & $0.8 \pm 0.07$ & $21 \pm 7$ & $1.2 \pm 0.5$ & 0.99 \\
1.0 & $93 \pm 2$ & $2.2 \pm 0.07$ & $7 \pm 0.8$ & $2.2 \pm 0.3$ & 0.99 \\
1.5 & $91 \pm 2$ & $2.1 \pm 0.08$ & $9.0 \pm 0.9$ & $2.1 \pm 0.2$ & 0.98 \\
\hline
\end{tabular}

Values after \pm signs are standard deviations of non-linear regression analysis. Since the total uncertainties of the analytical method, including that of the regression analysis, are greater than the values of the standard deviations shown above, only two significant figures in the values of the rate constants are justified. 
Table 3.3 Effect of concentration of Alcoa Activated Alumina (115-170 mesh) on the kinetics of binding of nickel aquo ions by Alcoa Activated Alumina from a model solution containing aquo ions of cadmium, nickel, zinc, lead, and copper.

\begin{tabular}{cccccc}
\hline $\begin{array}{c}\text { Act. Alumina } \\
\%(\mathrm{w} / \mathrm{w})\end{array}$ & $\mathrm{C}_{1}{ }^{0}$ & $\mathrm{k}_{1} \times 10^{-2}$ & $\mathrm{C}_{2}{ }^{\circ}$ & $\mathrm{k}_{2} \times 10^{-3}$ & Correlation \\
& $\%$ & $\mathrm{~s}^{-1}$ & $\%$ & $\mathrm{~s}^{-1}$ & Coefricient \\
\hline 0.75 & $78 \pm 2$ & $1.5 \pm 0.06$ & $22 \pm 1$ & $1.6 \pm 0.2$ & 0.99 \\
1.0 & $88 \pm 1.5$ & $1.6 \pm 0.05$ & $12 \pm 1$ & $1.5 \pm 0.2$ & 0.99 \\
1.5 & $90 \pm 2$ & $2 \pm 0.06$ & $10 \pm 0.7$ & $1.5 \pm 0.2$ & 0.99 \\
\hline
\end{tabular}

Values after \pm signs are standard deviations of non-linear regression analysis. Since the total uncertainties of the analytical method, including that of the regression analysis, are greater than the values of the standaro deviations shown above, only two significant figures in the values of the rate constants are justified. 
of $1 \%(w / w)$ of Alcoa Activated Alumina was used in further studies.

Another experiment was done to study the effect of concentration of the metal on the rate of binding of Alcoa Activated Alumina. If diffusion of metal ions $\left(\mathrm{M}^{++}\right)$in solution through the particles of Alcoa Activated Alumina is the slowest process, than the rate of binding of Alcoa Activated Alumina should be independent of the concentrations of $\mathrm{M}^{\mathrm{at}}$ ions in the solution. Two sets of model solutions, one containing $\mathrm{Cu}(\mathrm{II}), \mathrm{Pb}$ (II), $\mathrm{Cd}(\mathrm{II}),: \mathrm{i}$ (II) and $\mathrm{Zn}$ (II) at $10 \mu \mathrm{gL}^{-1}$ and the other containing the same metals, at $20 \mu \mathrm{g} / \mathrm{L}$ were prepared ( $\mathrm{pH} 8.2$ ) and left to stand overnight for equilibration. As mentioned earlier the concentration of the solution was always reduced probably because of to the basicity of the solution. The concentration of the metals at the time of the analysis was $\mathrm{Pb} 0.25$ $\mu \mathrm{gL}^{-1}, \mathrm{Cu} 6 \mu \mathrm{gL}^{-1}, \mathrm{Cd} 1.8 \mu \mathrm{gL}^{-1}, \mathrm{Zn} 7.4 \mu \mathrm{gL}^{-1}$, and $\mathrm{Ni} 5 \mu \mathrm{gL}^{-1}$ for the solution which has initially a concentration of $10 \mu \mathrm{gL}^{-1}$ of each metal. For the solution which contained initially $20 \mu \mathrm{gL}^{-1}$ of each metal the concentration of the metals at the time of the analysis was $\mathrm{Pb} 0.5 \mu \mathrm{gL}^{-1}, \mathrm{Cu} 4.6 \mu \mathrm{gL}^{-1}, \mathrm{Cd} 13 \mu \mathrm{gL}^{-1}, \mathrm{Zn} 11 \mu \mathrm{gL}^{-1}$, and $\mathrm{Ni} 17.8 \mu \mathrm{gL}^{-1}$. The concentration of the metals was always measured immediately before the experiment because the loss was unpredictable and uncontrollable over the period of standing.

The experimental data were analyzed by the Iterative Deconvolution Method (see section 3.5.2.1) and the results are listed in Table 3.4. The proportion of the component removed at the faster rate appeared to be greater in the solution with the higher concentration. Therefore, that concentration was chosen for subsequent experiments.

It has been reported that the rate of binding by Alcon Activated Alumina depends upon the $\mathrm{pH}$, concentration of electrolyte, and ionic strength [76]. Therefore, the slight 
Table 3.4 Efrect of concentration of metal ions on the rate of binding by Alcoa Activated Alumina from a model solution containing, cadmium, nickel, zinc, lead, and copper.

\begin{tabular}{cccccc}
\hline M(II)] & Element & $\mathrm{C}_{1}{ }^{0}$ & $\mathbf{k}^{1} \times 10^{-2}$ & $\mathrm{C}^{20}$ & $\mathbf{k}_{2} \times 10^{-3}$ \\
$\mu \mathrm{g} \mathrm{\textrm {L } ^ { - 1 }}$ & & $\%$ & $\mathrm{~s}^{-1}$ & $\%$ & $\mathbf{s}^{-1}$ \\
\hline 1.8 & $\mathrm{Cd}$ & $88 \pm 5$ & $1.4 \pm 0.09$ & $12 \pm 0.6$ & $0.50 \pm 0.05$ \\
13 & $\mathrm{Cd}$ & $92 \pm 2$ & $1.7 \pm 0.05$ & $8 \pm 0$ & $0.45 \pm 0.02$ \\
5 & $\mathrm{Ni}$ & $87 \pm 3$ & $1.5 \pm 0.06$ & $13 \pm 0.4$ & $0.4 \pm 0.03$ \\
17.8 & $\mathrm{Ni}$ & $91 \pm 2$ & $1.4 \pm 0.0$ & $9 \pm 0.2$ & $0.4 \pm 0.02$ \\
7.4 & $\mathrm{Zn}$ & $86 \pm 6$ & $1.0 \pm 0.1$ & $14 \pm 1$ & $0.6 \pm 0.07$ \\
11 & $\mathrm{Zn}$ & $98 \pm 9$ & $2.8 \pm 0.3$ & $2 \pm 0.2$ & $0.6 \pm 0.01$ \\
\hline
\end{tabular}

Values after \pm signs are standard deviations of non-linear regression analysis. Since the total uncertainties of the analytical method, including that of the regression analysis, are greater than the values of the standard deviations shown above, only two significant figures in the values of the rate constants are justinied. 
differences in the rates of binding for experiments performed on different days may be due to differences in ionic strength of the solutions.

Alcoa Activated Alumina gave a slower rate of binding for copper and lead than the other metals, and measurements on these metals were not continued.

3.8.2 Comparison of kinetics of binding of $\mathrm{Ni}(\mathrm{II}), \mathrm{Cd}(\mathrm{II})$, and $\mathrm{Zn}$ (II) by Chelex-100 (100-200 mesh) and by Alcoa Activated Alumina (115-170 mesh) from a model solution containing aquo ions of cadmium, nickel, zinc.

Figure 3.6, 3.7, and 3.8, show the rates of binding of $\mathrm{Ni}(\mathrm{II}), \mathrm{Cd}(\mathrm{II})$, and $\mathrm{Zn}(\mathrm{II})$ by Chelex-100 (100-200 mesh) and by Alcoa Activated Alumina (115-170 mesh) from a model solution containing a mixture of the following metals $\mathrm{Cd}(\mathrm{II}), \mathrm{Ni}(\mathrm{II})$, and $\mathrm{Zn}$ (II) as the nitrate (pH $8.2 \pm 0.1$ ). For the solution depicted in Fig. 3.6-3.8, although the initial concentraticu of the metals was 15,25 and $30 \mu \mathrm{g} \mathrm{L}$ of $\mathrm{Zn}, \mathrm{Ni}$, and $\mathrm{Cd}$ respectively, at the time of the analysis the concentrations of the metals decreased to a level of $\mathrm{Zn} 1.5$ $\mu \mathrm{g} \mathrm{L}^{-1}, \mathrm{Ni}: 14 \mu \mathrm{gL}^{-1}$, and $\mathrm{Cd} 24 \mu \mathrm{g} \mathrm{L}^{-1}$.

From these figures it can be seen qualitatively that the rate of binding by Alcoa Activated Alumina (115-170 mesh) is much faster than the rate of binding by Chelex-100 (100-200 mesh) for all the metals studied under these experimental conditions. This suggests that Alcoa Activated Alumina is more effective than Chelex-100 in the removal of metal ion from solutions. Figures 3.6, 3.7 and 3.8, illustrate also that the Chelex-100 does not reduce the concentration of the metals to zero, as does the Alcoa Activated Alumina. 


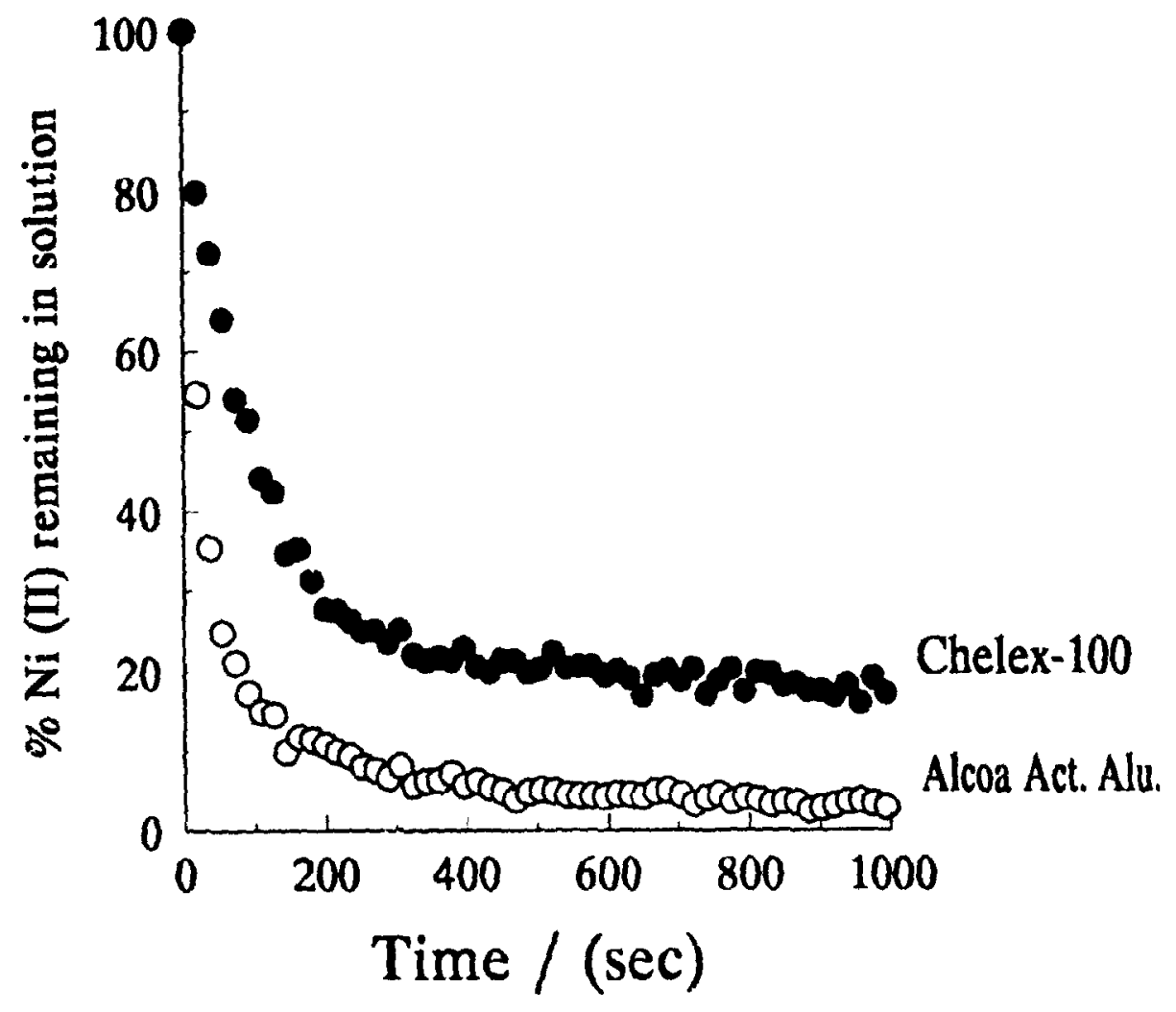

Figure 3.6 Percentage of nickel remaining in a model solution $\mathrm{pH} 8.2 \pm 0.1$ after binding by Chelex-100 (100-200 mesh) ; and by Alcoa Activated Alumina $(115-170$ mesh $) 0 ;[$ Chelex -100$]=1 \%(w / w) ;[$ Alcoa Activated Alumina $]=1 \%(w / w)$. 

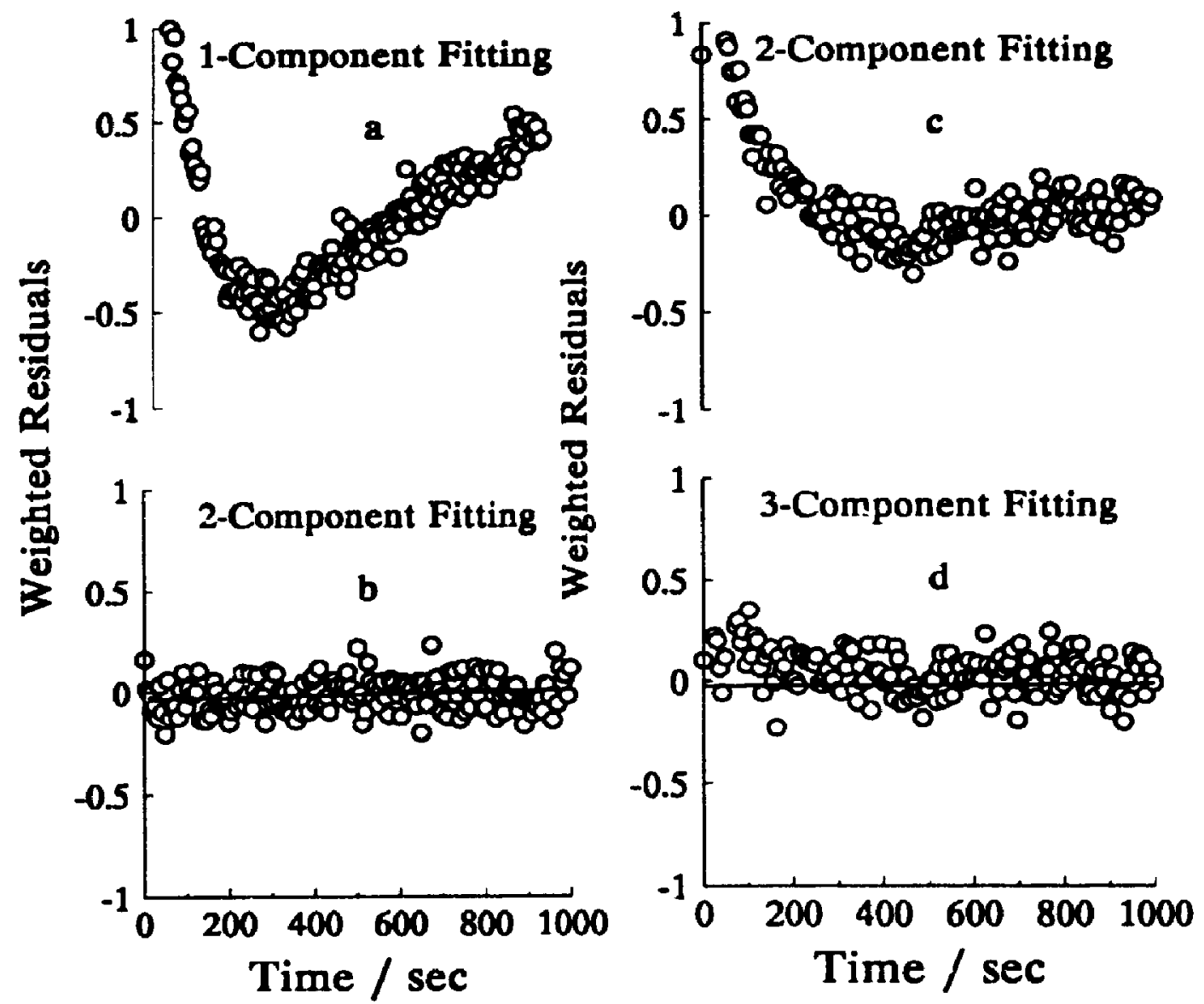

Figure 3.6a Plots of weighted residuals as a function of tire of binding nickel by Chelex-100 at pH $8.2 \pm 0.1$ (Curves a and b) and by Alcoa Activated Alumina (Curves $\mathrm{c}$ and $\mathrm{d}$ ). Curve a: 1-component-fitting. Curve b: 2components fitting. Curve c: 2-component-fitting. Curve d: 3-componentfitting. 


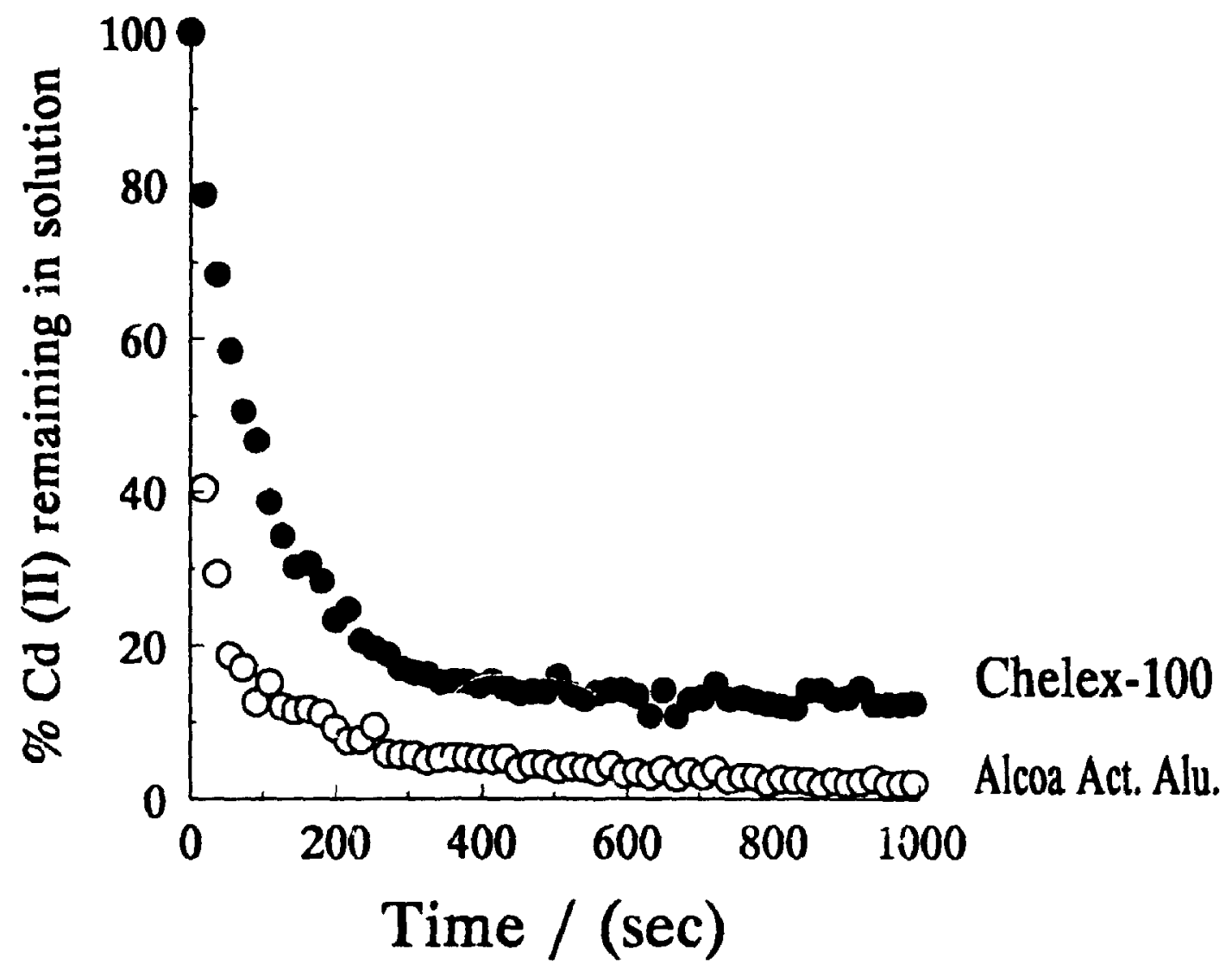

Figure 3.7 Percentage of cadmium remaining in a model solution $\mathrm{pH} 8.2 \pm 0.1$ after bindi.: by Chelex-100 (100-200 mesh) ; and by Alcoa Activated Alumina $(115-170 \mathrm{mesh}) 0 ;[$ Chelex -100$]=1 \%(w / w) ;[$ Alcoa Activated Alumina $]=1 \%(w / w)$ 

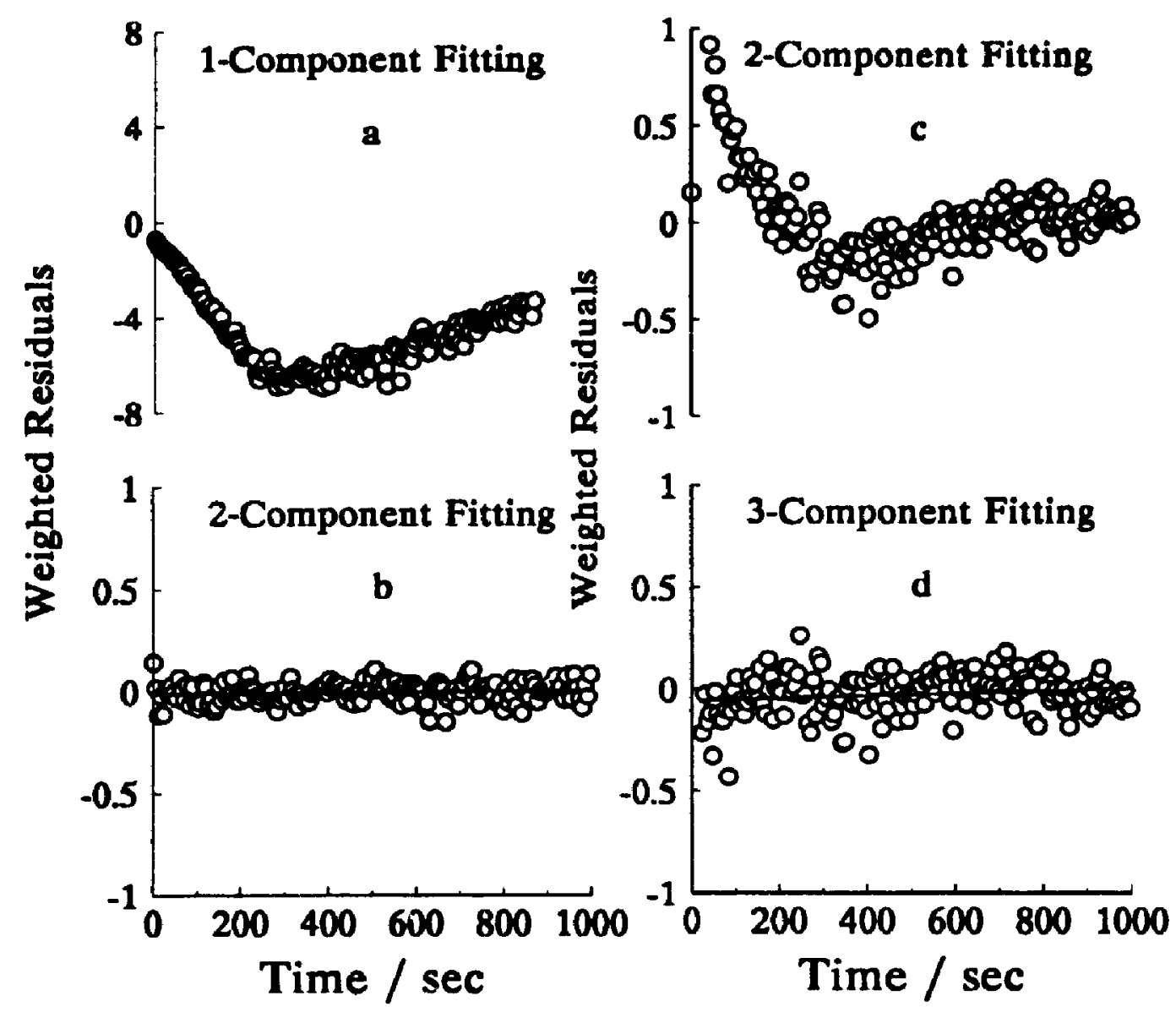

Figure 3.7a Plots of weighted residuals as a function of time of binding cadmium by Chelex-100 at $\mathrm{pH} 8.2 \pm 0.1$ (Curves a and b) and by Alcoa Activated Alumina (Curves $c$ and d). Curve a: 1-component-fitting. Curve b: 2components fitting. Curve $c$ : 2-component-fitting. Curve d: 3-componentfitting. 


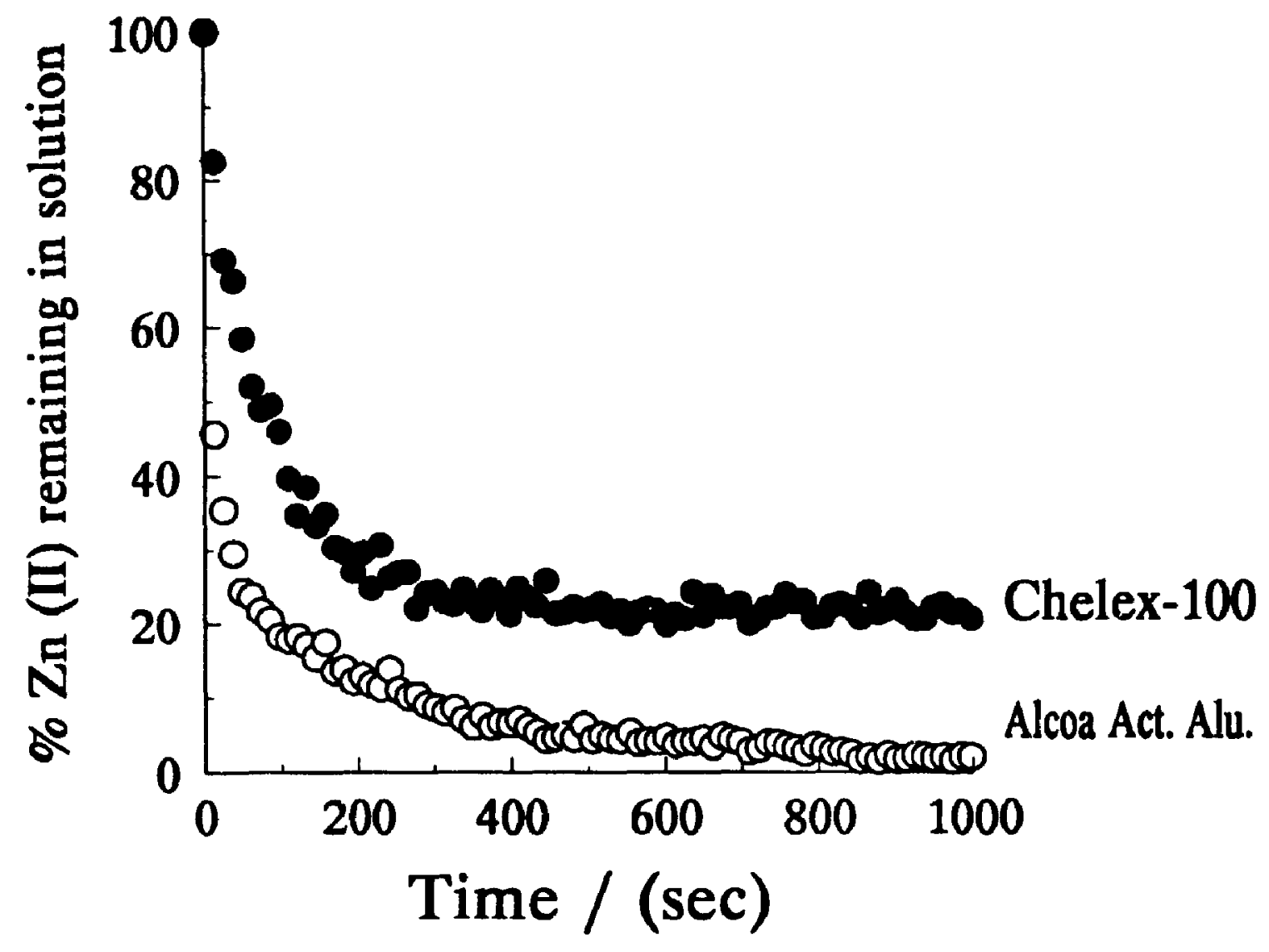

Figure 3.8 Percentage of zinc remaining in a model solution $\mathrm{pH} 8.2 \pm 0.1$ after binding by Chelex-100 (100-200 mesh) $O$; and by Alcoa Activated Alumina $(115-170 \mathrm{mesh}) \circ[$ Chelex-100] $=1 \%(\mathrm{w} / \mathrm{w}) ;[$ Alcoa Activated Alumina $]=1 \%(w / w)$. 


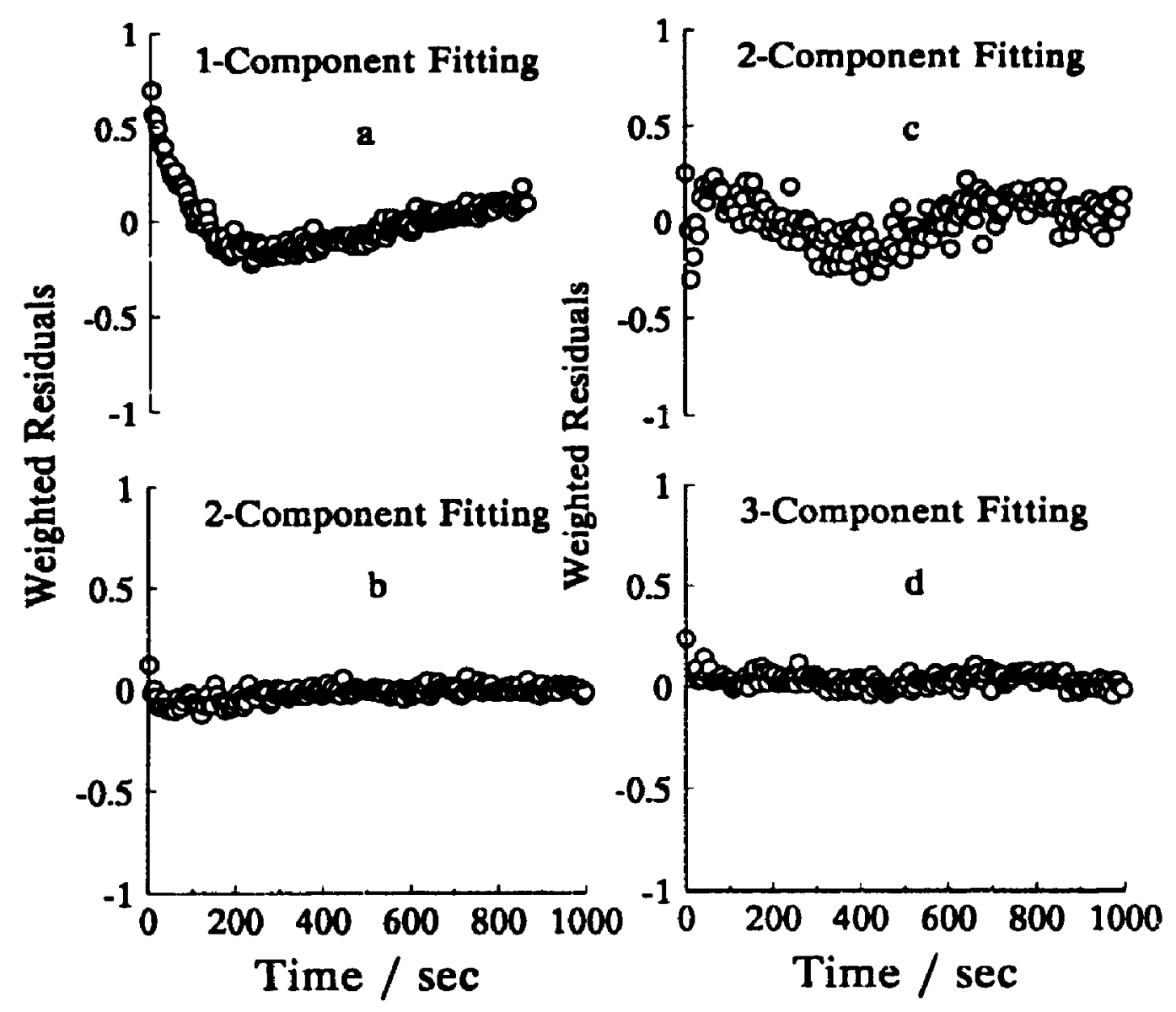

Figure 3.8a Plots of weighted residuals as a function of time of binding zinc by Chelex-100 at $\mathrm{pH} 8.2 \pm 0.1$ (Curves $\mathrm{a}$ and $\mathrm{b}$ ) and by Alcoa Activated Alumina (Curves $\mathrm{c}$ and d). Curve a: 1-component-fitting. Curve b: 2-components fitting. Curve c: 2component-fitting. Curve d: 3-component-fitting. 
With Chelex-100 there was no difference in the concentration of the metal remaining in solution between $1000 \mathrm{sec}$ and $4500 \mathrm{sec}$. Since this behaviour of the Chelex-100 was common with all the metals, this suggests that for these experimental conditions, Chelex100 has reached its limit for binding of the metals.

The data were analyzed using the Iterative Deconvolution Method [6.3] as outlined in section 3.5.2.1. The results of the analysis are listed in Table 3.5. The results obtained by the Iterative Deconvolution Method were further tested by using the method of the plot of weighted residuals as a function of time. Figures $3.6 \mathrm{a}, 3.7 \mathrm{a}$ and $3.8 \mathrm{a}$ show the plot of weighted residuals for different number of components.

Table 3.5, compares the kinetics of binding of $\mathrm{Ni}(\mathrm{II}), \mathrm{Cd}(\mathrm{II})$, and $\mathrm{Z}$ (II) by Alcoa Activated Alumina and by Chelex-100. The analysis of the data with Chelex-100 shows two components, but the rate constant of the second component is very small. Such a small rate constant suggests that the limit of binding of metal ions by Chelex-100 under these experimental conditions has been reached. Hence, only one component of the metal ion is considered to be present for all the elements that were studied. Furthermore, the first rate constants obtained with Chelex-100 were similar for all the three elements. Therefore, Chelex -100 , under these experimental conditions, shows no selectivity towards the metals.

According to the results of Table 3.5 the largest rate constant obtained with the Alcoa Activated Alumina is always greater than the largest rate constant obtained with Chelex-100. These values for Alcoa Activated Alumina are different from the rate constants obtained in the experiments described in section 3.8 .1 , where the largest rate 


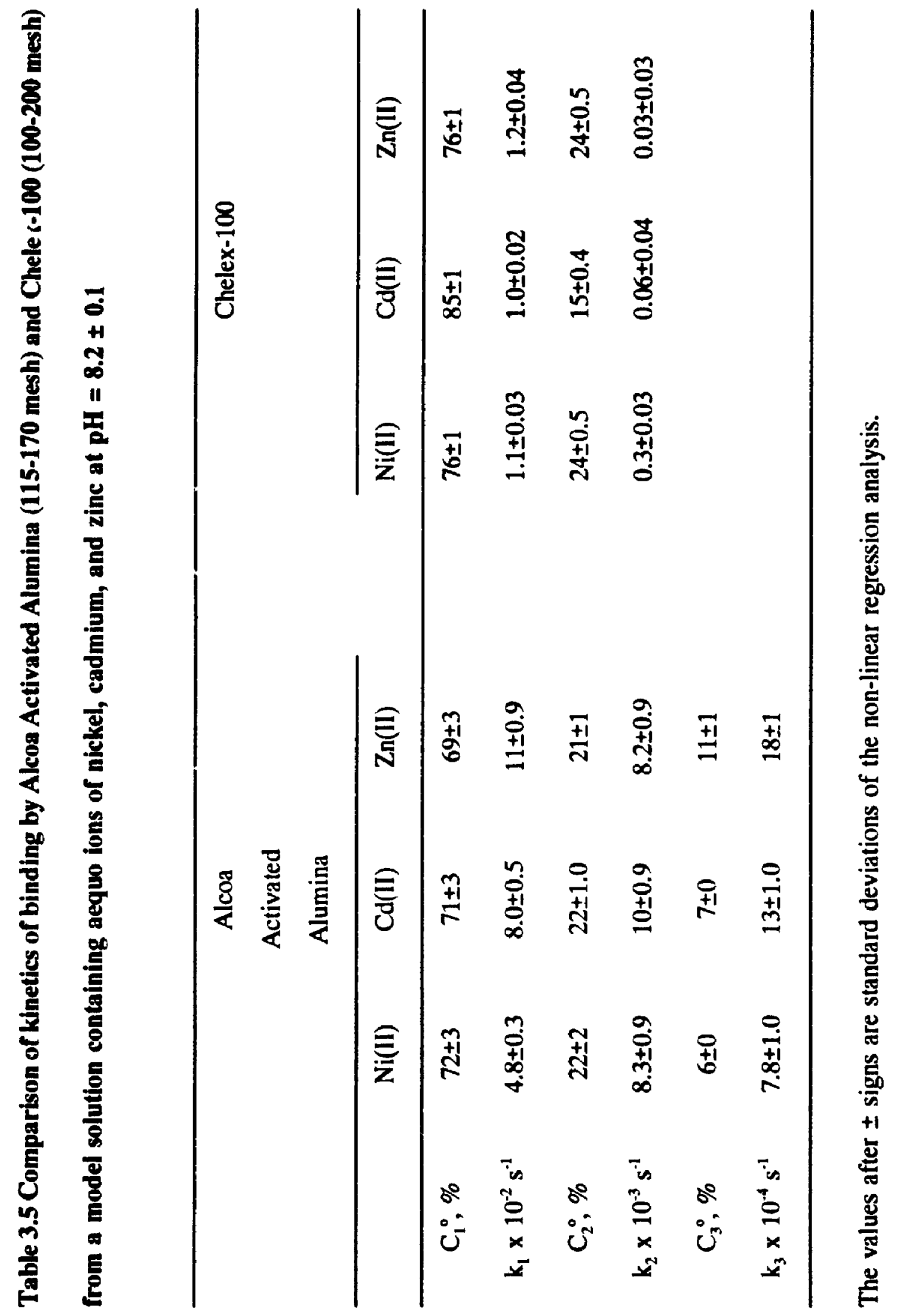


constant measured with Alcoa Activated Alumina was similar to the largest rate constant measured with Chelex-100.

The difference in the solutions used in section 3.8.1 and 3.8.2 is the absence of lead and copper from the solution used in section 3.8.2. Therefore, increase in rate of binding of $\mathrm{Ni}(\mathrm{II}), \mathrm{Cd}(\mathrm{II})$, and $\mathrm{Zn}$ (II) by Alcoa Activated Alumina was probably due to the absence of $\mathrm{Pb}$ (II) and $\mathrm{Cu}$ (II) from the solution. Also the first rate constant increases in the order $\mathrm{Ni}(\mathrm{II}), \mathrm{Cd}(\mathrm{II})$ and $\mathrm{Zn}$ (II) with Alcoa Activated Alumina, whereas with Chelex-100 the value of the first rate constant is similar for all the three elements. This different behaviour of the first rate constant (Alcoa Activated Alumina and Chelex-100) indicates that Alcoa Activated Alumina has a selectivity towards the metals, whereas Chelex-100 under these experimental conditions shows no selectivity.

Three components were resolved for Alcoa Activated Alumina. At pH 8.2 and the concentrations of the metals of only few $\mu \mathrm{g} \mathrm{L}^{-1}$ only the free aquo ion of $\mathrm{Ni}(\mathrm{II}), \mathrm{Cd}(\mathrm{II})$ and $\mathrm{Zn}(\mathrm{II})$ should be present [87]. The second and the third components in the solution can represent stable complexes, such as $M L_{i}$ in equation (10), only if such complexes with $\mathrm{OH}^{-}$are formed under these experimental conditions. Because this appears unlikely a possible explanation for the three rates of removal may lie in the mechanisms for binding of the metal by Alcoa Activated Alumina. The method of binding of the metal by Alcoa Activated Alumina is apparently different from that by Chelex-100. The fast removal may represent the transport of the metal from the solution to the surface of the Alcoa Activated Alumina and the two slow removals may indicate a slower process of diffusion through the pores of the adsorbents, a slow ion exchange process, or other slow 
adsorption processes, or a combination of two or more or all of the above processes.

\subsubsection{Results of Kinetic Analysis of Ni(II), Cd(II), and Zn(II) complexes in a Rideau River Surface Water Sample}

Figure 3.9 to 3.13 show the percentage of nickel, cadmium and zinc remaining in the Rideau river surface water sample after binding by Chelex-100 (100-200 mesh) and by Alcoa Activated Alumina (115-170 mesh). In these figures, are also shown the plots of weighted residuals as a function of time for two and three components. In each case the plot of weighted residuals with two components shows marked a curvature, whereas with three components the weighted residuals are randomly distributed around zero. Therefore, three components better represent the experimental data. This finding was common for all the metals, by using either Alcoa Activated Alumina or Chelex-100. The rate constants and the percentage of each component obtained by the Iterative Deconvolution Method (see section 3.5.2.1) are listed in Table 3.6.

It is noteworthy that the same number of kinetically distinguishable components were obtained using the cation exchange resin Chelex-100 and the adsorbent Alcoa Activated Alumina. Thus both the reagents indicate the presence of slowly-dissociating complexes in the river water. With the Chelex it appears that two complexes are present for each metal. The slowest rate constant, $\sim 2 \times 10^{-4} \mathrm{~s}^{-1}$ is still larger than the values of $0.6 \times 10^{-4}$ and $0.3 \times 10^{-4} \mathrm{~s}^{-1}$ for $\mathrm{Cd}$ and $\mathrm{Zn}$ respectively, observed in the model solution where it was suggested that the limit of binding had been reached.

In the case of Alcoa the proportion of the second and third components is much 
observed with the model solution are no longer distinguishable in the presence of the large concentrations of metal complexes.

As in the model solution, Chelex-100 showed no selectivity towards the three metals studied. Also the first rate constant is similar to the first rate constant obtained in the model solution.

The values for $k_{1}$ obtained in the Rideau river sample with Alcoa Activated Alumina were similar to those obtained with the model solutions used in section 3.8.1. These solutions and the Rideau River water samples both contain lead and copper. Thus consistent rates of adsorption by Alcoa Activated Alumina were obtained for the these metals. The proportion of free aquo ion in the Rideau river water sample is much less than in the model solutions, as expected in the presence of naturally-occurring complexing ligands in the Rideau river water sample. 

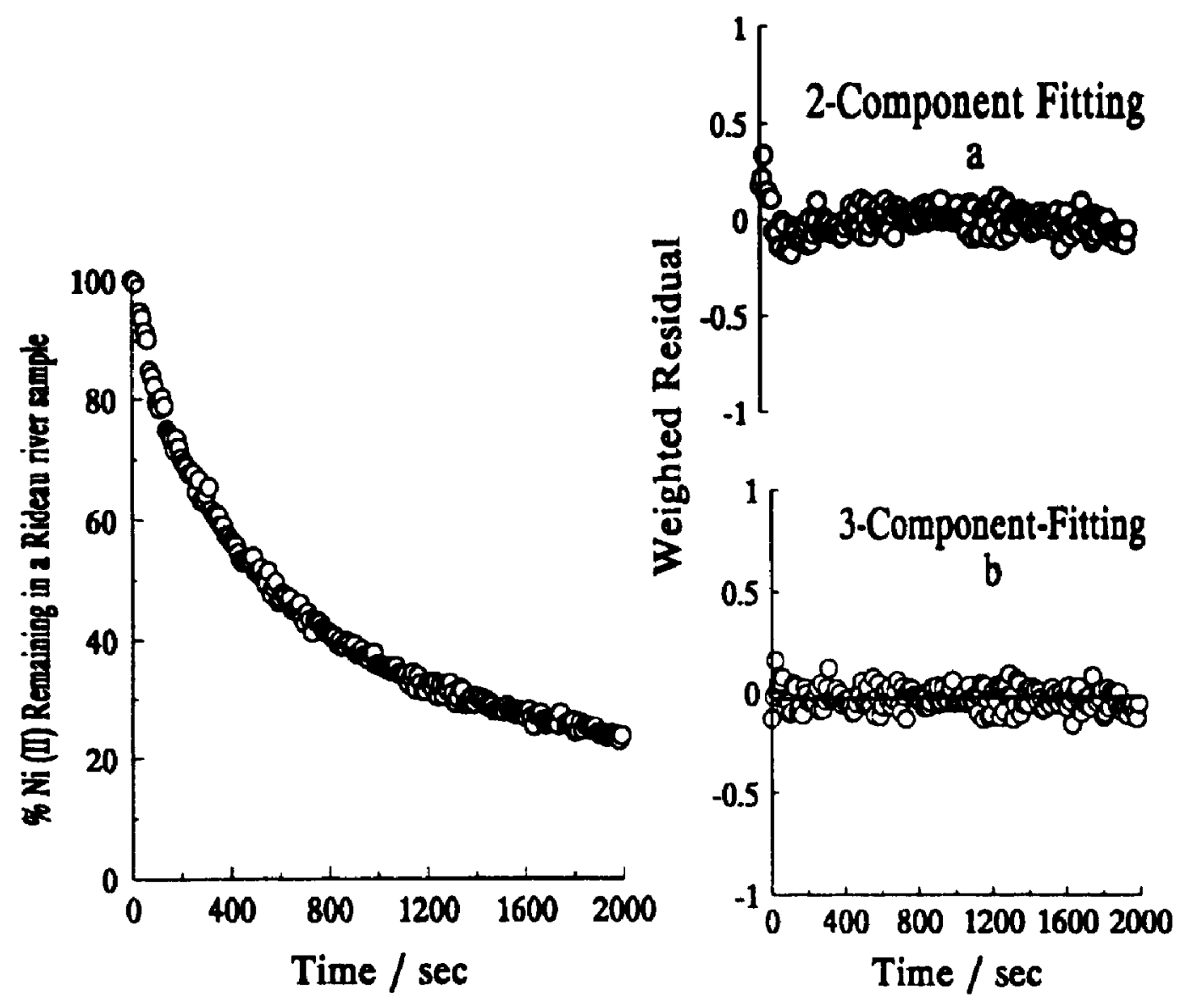

Figure 3-9 Percentage of nickel remaining in the Rideau river surface water sample, as a function of time, after binding by Chelex-100 (100-200 mesh): $0, \mathrm{pH}$ 8.3 \pm 0.1 . Curve a: weighted residuals as a function of time, 2-co:nponentfitting. Curve b: weighted residuals as a function of time, 3-component fitting. 

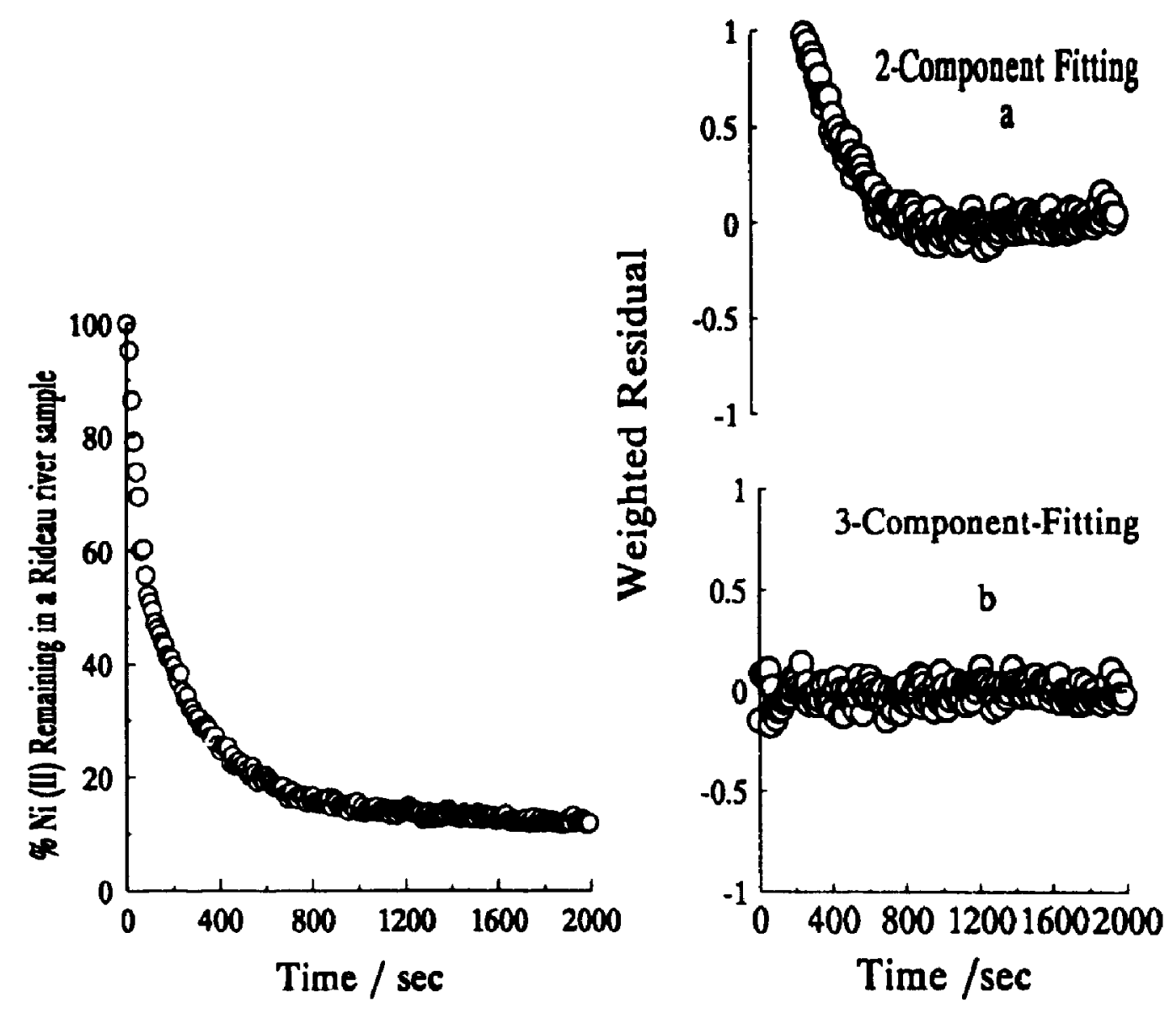

Figure 3.10 Percentage of nickel remaining in the Rideau river surface water sample, as a function of time, after binding by Alcoa Activated Alumina (115-170 mesh): $0, \mathrm{pH} 8.3 \pm 0.1$. Curve a: weighted residuals as a function of time, 2-component-fitting. Curve b: weighted residuals as a function of time, 3component fitting. 

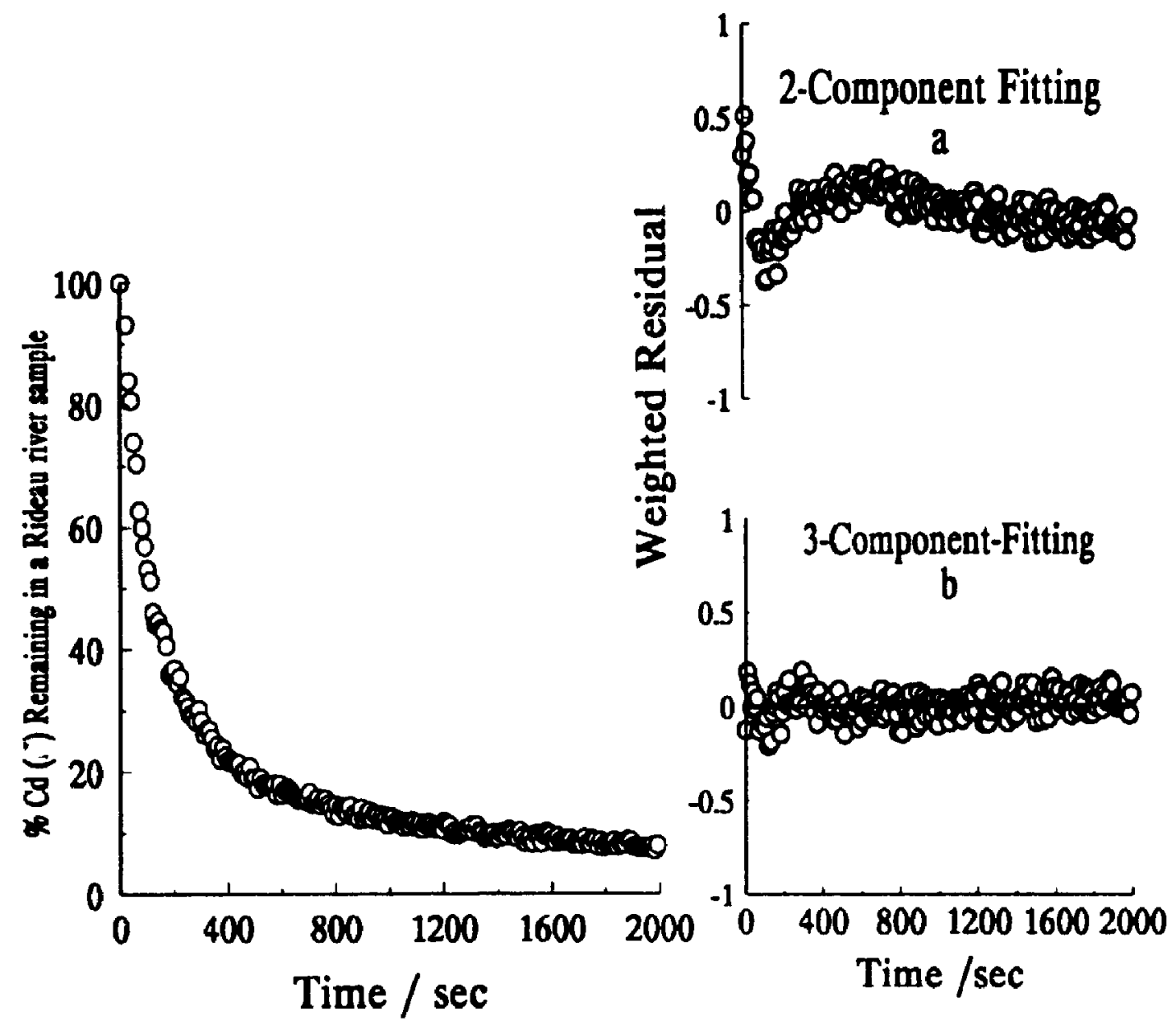

Figure 3.11 Percentage of cadmium remaining in the Rideau river surface water sample, as a function of time, after binding by Chelex-100 (100-200 mesh): $0, \mathrm{pH} 8.3 \pm 0.1$. Curve a: weighted residuals as a function of time, 2-component-fitting. Curve b: weighted residuals as a function of time, 3 component fitting. 

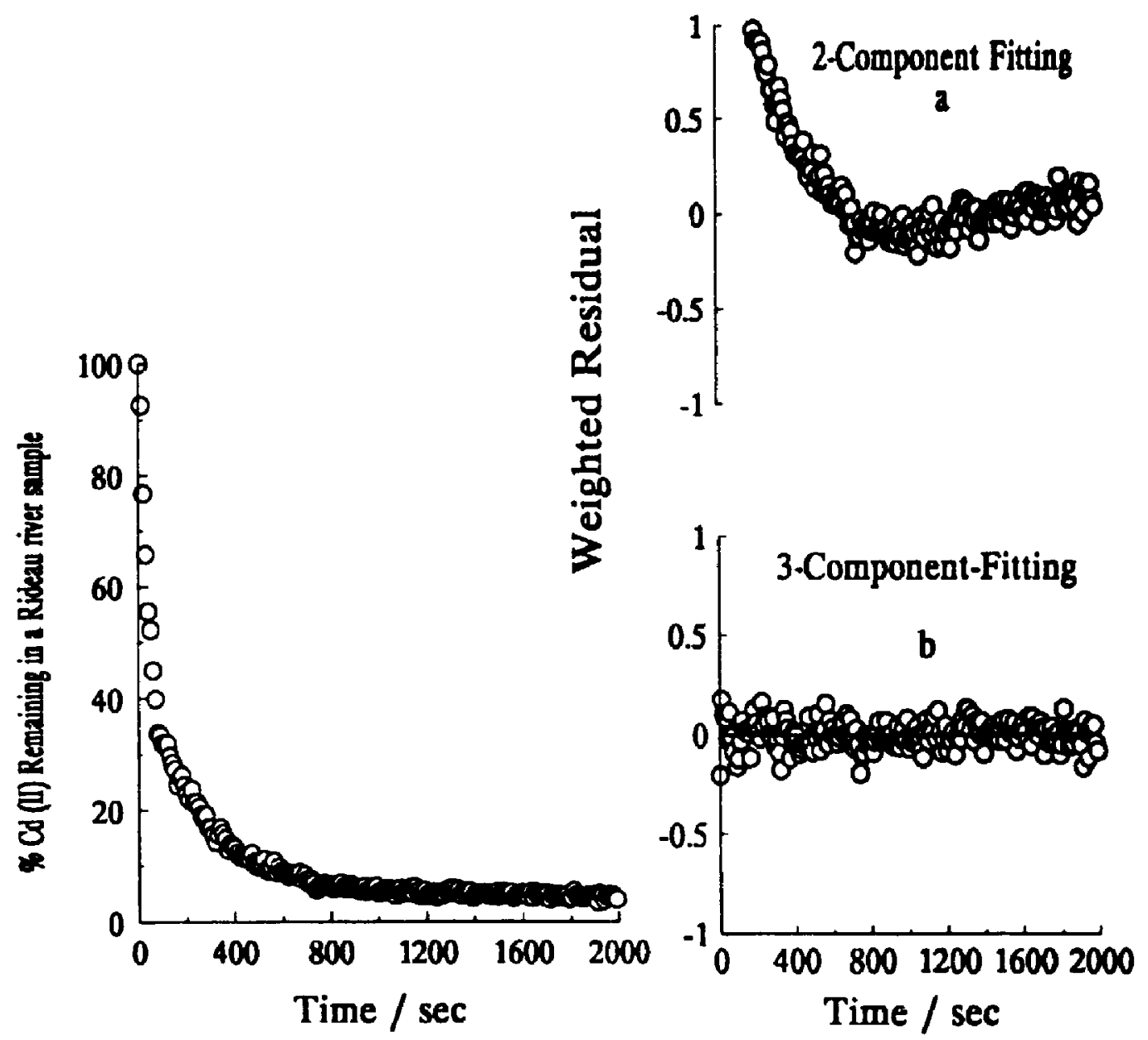

Figure 3.12 Percentage of cadmium remaining in the Rideau river surface water sample, as a function of time, after binding by Alcoa Activated Alumina (115-170 mesh): $0, \mathrm{pH} 8.3 \pm 0.1$. Curve a: weighted residuals as a function of time, 2-component-fitting. Curve b: weighted residuals as a function of time, 3-component fitting. 

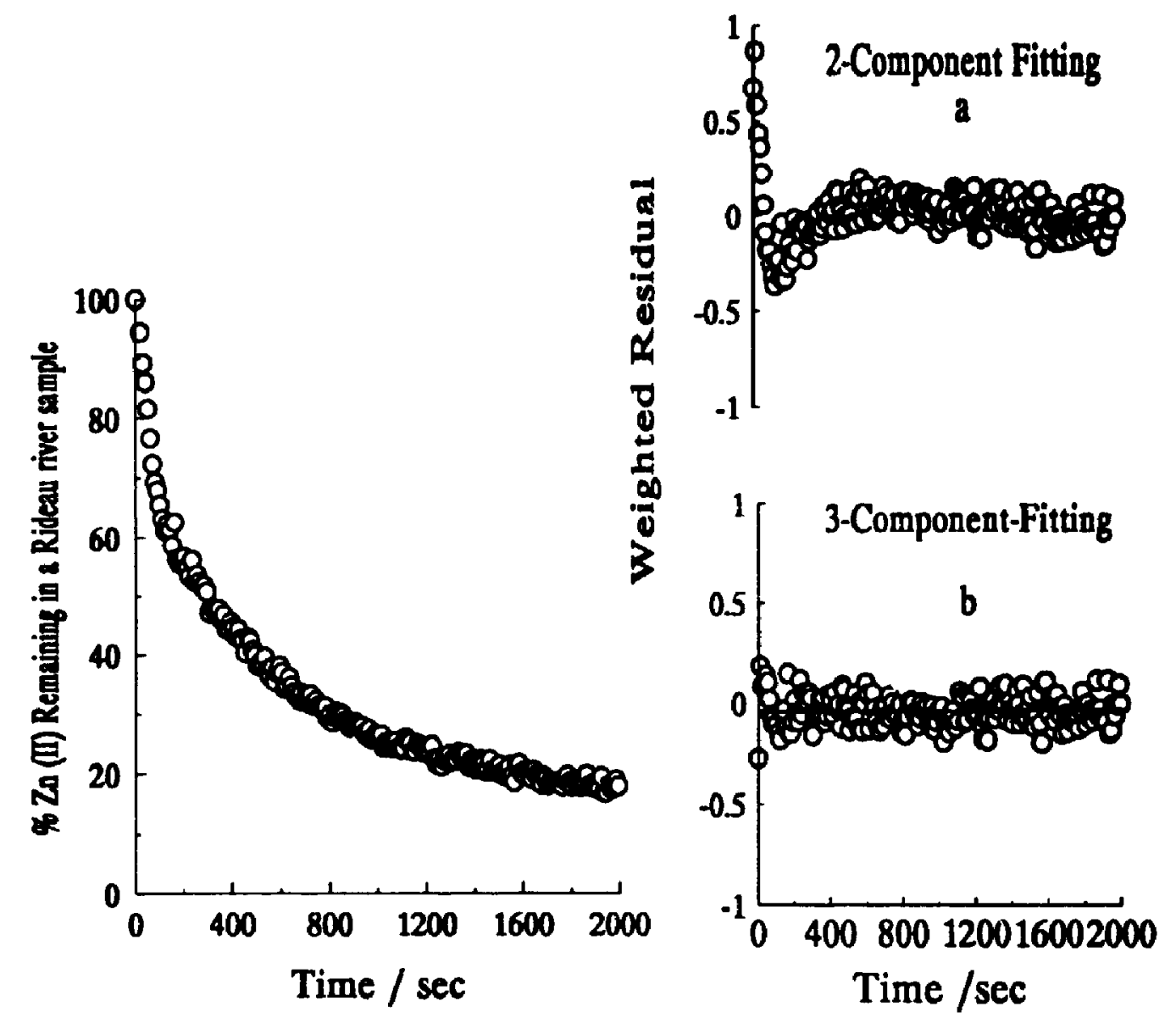

Figure 3.13 Percentage of zinc remaining in the Rideau river surface water sample, as a function of time, after binding by Chelex-100 (100-200 mesh): $0, \mathrm{pH}$ $8.3 \pm 0.1$. Curve a: weighted residuals as a function of time, 2-componentfitting. Curve b: weighted residuals as a function of time, 3-component fitting. 


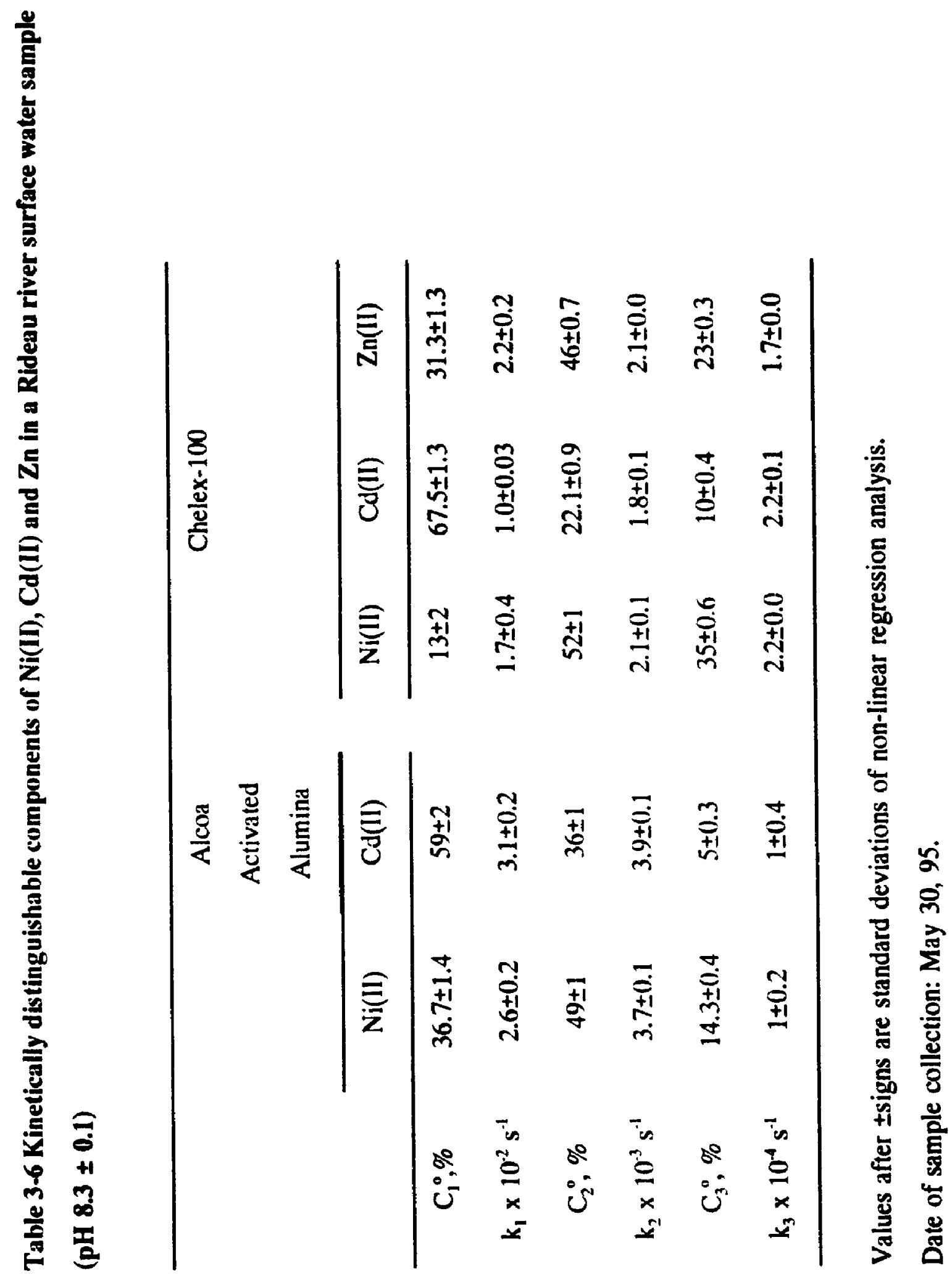




\subsection{CONCLUSIONS}

Kinetic studies of metal speciation can provide valuable information on the number of kinetically distinguishable components, the initial concentration of each component, the concentration of each component at any specific time during the kinetic run and their rate constants. The use of the Alcoa Activated Alumina for kinetic studies of $\mathrm{Ni}(\mathrm{II}), \mathrm{Cd}(\mathrm{II}), \mathrm{Zn}$ (II) in Rideau river surface water samples has some advantages.

1) Under some experimental conditions it has faster rate of metal binding than Chelex-100 at pH $8.2 \pm 0.1$. This is the $\mathrm{pH}$ of most river water (unpolluted).

2) Since activated alumina is negatively charged at high $\mathrm{pH}$ and positively charged at low $\mathrm{pH}$ it is selective toward cations at high $\mathrm{pH}$ and towards anions at low $\mathrm{pH}$. Thus by varying the $\mathrm{pH}$ of the sample one can obtain a wider picture of the distribution of the species. Such changes, change the speciation of the sample and this must taken into account. Also, due to its amphoteric character it can bi used for acidic or basic samples.

3) Alcoa Activated Alumina is a good adsorbent at the $\mathrm{pH}(\sim 8)$ of unpolluted river water and thus no additional reagents need to be added.

4) Good precision is obtained with replicate measurements of the same sample.

The limitations of this method are:

1) The species cannot be identified. Only the number of kinetically distinguishable species can be obtained with their concentrations and rate constants. However, it is very important from the point of view of bioavailability and toxicity to know the reactivity (kinetics) of the metal species. 
2) The rate of adsorption of metals by Alcoa Activated Alumina is sensitive to the experimental conditions, such as $\mathrm{pH}$, ionic strength and other variables. Hence, some difficulty in reproducibility in different days with different samples was encountered.

\subsection{FUTURE WORK}

It will be interesting to study a well-characterized, metal-fulvic acid system by using Alcoa Activated Alumina. 


\section{REFERENCES}

1. K.S. Subramanian, C.L. Chakrabarti, J.E. Sueiras and I.S. Maines, Anal. Chem., 50, 444, (1978).

2. G.E. Batley and D. Gardner, Water Research, 11, 745, (1977).

3. M.P. Maskarinec and R.L. Mondy, in: Principles of Environmental Sampling, L.H. Keith, Editor, American Chemical Society, Washington, D.C., Chap.9, (1988).

4. H.W. Nurnberg and L. Mart., in: The Determination of Trace Metals in Natural Waters, T.S. West and H.W. Nurnberg (Eds)., Blackwell, Oxford, Chap.2 (1988).

5. J. Buffle, Complexation Reactions in Aquatic Systems: an Analytical Approach, Ellis Horwood, Chichester, (1988).

6. G.E. Batley in: Trace Element Speciation: Analytical Methods and Problems, G.E. Batley (Ed.), CRC Press, Inc., Boca Raton, FL, Chap. 1 (1989).

7. A.W. Struempler, Anal.Chem., 45, 2251, (1973).

8. R. Samlim and B.G. Cooksey, J. Electroanal.Chem.,106, 251, (1980).

9. R.E. Truit and Weber, Anal.Chem., 51, 2057, (1979).

10. P. Beneš and V.Majer, Trace Chemistry of Aquous Solutions, Elsevier, Amsterdam, (1980).

11. T.M. Florence, Water Res., 11, 681, (1977).

12. G.E. Batley and D.Gardner, Estuar.Coast. Mar.Sci., 7, 59, (1978).

13. D.P. Laxen and R. M. Harrison, ibid., 53, 337,(1981). 
14. L. Mart, Fresenius Z. Anal. Chem., 296, 350, (1979).

15. H.W. Nurnberg, P. Valenta, L. Mart, B. Raspor and L. Sipos, ibid., 282, 357, (1976).

16. S.R. Piotrowitz, G.R. Harvey, M. Springer-Young, R.A. Courant, and D.A. Boren in: Trace Metals in Seawater, Wong, C.S. Bunton, J.D. Boyle, K. Bruland, and E.D. Goldberg, Editors. Plenum Press, New York, 699, (1984).

17. T.M.Florence, Talanta, $\underline{29}, 345,(1982)$.

18. W. Stumm and H. Bilinski, in S.H. Jenkins, Advances on Water Pollution Research, Pergamon Press, New York, (1972).

19. E.D.Goldberg, M. Baker, and D.L.Fox. J.Mar. Res.11, 197, (1952).

20. M. Zief and J.W. Mitchell, in: Contamination Control in Trace Ele went Analysis P.J. Elving (Ed.) J. Wiley \& Sons Chap.4.

21. D.E. Robertson, Anal. Chem., 40, 1067,(1968).

22. G.E. Batley and T.M. Florence, Mar. Chem. 4, 347, 1977.

23. P.B. Adams, in: Ultrapurity, Methods and Techmiques, M. Zief, and R. Speights, (Eds.), Marcel Dekker, New York, 297 (1972).

24. R.H.Dorumus, Ion Exchange in glasses, Ion Exch. Surv., 2, 1, (1969).

25. R.O. James and TY.W. Healy., J.Colloid Interface Sci., 40, 65, (1972).

26. R.M.Harrison and D.P.H. Laxen, Chem. Brit., 16, 316, (1980).

27. J.R. Moody and R.M. Linstrom, Anal. Chem. 49, 14 2264, (1977).

28. Shimazu Total Organic Carbon Analyzer Manual TOC-5000

29. Anal. Chim. Acta, 40 1067, (1968). 
30. Proceeding Workshop Toxicity to aquatic biota of metals forms in natural water, R.W. Andrew, P.V. Hodson and D.E. Konasewich (Eds.), Oct. 7-8, 1975, Duluth, Minnesota, Int. Joint Comm., 329, (1976).

31. T.M. Florence and G.E. Batley, CRC Crit. Rev. Anal.Chem. 9 219, (1980).

32. D.P.H. Laxen and R.M. Harrison, Water Res., 11, 14, (1977).

33. R.D.Guy and C.L. Chakrabarti, Can. J. Chem. 54, 2600 (1976).

34. G.E. Batley, "Trace Element Speciatin in Surface water and its Ecological Implications" Gary G. Leppard (Ed.), Plenum Press, New York, 17, (1983).

35. S.J. De Mora and R.M. Harrison, Water Res., 17, 723, (1983).

36. C. Staub, J. Buffle and W. Haerdi, Anal. Chem., 6, 2843, (1984).

37. R.D.Guy. and C.L. Chakrabarti, in Proceedings of International Conference on Heavy Metals in Environment, Toronto, Ontario, Canada, October 27-31, 1975, p.275;

38. R.D.Guy and C.L.Chakrabarti, Chemistry in Canada, 28 (1976) 26

39. M.R. Hoffman, S.J. Yost Eisenreich and W.J. Maier, Environ. Sci. Tech., 15, 655, (1981).

40. Y. Tanizaki, M. Yamazaki and S. Nagatsuka, Bull. Chem. Soc. Jpn. 58, 2995, (1985).

41. J.C. Kwak, R.W.P. Nelson and D.S. Gamble Geochim. Cosmochim. Acta 41, 993, (1977).

42. A.J. Fane, J. Memb. Sci., 20, 249 (1984).

43. R.W. Sheldon, Limnol. Oceanogr., 17, 494, (1972). 
44. R.W. Sheldon, Limnol. Oceanogr., 14, 441, (1969).

45. J. Buffle, D. Perret, M. Newman, "The Use of Filtration and Ultrafiltration for Size Fractionation of Aquatic Particles, Colloids, and Macromolecules" in: Environmental Analytical and Physical Chemistry Series Environmental Particles Vol.1 J. Buffle and H.P. van Leeuwen (Eds.) Lewis Publishers, (1992).

46. K.J. Kim, V. Chen and A.G. Fane, J. Memb. Sci., 88,93 (1994).

47. K.J. Kim, V. Chen and A.G. Fane J.Colloid Interface Sci., 155, 347, (1993).

48. Z.D. Wang, B.C. Pant and C.H. Langford, Anal. Chim. Acta, 232, 43, (1990).

49. Amicon Catalogue, Amicon Canada Limited 1226 White Oaks Boulevard Oakville, Ontario, L6H 9Z9.

50. T.M. Florence and G. E. Batley, Talanta, 24, 151, (1977).

51. Walter Lund, Fresenius J.Anal. chem. 337, 557, (1990).

52. W.G. Sunda, R.R.Guillard, J. Mar. Res.,34, 511, (1976).

53. M.A. Anderson, F.M.M. Morel, Limonol. Oceanogr. 27, 789, (1983).

54. M.S. Shuman, B.J. Collins, P.J. Fitzgerald and D.J. Olson, in: Aquatic and Terrestial Humic Materials, Ann Arbor Science Publ., Ann Arbor, MI, Chap.17 349, (1983).

55. M.R. Hoffman, Environ. Sci. Technol., 15, 345, (1981).

56. P. Figura, B. McDuffie, Anal. Chem.52, 1433, (1980).

57. C.H. Langford, T.R. Khan, Can. J. Chem., $\underline{53}$, 2979, (1975).

58. J.A. Lavigne, C.H. Langford and M.K.S. Mak, Anal. Chem., 29, 2616, (1987).

59. D.L. Olson and M.S. Shuman, Anal.Chem., 55, 1103, (1983). 
60. D.L. Olson and M.S. Shuman, Geochim. Cosmochim. Acta, 49, 1371, (1985).

61. C.L. Chakrabarti, Yanjia Lu, D.C. Gregoire, M.H.Back, and W.H. Schroeder, Environ. Sci. Technol. 28, 1957, (1994).

62. J.G. Hering and F.M.M. Morel, Environ. Sci. Technol., 24 (1990) 242

63. Yanjia Lu, C.L. Chakrabarti, M.H.Back, D.C. Gregoire, W.H. Szabo, L. Bramall, Anal.Chem. Acta, 288, (1994), 131

64. SPSS User Manual, 3rd Edition, SPSS Inc., Chicago, IL,(1990)

65. R.M. Alcock, F.R. Hartley and D.E. Rogers, J. Chem. Soc. Dalton Trans., 123 (1978).

66. P.Figura and B. McDuffie, Anal. Chem., 51, 120, (1979).

67. F. Rubel, R.D. Woolsey "Removal of Excess of fluoride from drinking water", EPA-570/9-78-001, Office of Water Supply, EPA: Washington, D.C., 1978.

68. G. Singh, D.A. Clifford, "The equilibrium Fluoride capacity of Activated Alumina", EPA-600/2-81-082; EPA: Cincinnati, Ohio, 1981.

69. E.R. Rosenblum, D.A. Clifford,"The equilibrium Arsenic capacity of Activated Alumina", EPA-600/2-83-107; EPA: Cincinnati, Ohio, 1983.

70. E. Bellack, J. Am. Works Assoc., 63, 454, (1971).

71. R.R. Trussel, A. Trusel, P. Kreft "Selenium Removal from Groundwater Using Activated Alumina", EPA-600/2-80-153; EPA: Cincinnati, Ohio, (1980).

72. D.A. Clifford, J.V. Matson, R. Kennedy, Ind. Water Eng., 15, 6, (1978).

73. S.H. Eberle, H. Stober, D. Donnet, in: Translation of Reports on Special Problem of Water Technoicgy, EPA-600/9-76-030; 9 380, EPA: Cincinnati, Ohio, (1976). 
74. J.W. Nowak, Jr. R.R. Burr, and R. Bednarik "Mechanisms of Metal Ion Adsorption on Activated Alumina" in: Metals Speciation Separation and Recovery "Procededings of International Symposium on Metal Speciation, Separation, and Recovery", Chicago, Illinios July 27-August 1, (1986) J.W. Patterson and R. Passino (Eds.) Lewis Publishers Inc. (1987).

75. D. Clifford, S. Subramonian, J. Sorg Thomas, Environ. Sci. Technol., 20, 1072, (1986).

76. David G. Kinniburgh, Marion L. Jackson "Cation Adsorption By Hydrous Metal Oxides and Clay" in: Adsorption of inorganics at solid-liquid Interfaces, Marc A. Anderson and Alan J.Rubin (Eds.) Ann Arbor Science Publishers, Inc. (1981).

77. Cameron W. Mc Leod, J. of Anal. Atom. Spectrometry, 2, 549 (1987).

78. W. Stumm, J.J. Morgan, Aquatic Chemistry an Introduction Emphasizing Chemical Equilibria in Natural Waters, 2nd Ed. John and Wiley Interscience.

79. S.C. Churms, J. S. Afr. Ind. Chem. Inst., 19, 108, (1966).

80. M.K.S. Mak and C.H. Langford, Inorg.Chim. Acta,70, 237, (1983).

81. H.B. Jr. Mark, G.A. Rechnitz "Kinetics in Analytical Chemistry" Interscience: New York, Chap.7, (1968).

82. H.A. Mottola, CRC Crit. Rev. Anal. Chem. 4 . 229, (1974).

83. R.G. Garmon, C.N. Reilley, Anal. Chem., 34, 600, (1962).

84. B.G. Willis, W.H. Woodruff, J.R. Frysing, D.W. Margerum, and H.L. Pardue, Anal. Chem., 42, 1350, (1970).

85. E.A. Guggenheim, Philos. Mag., 2 , 5328, (1926). 
86. A.E. McKinnon, A.G. Szabo, D.R. Miller, J. Phys. Chem. 81, 1564, (1977).

87. C.F. Baes Jr., R.E. Mesmer, Hydrolysis of cations, John Wiley \& Sons, Inc. 1976. 

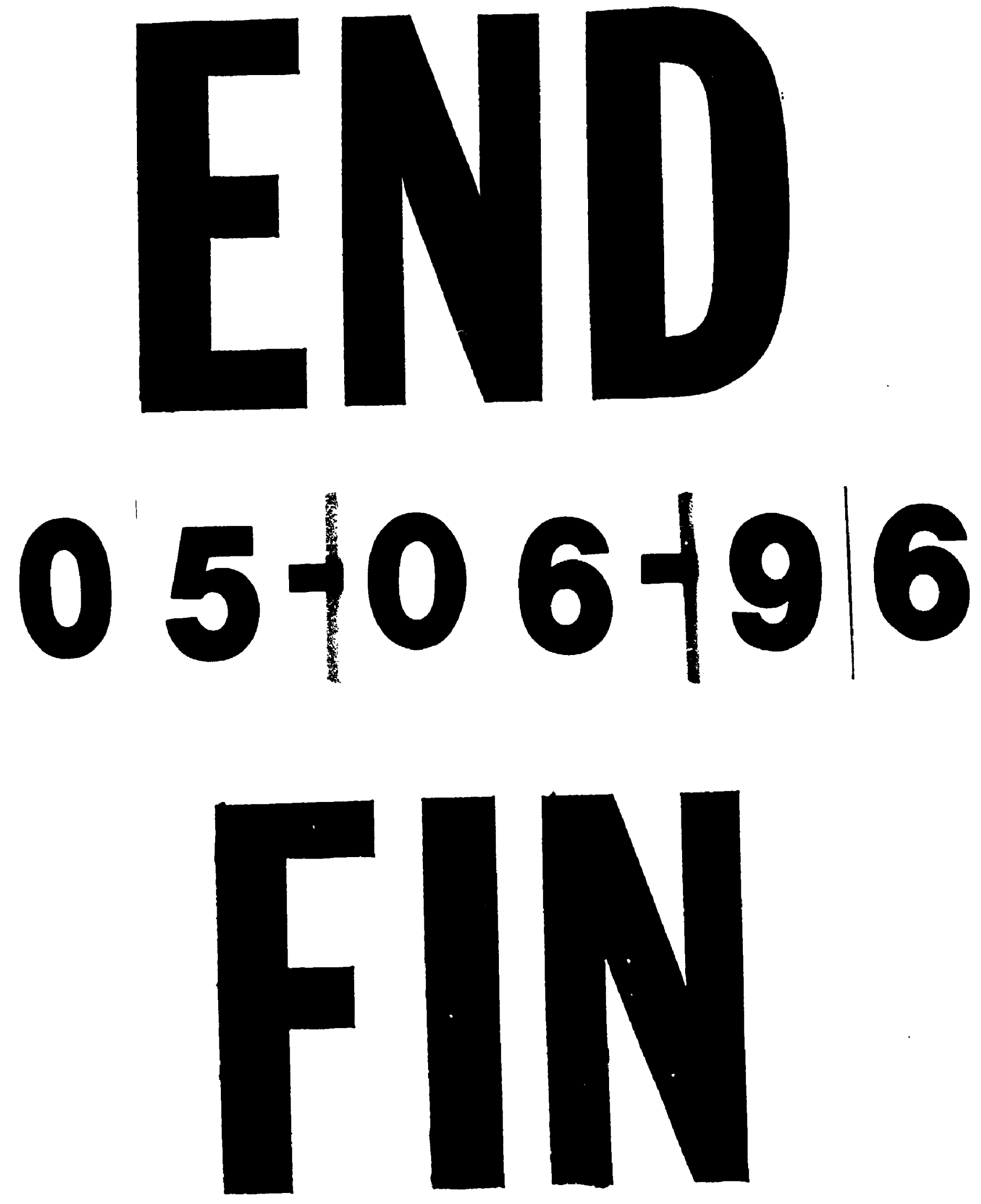